\title{
Becoming a Mindful Sport Psychology Consultant: Defining, Developing, and Integrating Mindfulness into Practice
}

Michelle M. McAlarnen

Follow this and additional works at: https://researchrepository.wvu.edu/etd

\section{Recommended Citation}

McAlarnen, Michelle M., "Becoming a Mindful Sport Psychology Consultant: Defining, Developing, and Integrating Mindfulness into Practice" (2015). Graduate Theses, Dissertations, and Problem Reports. 6183.

https://researchrepository.wvu.edu/etd/6183

This Dissertation is protected by copyright and/or related rights. It has been brought to you by the The Research Repository @ WVU with permission from the rights-holder(s). You are free to use this Dissertation in any way that is permitted by the copyright and related rights legislation that applies to your use. For other uses you must obtain permission from the rights-holder(s) directly, unless additional rights are indicated by a Creative Commons license in the record and/ or on the work itself. This Dissertation has been accepted for inclusion in WVU Graduate Theses, Dissertations, and Problem Reports collection by an authorized administrator of The Research Repository @ WVU.

For more information, please contact researchrepository@mail.wvu.edu. 
Becoming a Mindful Sport Psychology Consultant:

Defining, Developing, and Integrating Mindfulness into Practice

Michelle M. McAlarnen

Dissertation submitted to the

College of Physical Activity and Sport Sciences

at West Virginia University

in partial fulfillment of the requirements

for the degree of

Doctor of Philosophy

in

Sport and Exercise Psychology

Edward Etzel, Ed.D., Chair

Sam Zizzi, Ed.D.

Malayna Bernstein, Ph.D.

Monica Leppma, Ph.D.

Matthew Martin, Ph.D.

Department of Sport Sciences

Morgantown, West Virginia

2015

Keywords:

Sport psychology consultation; mindfulness;

cognitive flexibility; communication flexibility

Copyright 2015 Michelle M. McAlarnen 


\section{Abstract \\ Becoming a Mindful Sport Psychology Consultant: Defining, Developing, and Integrating Mindfulness into Practice}

\section{Michelle M. McAlarnen}

Sport psychology consultation is a problem solving situation and process (Sears, Rudisill, \& Mason-Sears, 2006) in which sport psychology consultants (SPCs) are interpersonal and content communicators. To date, research in applied sport psychology has not examined consultants from the perspective of consultants as communicators in problem solving situations. Additionally, it remains unclear how consultants' graduate education and applied training experience relates to certain communication skills, such as mindfulness, cognitive flexibility, and communication flexibility. Yet, these skills, and its influence on consultants, have garnered interest for further study in professional practice literature (Baer et al., 2008; Davis, 2013; Poczwardowski \& Sherman, 2011). Therefore, this study examined the relation between graduate education and applied training and three consultant skills: (a) mindfulness, (b) cognitive flexibility, and (c) communication flexibility. Professional consultants $(n=157)$ and graduate level consultants $(n=72)$ completed an online survey, which included three brief questionnaires (i.e., educational background, mindfulness exposure, and demographic questionnaires) and three scales: (a) Comprehensive Inventory of Mindfulness Experiences-beta (Bergomi, Tshacher, \& Kupper, 2013a), (b) Cognitive Flexibility Scale (Martin \& Rubin, 1995), and (c) the Communication Flexibility Scale (Martin \& Rubin, 1990; 1994).

Results from structural equation modeling indicated a partially mediated model in which mindfulness mediated the relation between mindfulness exposure and cognitive flexibility and communication flexibility. Mindfulness exposure also directly related to communication flexibility. Applied training directly related to cognitive flexibility and communication 
flexibility. However, the revised model was not significantly different than the hypothesized theoretical model and demonstrated poor model fit. Mindfulness did not significantly differ between type of graduate education, thought cognitive flexibility and communication flexibility did.

Additionally, participants $(n=7)$ were interviewed regarding how they developed mindfulness and its role in their applied practice. Following a grounded theory approach (Charmaz, 2014), results suggested that after exposure to mindfulness, participants engaged in self-directed learning. Integration of mindfulness into consultation occurred in client-directed and SPC-directed ways and reflected SPCs' definitions of mindfulness.

These results aim to: (a) contribute to the on-going discussion about sport psychology training and (b) inform professional development programming in graduate programs and professional organizations, (c) understand the role of mindfulness in consultation. 
Dedication

To the Swamp:

Under the glare of your fluorescent sun, a friend who had chocolate was never far. 


\section{Acknowledgments}

We carry with us the voices of our mentors. I am thankful for the following voices that have encouraged, challenged, laughed, and humored me over the last few years.

To:

Dr. Ryan Flett, for meeting with me in the evenings to talk about SEM and psychometric properties with his dry erase board.

Dr. Christa Lilly, for welcoming me into the SEM world and guiding me in a friendly and understandable manner, and West Virginia Clinical Trial and Translational Science Institute, for providing funding for these meetings. The content is solely the responsibility of the author.

Dr. Matthew Martin, for welcoming a wayward SEP student into Communication Studies and for always making time to meet.

Dr. Monica Leppma, for spending quality statistics time with me during an early stage of this project, supervising my clinical work, and letting me pop by her office whenever to chat.

Dr. Malayna Bernstein, for office/PRT chats, granola bars, understanding the importance of windows, and cultivating my researcher self.

Dr. Sam Zizzi and his Zen cave, for the many walks and talks. Somehow, you pulled out the quantitative researcher in me. Truly, it is a multivariate world.

Dr. Ed Etzel, for showing patience and trust in me.

I am indebted and honored.

To my friends, especially Jes, who has weathered me throughout all of the graduate school years, and to Rachel, Luciana, and Lindsay, who made dissertation a time of friendship.

And

To my family:

who has always let me wander,

but are always there for me wherever I go.

Thank you. 


\section{Table of Contents}

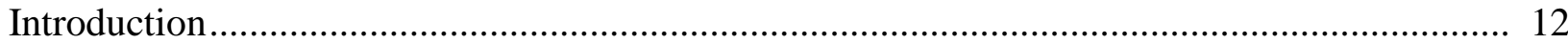

Mindfulness, Cognitive Flexibility, and Communication Flexibility................................ 14

Graduate Education and Mindfulness..................................................................... 18

Statement of the Problem.............................................................................................. 20

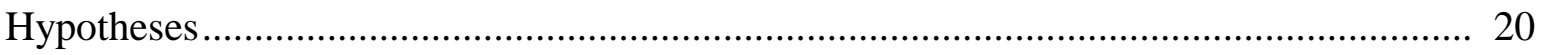

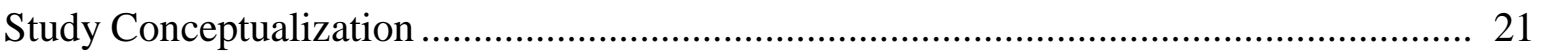

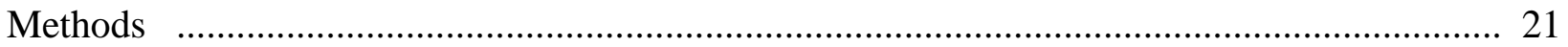

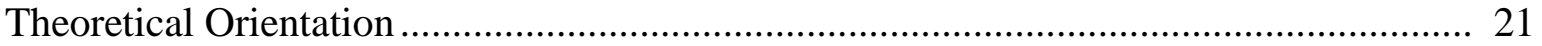

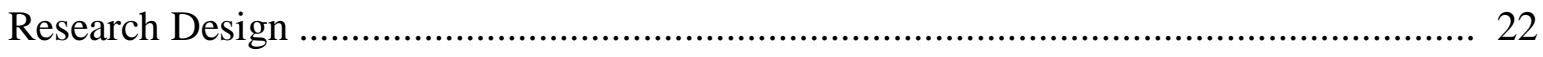

Phase I: Theory verification................................................................................ 22

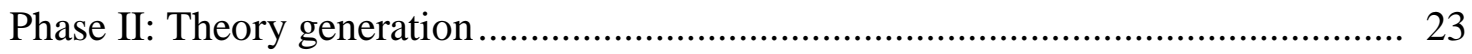

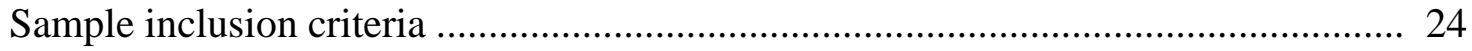

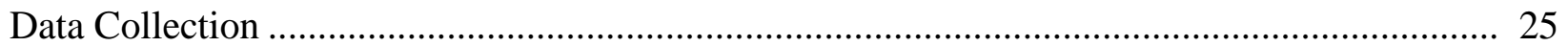

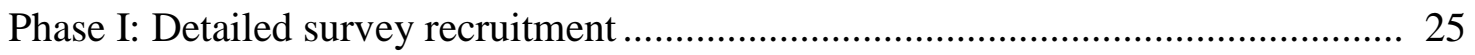

Phase II: Detailed interview recruitment ................................................................ 26

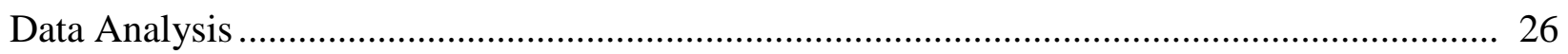

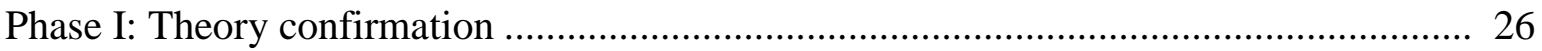

Phase II: Theory generation ........................................................................................ 27

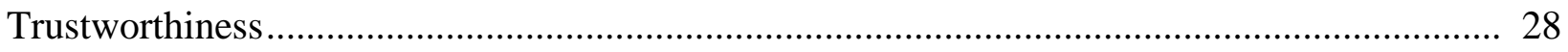

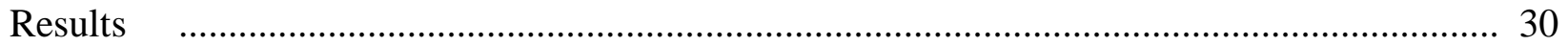

Sample Characteristics..................................................................................... 30

Survey participants' demographics .................................................................... 30 
Graduate education characteristics. .................................................................. 30

Applied training characteristics ..................................................................... 31

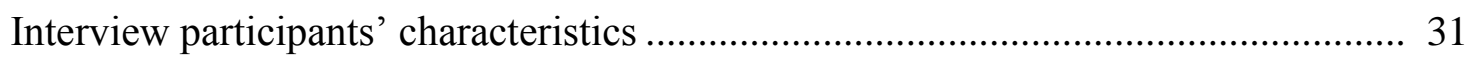

Assessment of Psychometric Properties ……………….................................................. 32

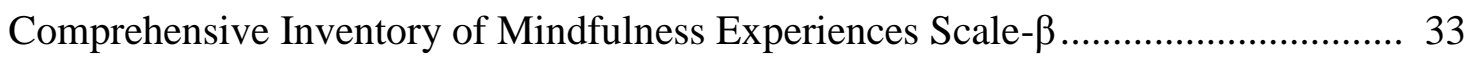

Cognitive Flexibility Scale ……………………................................................ 34

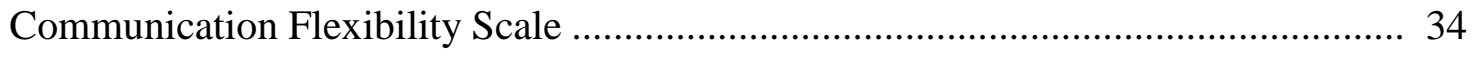

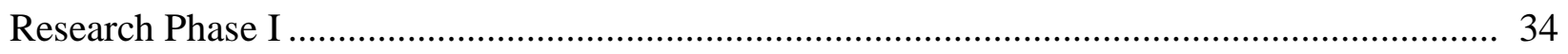

Model of Mindfulness Mediation .............................................................................. 34

The measurement model of mindfulness .............................................................. 35

The structural model ........................................................................................... 37

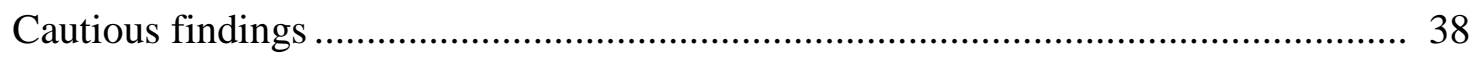

Comparisons between professional status, graduate education and age ............................ 39

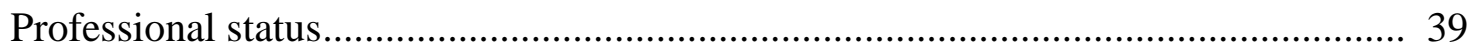

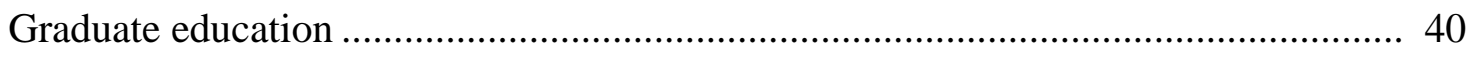

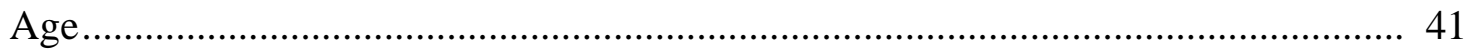

Survey participants' exposure to mindfulness .......................................................... 41

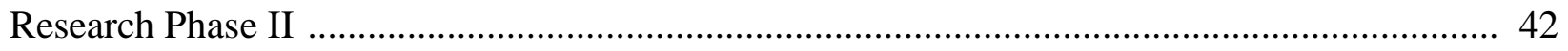

Interviewees' definitions of mindfulness........................................................................ 43

Unease with the term, mindfulness.......................................................................... 45

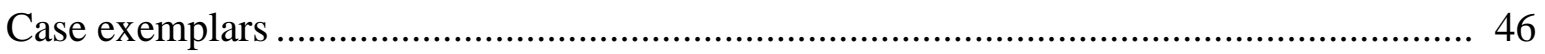

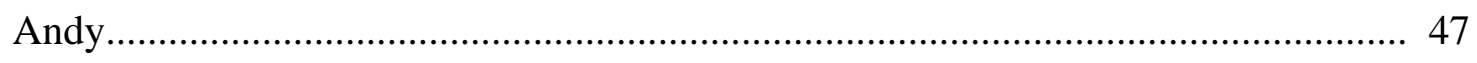

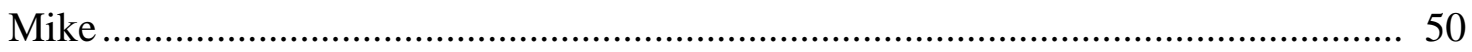


Jacob

Dan.

Discussion

Research Purpose I.

Mindfulness development through self-directed learning

Research Purpose II

Client-directed integration of mindfulness

SPC-directed integration of mindfulness .

Defining and "Blending" Mindfulness .... 66

An Adjusted, Preliminary Composite Conceptualization...

Limitations

Strengths

Future Directions

Conclusion

References

Figures

Figure 1: Overall conceptualization for study

Figure 2: The hypothesized, theoretical, recursive structural equation model.

Figure 3: Conceptualization of a mix-methods design applied to this study

Figure 4: Initial, Theoretical Model (with CFA adjustments).

Figure 5: Standardized Results for Initial Model 93

Figure 6: Revised Model 2 94

Figure 7: Andy's Conceptualization of Mindfulness 
Figure 8: Mike's Conceptualization of Mindfulness ..................................................... 96

Figure 9: Amy’s Conceptualization of Mindfulness........................................................... 97

Figure 10: Jacob's Conceptualization of Mindfulness ……………………………........ 98

Figure 11: Sarah's Conceptualization of Mindfulness …………………….................... 99

Figure 12: Jill's Conceptualization of Mindfulness............................................................100

Figure 13: Dan's Conceptualization of Mindfulness .......................................................101

Figure 14: Bishop and colleagues (2004) definition .........................................................102

Figure 15: Andy's Developmental and Integration Process .............................................103

Figure 16: Mike's Developmental and Integration Processes ............................................104

Figure 17: Jacob's Developmental and Integration Processes............................................105

Figure 18: Dan's Developmental and Integration Processes .............................................106

Figure 19: Preliminary composite conceptualization of mindfulness development and role in sport psychology consultation ....................................................................... 71

Tables

Table 1: Demographic categories with frequency and valid percentages ..........................107

Table 2: Graduate students' current academic programs in descending order ...................108

Table 3: Highest and additional degrees earned by professional participants ....................109

Table 4: Cross tabulation of years and hours per week of applied training (consulting) reported by graduate student and professionals ......................................................110

Table 5: Demographics of interview participants ............................................................111

Table 6: Interview participants' current consulting experience and focus ..........................112

Table 7: Spearman's rho correlational matrix for variables included in CFA and SEM....113

Table 8: Cronbach's alpha scores for scales and subscales .............................................114 
Table 9: CHIMES- $\beta$ psychometric properties: Subscale and item reliability and deletion Process

Table 10: Goodness-of-Fit results for confirmatory factor analysis of CHIMES- $\beta$

$$
(n=185)
$$

Table 11: Manifest variable loadings of the latent factor, Internal Mindfulness, from confirmatory factor analysis 118

Table 12: Goodness-of-Fit indices for various models $(n=159)$

Table 13: Mean comparisons of graduate students and professionals and mindfulness (CHIMES-IM), cognitive flexibility (CFS), and communication flexibility (COMMFS)

Table 14: Variance comparisons of professionals' graduate education and mindfulness (CHIMES-IM), cognitive flexibility (CFS), and communication flexibility (COMMFS)

Table 15: Variance comparisons of graduate students' graduate education and mindfulness (CHIMES-IM), cognitive flexibility (CFS), and communication flexibility (COMMFS)

Table 16: Results for ANOVA between CHIMES-IM and age group

Appendices

Appendix A: Extended Review of Literature .124

Appendix B: Key Terms 188

Appendix C: Internet-based Questionnaire; Graduate Education and Applied Training ...191 Appendix D: Internet based Questionnaire: Comprehensive Inventory of Mindfulness

Experience-beta 
Appendix E: Internet-based Questionnaire: Cognitive Flexibility Scale .........................196

Appendix F: Internet-based Questionnaire: Communication Flexibility Scale

Appendix G: Internet-based Questionnaire: Mindfulness Exposure Questions

Appendix H: Internet-based Questionnaire: Basic Demographic Questions.....

Appendix I: Mindfulness Interview Schedule .201

Appendix J: Internet-based Survey: Cover Letter, Introduction and Inclusion Criteria.....202

Appendix K: WVU IRB Protocol Approval. .203

Appendix L: Recruitment Script 1: Pre-survey Notice. .204

Appendix M: Recruitment Script 2: Invitation to Participate .205

Appendix N: Invitation to SPORTPSY Listserv .206

Appendix O: Invitation to Participate to Division 47 Members .208

Appendix P: Social Media Postings .210

Appendix Q: Invitation to Private Consultants. .211

Appendix R: Invitation to Colleagues for Snowball Sampling .213

Appendix: S: Invitation for Follow-up Interviews

Appendix T: Bracketing Statement: Mindfulness Interview with Memos .215

Appendix U: Analytic Memos 


\section{Sport Psychology Consultants as Communicators in Problem Solving Situations:}

\section{Exploring the Relations between Educational Background and Mindfulness, Cognitive}

\section{Flexibility, and Communication Flexibility}

Sport psychology consultants (SPCs) facilitate performance, enjoyment, and participation in sport through the application and communication of performance psychology knowledge (Association for Applied Sport Psychology [AASP], 2013a; Portenga, Aoyagi, Balague, Cohen, \& Harmison, 2012). How SPCs approach and carry out consultations influence the information and skills shared, the consultee-consultant relationships developed, and potentially, the progress made during sport psychology consultations. In general, sport psychology consultation can be understood as a conversation between a consultant and consultee(s) focused on systemic change through a collaborative problem solving process within a performance context (Davis, 2011; Meyers, 2002; Sears, Rudisill, \& Mason-Sears, 2006; Tod, 2010). As such, SPCs can be thought of as communicators within problem solving situations (i.e., consultation; Sears et al., 2006), who help performers achieve their aspirations (Andersen, 2000; Portenga et al., 2012).

The dynamic consultation environments in which SPCs find themselves require the capacity to problem solve and communicate. Sport psychology consultants physically work in varied environments, such as meeting rooms, performance settings (e.g., pool, field, ice rink), or in less structured locales (e.g., bus, locker room) with socially dynamic entities (e.g., individuals, groups, organizations), who desire to excel in some performance area. Through a problem solving process (Sears et al., 2006), SPCs teach and facilitate the "mental and emotional knowledge, skills, and abilities required for excellence in [performance] domains" (Portenga et al., 2012, p. 14). When SPCs work with consultees, some typical problem solving tasks that occur are: (a) problem identification and clarification, (b) assessment of each consultee or 
entity's problems and needs, (c) transitioning consultees through the multiple stages of consultation and interventions, and (d) adjusting to changes as the consultation progresses (Maher, 2013; Poczwardowski, Sherman, \& Ravizza, 2004).

Within applied sport psychology there is a growing desire to understand SPCs as "professional decision makers" (Martindale \& Collins, 2007, p. 397), as well as discuss what knowledge, skills, or abilities contribute to SPCs' competency (Poczwardowski et al., 2004; Tenenbaum, Papaianou, \& Samulski, 2003; Ward, Sandstedt, Cox, \& Beck, 2005). Professional Judgment and Decision Making (PJDM) research offers one approach to understanding professionals' processes and has be utilized in other helping professions (Martindale \& Collins, 2005). Martindale and Collins (2005; 2007; 2012) advocated for PJDM research to be applied to sport psychology in order to make the decision making process of SPCs overt. Because PJDM research is oriented toward understanding what is happening within the practitioner and the process of the work, detailed and complex accounts of consultants and consultations are emphasized. These accounts and ensuing dialogues provide an opportunity to understand and evaluate practice (for example, see Martindale \& Collins, 2007). These discussions can promote reflexivity of SPCs, inform education and training, and advise professional regulation committees to better ensure the quality and competencies of practicing SPCs (Martindale \& Collins, 2005; 2007).

In addition to problem solving, communication is inherent throughout the consultation process (Maher, 2013; Poczwardowski et al., 2004). In fact, consultant-consultee interactions and conversation are the intervention (Davis, 2011; Sears et al., 2006; Wagner, 2000). Interpersonal and content delivery communication skills are necessary to work with individuals, groups, and organizations (AASP, 2013c; British Psychological Society [BPS], 2012). 
Interpersonal communication aids the development of relationships with consultees (Andersen, 2000; Lubker, Visek, Geer, \& Watson, 2008; Sharp \& Hodge, 2011) and SPCs, who are competent content communicators, can explain and disseminate sport psychology knowledge to consultees (BPS, 2012). In order to generate and sustain this productive relationship, consultants should possess knowledge in "assertiveness, supportiveness, confrontation, listening, management style, and group process" (Sears et al., 2006, p. 16), as well as conflict resolution, directing conversation, and sending and receiving communication messages (Parsons \& Myers, 1984).

Both problem solving and communication skills are considered competencies for helping professionals (Epstein \& Hundert, 2002), such as SPCs, and are tied to the ethical guidelines of the profession (Principle A of the AASP Ethical Code, 2013c). Competencies are important to teach through education and training and also advance and refine throughout a professional career (for a discussion on competency-based training in applied sport psychology, see Fletcher \& Maher, 2013). Mindfulness, cognitive flexibility and communication flexibility are three skills that may support problem solving and communication tasks of SPCs, but have not received attention within applied sport psychology professional development literature.

\section{Mindfulness, Cognitive Flexibility, and Communication Flexibility}

Mindfulness can be understood as a quasi-trait in that all individuals have the natural capacity to experience it and through training mindfulness can be improved or elicited more readily (Bergomi, Tshacher, \& Kupper, 2013a). For this study, mindfulness is operationally defined by the two-component definition constructed by Bishop and colleagues (2004): 
The first component is the self-regulation of attention so that it is maintained on immediate experience, thereby allowing for increased recognition of mental events in the present moment. The second component involves adopting a particular orientation toward one's experiences in the present moment, an orientation that is characterized by curiosity, openness, and acceptance. (p. 232)

Mindfulness is associated with improved insight problem solving (Ostafin \& Kassman, 2012), self-care and improved therapeutic relationships in clinicians (Aggs \& Bambling, 2010) and counseling graduate students (Buser, Buser, Peterson, \& Seraydarian, 2012; Campbell \& Christopher, 2012; Leppma, 2011), and improved cognitive flexibility (Carson \& Langer, 2006; Moore \& Malinowski, 2009). Specific activities, such as meditation (Sedlmeier et al., 2012), yoga (Hewett, Randsdell, Gao, Petichkoff, \& Lucas, 2011), and music (Langer, Russell, \& Eisenkraft, 2009) are related to increased levels of mindfulness.

The role of mindfulness in consultation is in its infancy, but a recent literature review conducted by Davis (2013) identified how mindfulness may enhance important cognitive, attitudinal, social skills that correspond to effective consultation. The review searched for the following key terms: (a) mindfulness and consultation, (b) mindfulness and therapy, coaching, supervision, counseling, and meditation, (c) consultation and skills, and (d) mindfulness and identified consultant skills (e.g., empathy, problem solving, and meta-cognition). Results categorized consultation areas into three domains (i.e., cognitive, attitudinal, and social processes) to which mindfulness might be applied. Then, sub-categories listed within each domain classified particular consultant skills or qualities that emerged from the review. The cognitive domain specified recollection, meta-perspective, creative thinking (including cognitive flexibility), and bracketing. The attitudinal domain consisted of presence and acceptance/nonjudgment. The social processes domain included relationship development, empathy, collaborative working, positive regard, and awareness of social dynamics. These early findings 
suggested the potential for mindfulness to support a broad range of consultation behaviors and "ways of being" that, in turn, facilitate performing objective consultant skills (e.g., reflective statements, role playing) (Davis, 2013). Overall, these findings encourage more formal inquiry into the role and influence of practitioners' mindfulness and its influence on their consultation. In addition to mindfulness, cognitive flexibility and communication flexibility can be considered two consultant skills that support consultant tasks. Both cognitive flexibility and communication flexibility are considered essential elements of communication competence, or "an individual's ability to adapt effectively to the surrounding environment over time" (Spitzberg \& Cupach, 1984, p. 35).

Cognitive flexibility refers to "the human ability to adapt cognitive processing strategies to new and unexpected conditions in the environment" (Cañas, Antolí, Fajardo, \& Salmerón, 2003, p. 95) by selecting knowledge from a broad knowledge base in order to adapt it to a specific situation (Spiro, Coulson, Feltovich, \& Anderson, 1988). It is suggested that cognitive flexibility is an essential factor within inter-personal communication (Booth-Butterfield, 1998; Duran, 1992), counseling effectiveness (Doyle \& Conklin, 1970; Passons \& Olsen, 1969; Whiteley, Sprinthall, Mosher, \& Donaghy, 1967), knowledge acquisition in ill-structured domains (Spiro et al., 1988), creativity (Ritter et al., 2012), and adaptation to environmental changes during problem solving tasks (Cañas et al., 2003; Reder \& Shcunn, 1999). In regards to communication traits, cognitive flexibility has been positively related to argumentativeness and tolerance for disagreement, as well as negatively related to verbal aggression (Martin, Anderson, \& Thweatt, 1998).

Whereas cognitive flexibility pertains to cognitive processing strategies, communication flexibility is "concerned solely with one's communication behavior and how one changes his/her 
communication behavior to be effective within the constraints of the situation" (Martin \& Rubin, 1990, p. 5). Communication flexibility is positively related to communication adaptability (Martin \& Rubin, 1994) and it is speculated that persons in specific occupations, such as counseling, teaching, and marketing, may demonstrate more communication flexibility than other individuals due to the required skills set of job (Martin \& Rubin, 1990). Similar to cognitive flexibility, communication flexibility is positively correlated with argumentativeness and tolerance for disagreement, but negatively related to verbal aggression, as well as Machiavellianism (Martin, Anderson, \& Thweatt, 1998). Working adults exhibited lower levels of communication flexibility than college students, suggesting that age may influence its levels (Booth-Butterfield, 1998). Finally, communicatively flexible individuals receive less negative feedback, engage in more social interactions, and require less interpersonal energy from others due to their situational and behavioral adaptability (Bochner \& Kelly, 1974; Booth-Butterfield, 1998).

In sum, the definitions of and previous research regarding mindfulness, cognitive flexibility, and communication flexibility convey how individuals may approach and mediate their interactions with environments (including persons and events) in which they find themselves. Because SPCs must navigate dynamic physical and social environments within their work, the skills of mindfulness, cognitive flexibility, and communication flexibility may benefit SPCs ability to problem solve and communicate. As previously mentioned, problem solving and communication skills can be considered important consultation tasks and, therefore, areas of competency for SPCs. Graduate school and applied training are when professional competencies are first developed in order for future SPCs to perform ethically and competently (see, Etzel \& Watson, 2011). Thus, understanding the ways in which type of graduate education and applied 
training experiences relate to these skills, particularly mindfulness, constitutes an important area of study.

\section{Graduate Education and Mindfulness}

At this time, it is unclear what, if any, role education has in the development of mindfulness. Baer and colleagues (2008) reported that a significant relationship was not observed between a high education sample (i.e., graduate degrees in psychology) and the mindfulness facet, act with awareness. Potentially, these findings suggest that education already supports the development of acting with awareness, which minimized the impact of the meditation intervention used (Baer et al., 2008). With limited research on type and level of education and mindfulness, the extent to which education and mindfulness relate remains unclear.

Within sport psychology, mindfulness is considered an emerging topic in sport psychology. In study of experienced, expert SPCs, Poczwardowski and Sherman (2011) noted, "Newly trained sport psychology consultants (e.g., 5-10 years into their careers) might offer rich perspectives on [mindfulness] and other elements of effective practice" (p. 529), which more established SPCs did not learn in graduate school and did not mention in their accounts. Indeed, early career professionals may offer different insights than experienced professionals when the aim of research is to examine theoretical and empirical developments that have recently been implemented into graduate programming. Both Poczwardowski and Sherman and Baer and colleagues (2008) recommended further exploration of education and mindfulness.

In general, graduate education and applied training are subjects often debated and critiqued within sport psychology (see Andersen \& Tod, 2011; Fletcher \& Maher, 2013; Silva, 2013; Silva, Conroy, \& Zizzi, 1999; Silva, Metzler, \& Lerner, 2011). Many respected SPCs 
have acknowledged their winding paths, "chance" opportunities, and limited access to streamlined education in sport psychology (McCarthy \& Jones, 2013). Though no standardized graduate training model currently exists, professionals agree that an inter-disciplinary approach that interweaves courses from sport science and psychology can best equip SPCs with performance psychology knowledge, abilities, and skills (Moran, 2004; Weinberg \& Gould, 2011). Additionally, applied training experiences, in which novice, graduate level SPCs consult and receive supervision in their consultations, are often included in graduate programs that aim to produce practitioners.

To clarify the relevant educational and applied training competencies needed as a SPC, professional organizations, such as AASP, have developed certification that specify course content and applied training requirements. Coursework requirements are spread across twelve competency areas, which range from ethical practice, research and measurement, and sport psychology content knowledge to individual and group counseling skills and cognitive, behavioral, and social basis of behavior (AASP, 2013b). To satisfy the applied training requirements, potential Certified Consultant-AASPs (CC-AASPs) must complete 400 supervised hours, which include 100 hours of direct contact with clients and 40 hours of supervision (AASP, 2013b). After attaining the certification requirements, the SPC is designated as a CC-AASP. Other professional organizations require licensure in clinical/counseling psychology (Andersen \& Tod, 2011).

There are an estimated 3,000 SPCs worldwide (M. Sachs, personal communication, February 25, 2014) and 372 CC-AASPs (R. Harmison, personal communication, February 25, 2014). A majority of SPCs earn a doctorate degree in counseling/clinical psychology or sport sciences and consult within an academic setting (often in addition to teaching and research) or 
through a private practice (Meyers, Coleman, Whelan, \& Mehlenbeck, 2001). As a small and growing field, there is an opportunity to (a) explore SPCs' mindfulness, cognitive flexibility, and communication flexibility, (b) examine if these skills facilitate SPCs' problem solving and communication processes, and (c) inform graduate programming and training to develop competent SPCs.

\section{Statement of the Problem}

Sport psychology consultation is a problem solving situation and process (Sears et al., 2006) in which SPCs are interpersonal and content communicators. Previous literature suggests that the skills of mindfulness, cognitive flexibility, and communication flexibility may support consultant tasks (problem solving, communication) (Aggs \& Bambling, 2010; Cañas et al., 2003; Davis, 2013; Ostafin \& Kassman, 2012). Of question, then, is how these skills are developed. Research in sport psychology has not explored how SPCs' graduate education and applied training relate to these consultant skills (mindfulness, cognitive flexibility, and communication flexibility) despite interest and desire for further study of these relations (Baer et al., 2008; Poczwardowski \& Sherman, 2011).

Thus, this study had two purposes (Figure 1). The first purpose was to understand the relation between SPCs' graduate education and graduate applied training and self-reported levels of mindfulness, cognitive flexibility, and communication flexibility. It was hypothesized that levels of mindfulness, cognitive flexibility, and communication flexibility would differ between types of graduate education and mindfulness would mediate the relation between applied training and cognitive flexibility and communication flexibility. "Mindfulness exposure," or learning about mindfulness or participating in activities, was also expected influence mindfulness. This hypothesis is expressed as a structural equation model (Figure 2). 
The second purpose was to explore how SPCs developed their understandings and practices of mindfulness and the role of mindfulness in their consultation approach. No formal hypothesis was articulated, though it was believed education may be part of the developmental process. It was believed that mindfulness would support sport psychology service delivery, but the ways in which this support manifested were not specified.

Findings from this study aimed to contribute to the growing research on mindfulness and consultation by specifically exploring sport psychology consultations. Findings may also inform graduate education and training and benefit SPCs' consultation problem solving and communication processes.

\begin{tabular}{|c|c|c|c|c|}
\hline $\begin{array}{l}\text { Graduate Background: } \\
\text { (a) Graduate Education } \\
\text { (b) Graduate Applied } \\
\text { Training }\end{array}$ & --(1)-- & $\begin{array}{l}\text { Consultant Skills: } \\
\text { (a) Mindfulness } \\
\text { (b) Cognitive Flexibility } \\
\text { (c) Communication } \\
\text { Flexibility }\end{array}$ & --(2)-- & $\begin{array}{l}\text { Consultant Tasks: } \\
\text { (a) Problem Solving } \\
\text { (b) Communication }\end{array}$ \\
\hline
\end{tabular}

Figure 1. Study conceptualization. Each number denotes a research purpose.

\section{Method}

\section{Theoretical Orientation}

The researcher approached this study from a constructionist theoretical orientation. Constructionism posits that individuals are meaning-makers of their world, that knowledge emerges from continual interaction and interpretation of phenomenon within a socio-cultural context, and that reality is not fixed, but understood through varying subjective perspectives (Crotty, 2007; Fosnot, 2005; Martindale \& Collins, 2012; Polit \& Beck, 2008). The concepts of mindfulness, cognitive flexibility, and communication flexibility, have acquired some shared 
meaning by researchers as represented by some generally agreed upon definitions. Yet, defining and understanding these concepts is an on-going process attested by the varied definitions of each construct and discussions about definition and measurement (Bergomi et al., 2013b; Bishop et al., 2004; Bodhi, 2011; Dreyfus, 2011; Russell, 2011; Kabat-Zinn, 2003). This study aimed to enter into and extend the conversation regarding mindfulness, cognitive flexibility, and communication flexibility within a sport psychology consultation context.

\section{Research Design}

A cross-sectional, sequential, mixed-methods research design (Teddlie \& Tashakkori, 2009) was utilized (Figure 2). A mixed-methods approach provides several benefits to the quality of the study. For this study, a particular benefit of a mix-methods design was simultaneous examination of confirmatory and exploratory questions, which promoted theory verification and generation (Teddlie \& Tashakkori, 2009). In addition, a mix-method design allowed for divergent findings to emerge (Barry, 2002; Teddlie \& Tashakkori, 2009). Creating an opportunity for divergence was important for this study because the hypothesized structural equation model is based on early research and connecting concepts across disciplines. Thus, there was an opportunity to assess model fit from quantitative and qualitative perspectives, using the benefits of both methodological approaches to inform answers to both research aims. To accomplish these tasks, the study was divided into two phases.

Phase I: Theory verification. The first phase focused on theory verification of the hypothesized structural equation model of graduate education and training and consultant skills (i.e., research purpose one) using quantitative survey methods. The survey distributed in phase one consisted of three self-report instruments and three questionnaires, including (a) questionnaire about participants' educational, applied training, and work experiences (Appendix 
C), (b) the Comprehensive Inventory of Mindfulness Experiences beta (37 item, CHIMES- $\beta$, Appendix D; Bergomi et al., 2013a), (c) Cognitive Flexibility Scale (12 item, CFS, Appendix E; Martin \& Rubin, 1995; Martin \& Anderson, 1998), (d) Communication Flexibility Scale (14 item, COMMFS, Appendix F; Martin \& Rubin, 1990; 1994), (e) mindfulness exposure questionnaire (Appendix G), and (f) basic demographic questionnaire (Appendix $\mathrm{H}$ ). The CHIMES- $\beta$ Likert scales ranged from 1 (almost never) to 6 (almost always) and included eight subscales: (a) awareness toward internal experiences (i.e., aware internal), (b) awareness toward external experiences (i.e., aware external), (c) acting with awareness (i.e., act aware), (d) accepting and non-judgmental orientation (i.e., accepting), (e) decentering and nonreactivity (i.e., decentering), (f) openness to experience (i.e., open experience), (g) relativity of thoughts (i.e., relative thoughts), (h) insightful understanding (i.e., insight understanding). The CFS Likert scales ranged from 1 (strongly disagree) to 6 (strongly agree) and the COMMFS Likert scales ranged from 5 (a lot like you) to 1 (not at all like you).

Phase II: Theory generation. The second phase approached both research purposes through a grounded theory approach (Charmaz, 2014) using in-depth, unstructured qualitative interviews. Grounded theory focuses on theory generation based on the processes and actions emphasized within the data (Charmaz, 2014; Saldaña, 2013). Interviews explored the development and role of mindfulness for interviewees, who discussed personally salient experiences. Participants were presented with the following two prompts (Appendix I): (a) you scored high on the mindfulness instrument, looking back on your experiences, tell me about how you developed this skill and (b) help me understand the role of mindfulness for you as a sport psychology consultant. These prompts and follow-up questions were intentionally non-directive 
toward specific developmental experiences or ways in which mindfulness may influence consultation in order for findings to emerge from participants.

Sample inclusion criteria. Sport psychology graduate students or professionals, who had engaged in performance psychology consulting for at least one academic year, were eligible to participate. Consultations could focus on performance enhancement, life skills, or mental health concerns and sport psychology consultants could work with a variety of groups, such as athletes, medical professionals, exercisers, and military personnel. No exclusion criteria in regards to participant sex/gender, racial/ethnic, nationality, or age occurred. All participants were reminded of their rights as human subjects at the onset of the study (Appendix J).

\begin{tabular}{|c|c|}
\hline \multirow{4}{*}{ 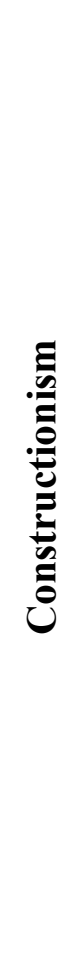 } & Theory Verification \\
\hline & $\begin{array}{l}\text { Phase 1: Quantitative } \\
\text { Purpose 1: Relation between education/ training and } \\
\text { mindfulness, cognitive flexibility, and } \\
\quad \text { communication flexibility }\end{array}$ \\
\hline & $\begin{array}{l}\text { Phase 2: Qualitative } \\
\text { Purpose 1: How participants develop mindfulness } \\
\text { Purpose 2: Role of mindfulness in consultation } \\
\text { Collection: Interviews } \\
\text { Analysis: Grounded Theory }\end{array}$ \\
\hline & Theory Generation \\
\hline
\end{tabular}

Figure 3. Conceptualization of mix-methods research design applied to this study. 


\section{Data Collection}

After approval from the Institutional Review Board (Appendix K), data collection proceeded in two phases that utilized purposive sampling of SPCs (Patten, 2000; Polit \& Beck, 2008). First, potential participants for the survey were contacted via personalized emails, graduate program specific emails, listserv distributions, and a website posting in an attempt to reach the estimated 3,000 performance psychology practitioners worldwide (M. Sachs, personal communication, February 25, 2014). In order to incentivize participants (Dillman, 2000) and to contribute to the support of applied sport psychology, participants were notified that the primary researcher would donate one dollar to the professional organization of their choice for each completed survey. After closing the survey, the second phase of recruitment occurred. Potential participants, who met the criteria for interview and had agreed to follow-up interviews, were contacted once via email $(n=13)$. Participants who agreed to the interview $(n=7)$ were scheduled and interviewed via Skype (Microsoft, Inc., 2015) or FaceTime (Apple Inc., 2015).

Phase I: Detailed survey recruitment. Participant recruitment began in early June 2014 and completed in December 2014. Following Dillman (2000) suggestions for successful internet-based research recruitment, CC-AASPs and graduate program directors received a personalized, pre-notice email explaining the study and requesting participation and sharing it with appropriate students and colleagues (Appendix L). A link to the survey was included and some participants opted to complete the survey at that time (Qualtrics Research Suite, 2014). After one week, an email with an invitation to participate was send to participants who had received the pre-notice email and also to the SPORTPSY listserv (Appendix M). A second email was sent at the beginning of September SPORTPSY listserv (Appendix N). In October, request for participation emails and postings were listed on the APA Division 47 listserv (Appendix O), 
as well as Twitter and Facebook (Appendix P). Additionally, 60 private practice performance psychology consultants were individually emailed after a search for consultants using the following key terms: sport psychology consulting, mental training consultation, sport mental training consultation, mental skills training, and performance skills training (Appendix Q). Last, in November a range of colleagues were contacted and asked to complete the survey and forward it to colleagues and students (i.e., snowball sampling; Appendix R). The survey data collection phase was completed at the beginning of December.

Phase II: Detailed interview recruitment. Participants, who indicated interest in a follow-up interview, were contacted in early January (Appendix S). Initially, the criterion for a follow-up interview was a score in the 95 percentile and these participants $(n=5)$ were first contacted. However, this criterion was expanded to one standard deviation $(\mathrm{SD}=.409)$ above the sample mean $(M=4.473)$ on the CHIMES- $\beta$ in order to acquire more participants $(n=13)$. Ultimately, a total of seven interviewees agreed to participate and interviews were concluded by the end of January.

\section{Data Analysis}

Phase I: Theory confirmation. Prior to statistical analysis, all scales were assessed for normalcy, multicollinearilty, and internal reliability. The a priori theoretical model was analyzed through confirmatory factor analysis (CFA) and structural equation modeling (SEM) using SAS 9.3 (O'Rourke \& Hatcher, 2013; Raykov \& Marcoulides, 2006). This model was recursive and suggested that mindfulness mediated the relations between (a) applied training and mindfulness exposure, and (b) cognitive flexibility and communication flexibility. Applied training was operationally defined as the standardized composite score of participants' standardized hours and years consulting as a graduate student. Mindfulness exposure was the 
standardized composite of participants' frequency per week engaging in activities that can elicit mindfulness and amount of ways they have been exposed to mindfulness training (both aspects were also standardized before multiplied). Statistical testing, including descriptive statistics, correlations, t-tests, and analysis of variance (ANOVA), were utilized to gain a more nuanced view of the differences between professional statuses, academic degrees, age, and mindfulness exposure.

Phase II: Theory generation. Phase two consisted of interview data and was analyzed through grounded theoretical approach (Charmaz, 2014). First, interviews were transcribed verbatim and reviewed to minimize mistakes. After transcription, a three-person trained team separately identified significant statements that answered the research purposes using initial coding with in vivo coding (Saldaña, 2013). The team met to discuss coding for one case and explain rationales for their coding decisions. After this conversation, the research team decided to group significant statements by overarching categories of "development" and "role" based on the two research aims and interview questions. Researchers reviewed their codes for the other participants and sent the primary researcher their coding and significant statements for all participants. The primary researcher proceeded to code using process-coding techniques (Saldaña, 2013). Throughout the coding process, the constant comparison technique was utilized in which the researcher compared sections of data, codes, and categories across data in order to identify relationships and processes that generated inductive theory building (Palmberger \& Gingrich, 2014). Additionally, analytic memos were written and reviewed about emerging themes and theory, inconsistencies, and reflections regarding the data and study (Charmaz, 2014). 


\section{Trustworthiness}

Trustworthiness is an on-going process throughout a research project. Several actions throughout data collection and analysis facilitated transparency and trustworthiness. Prior to data collection, the researcher performed a bracketing interview and both phase one and two were pilot tested. During data analysis, decision-making rationales and processes were documented.

The bracketing interview examined the researcher's perspectives as she answered the mindfulness interview questions. The researcher reviewed, holistically coded, and composed an analytic memo regarding the bracketing statement (Appendix T). Her exposure and development of mindfulness originated from mentors' teachings and role modeling, educational courses (religion and sport psychology), and readings from high school and in her doctoral program. Mindfulness influenced how she approached her own life and consultations. It was used to improve herself in both areas, namely through understanding of her reactions, thought processes, and attachments. Within the consulting session, she noted that she does not necessarily use formalized mindfulness activities or interventions, but brings mindfulness into the session to help her remain open, curious, and present to the client and her own experience.

Pilot testing helped improve the structure and quality of methods, as well as provide the researcher with interview practice. For phase one pilot testing, several doctoral students reviewed the survey for understanding, flow, and grammatical errors. For phase two pilot testing, a doctoral student with sport psychology consultation experience served as a pilot test for the mindfulness interview, which provided an opportunity to practice interviewing and confirm the structure of the interview procedures. The pilot interviewee shared that she learned about mindfulness through education and mentors, a counselor, and dancing, and that she was still 
exploring what it meant for her personal practice. As a SPC, mindfulness helped her be aware of environment and its impact, as well as be conscious of her word selection and how her responses shaped the consultation relationship and space.

Throughout data collection and data analysis, the researcher documented quantitative and qualitative methodological processes, including decision making steps, rationales, and early conceptualizations. For example, within the quantitative portion, psychometric property analyses and adjustments were required for the CHIMES- $\beta$ and COMMFS. Each decision to drop an item or subscale was documented with mathematical rationale and theoretical considerations. Throughout the qualitative coding process, analytic memos maintained records of decision-making, general procedures, and emerging thoughts about codes and findings (Appendix U). Analytic memos are considered an integral aspect of coding and theory development in grounded theory (Charmaz, 2014). The aim of these documents was to provide evidence of rationales that can demonstrate how findings developed.

Additional steps to facilitate trustworthiness during qualitative analysis included: (a) member checking with participants about the accuracy of their transcription and if they wanted to clarify or add information, (b) the use of thick description, (c) following up on statements contrary to expectations or emerging themes, and (d) working with a research team during qualitative data analysis (Creswell, 2009). The results were not aimed at generalizability outside of SPCs and every effort was made to represent the demographics and professional backgrounds of SPCs. 


\section{Results}

\section{Sample Characteristics}

Survey participants' demographics. A total of 229 participants initiated the survey and 187 were completed (81.6\% completion rate). Seventy-two participants (31.44\%) identified as graduate students and 157 participants $(68.56 \%)$ identified as professionals (Table 1$)$. Retention throughout the survey varied, but responses generally ranged between 140-190 cases. Therefore, valid percentages were reported. There were 104 males $(55.91 \%), 81$ females, $(43.5 \%)$, and one non-response. Caucasian, non-Hispanic race/ethnicity characterized a majority of participants $(n$ $=175,72 \%)$, as did United States nationality $(n=150,80.21 \%)$. Seventy-five percent of the participants were 35 years old or younger and as such, the data may represent graduate students and early career professionals perspectives and graduate training experiences more so than late career professionals. Table 1 presents detailed demographic, academic, and applied training characteristics.

Graduate education characteristics. The three most prominent academic degrees for both professionals (earned) and graduate students (enrolled) were Ph.D. Sport and Exercise Psychology, Ph.D. Kinesiology, and Ph.D., Clinical/Counseling Psychology. Graduate students earned an additional 56 Master's degrees and professionals earned 128 degrees ${ }^{1}$. Master's in Kinesiology was the most prevalent additional degree, followed by sport/performance psychology and counseling for graduate students and only counseling for professionals. Professionals held a variety of one or more certifications and licensures, namely CC-AASP $(n=$ 97), licensed psychologist $(n=34)$, licensed professional counselor $(n=8)$, Board Certified

\footnotetext{
${ }^{1}$ It is worth noting that this ratio reflects the sample ratio (1 graduate students : 2 professionals).
} 
Athletic Trainer $(n=5)$. Detailed characteristics provided for graduate students (Table 2) and professionals (Table 3), respectively.

Applied training characteristics. Athletics constituted the majority of professionals ( $n$ $=65)$ and graduate students $(n=133)$ applied training experience. Though both groups endorsed working with exercisers, professionals $(n=48)$ outnumbered graduate students $(n=$ 13). Professionals were also more likely to work with the arts $(n=16)$ and business $(n=13)$ than graduate students (arts $=8$, business $=5$ ). A few graduate students worked with military personnel $(n=5)$. Consultation focused on performance enhancement for both groups (75\% or greater). Around 75 percent of graduate students consulted for 10 or less hours per week for three or less years. During graduate school, 63 percent of professionals engaged in applied training for 10 or less hours per week. Around 37 percent consulted for five years, otherwise professionals spent two or three years consulting (16\% each year). Crosstabs of years by hours of graduate students and professionals provided in Table 4.

Interview participants' characteristics. Interviewees reported similar demographic backgrounds and educational experiences to each other and the overall sample (Table 5). All interviewees identified as Caucasian, non-Hispanic, as well as United States citizens. Ages ranged between 26 years old to 40 years old $(M=31.43, S D=14)$. Identified gender was evenly split $($ male $=4$, female $=3)$.

The academic training of interviewees focused on sport performance and clinical/counseling psychology. Two participants earned Ph.D./Ed.D. in Counseling Psychology with an emphasis in sport psychology. Two participants were enrolled in clinical or counseling psychology doctoral studies with sport or health psychology concentrations. Additionally, six of the seven participants earned a Master's in Sport and Exercise Psychology. Of note, only one 
participant earned a Ph.D. in sport and exercise psychology that was unattached to a counseling or clinical psychology program. However, this participant did earn a Master's in Counseling during doctoral studies. Only two participants did not have or were not in the process of earning a Ph.D., though one of these two participants stated an intention to enroll in doctoral studies. Professionally, six of the seven interviewees actively consulted and the non-consulting interviewee supervised consultations (and had previous clinical and consulting experience) (Table 6). Of those interviewees actively consulting, three participants considered it a full time job (and for one these participants it was in addition to a full-time academic position). For the remaining three participants, consultation occurred in addition to doctoral studies or academic professorship. Interviewees primarily consulted with an athletic population, particularly high school and elite, with a performance psychology focus. One participant worked with a military population, though previous consulting experience included collegiate athletics. Four participants held CC-AASP certification and one interviewee was also a licensed psychologist. The average amount of consulting experience was 8.714 years $(\mathrm{SD}=6.02)$ and 18.64 hours per week $(\mathrm{SD}=13.04)$, but this number varied depending on profession and time of year (i.e., sport season).

\section{Assessment of Psychometric Properties}

Prior to answering the research purposes, psychometric properties of each scale were assessed using SPSS (IBM Corp, 2012). All three scales were analyzed for normality, multicollinearity, and reliability. Normality was assessed through review of skewness and kurtosis. Acceptable ranges of skewness and kurtosis are \pm 2 (Aggs \& Bambling, 2010), which were met (Table 7). One regression outlier was identified based on leverage and deleted. Multicollinearity $(r>.80)$ between the sub-scales and each scales was not indicated. Therefore, 
all assumptions regarding the scales were met. Both the CHIMES- $\beta$ and COMMFS underwent scale modification that resulted in deleted items (and subscales of CHIMES- $\beta$ ). The CFS demonstrated internal reliability and no changes were made.

Reliability testing and psychometric analysis followed a decision-making process. Item and subscale deletions were considered based on mathematical and theoretical rationales, such as negative correlation, inter-item correlational means, impact of removing item on alpha level, number of items in subscale, and item wording. Furthermore, while scale modification can improve sample fit, modification may hinder generalization of results to previous and future scales. As a result, psychometric analysis aimed to maintain conceptual integrity of the CHIMES- $\beta$, CFS, and COMMF, but also modify as appropriate. Unlike CFS and COMMF, the CHIMES- $\beta$ had subscales (a total of eight). It is recommended to have at least three items (i.e., observed variables) per factor and to maintain more factors and items in early scale development and this recommendation was followed ("Factor analysis using SAS PROC FACTOR", 2015). After reliability testing and scale modification, CHIMES $(\alpha=.806)$, CFS $(\alpha=.777)$, and COMMFS $(\alpha=.700)$ reported Cronbach's alpha levels in the "good" range (Table 8).

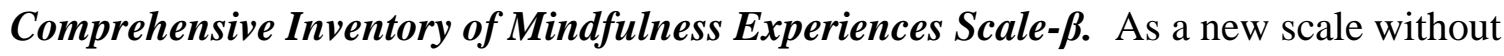
prior use with a North American sample, the CHIMES- $\beta$ psychometric properties were closely analyzed. The CHIMES- $\beta$ used in this study is 33 items due to omission of four items, each from a different sub-scale. Nonetheless, all subscales were represented by four to five items, except relativity of thoughts, which had three items.

The initial eight factor CHIMES- $\beta$ produced a Cronbach's alpha level of "acceptable" ( $\alpha$ $=.683)$. Reliability analysis between and within the eight factors resulted in deletion of one subscale, open to experiences $(\alpha=.228$ ) and four items (items $6,28,29,32)$ (see Table 9 for 
psychometric decision making process). After scale modification, all subscales met inter-item correlational mean critical value ( > 0.200; Flett, Gould, \& Lauer, 2012) and the corrected Cronbach alpha level of the CHIMES- $\beta$ was "good" $(\alpha=.781)$. The initial CHIMES- $\beta$ reported excellent reliability $(\alpha=.95)$ (Bergomi et al., 2013a).

Cognitive Flexibility Scale. The psychometrics of the CFS were sound. Initial reliability tested produced a Cronbach's alpha level of "good" $(\alpha=.777)$, which mirrored previous research (Ahn, Kim, \& Park, 2009; Shibl, 2010; Martin \& Rubin, 1995). Item deletion would decrease the alpha level and as a result, no items were deleted from this scale.

Communication Flexibility Scale. Initial reliability tested resulted in a Cronbach's alpha level of "acceptable" $(\alpha=.634)$ and was improved to "good" $(\alpha=.700)$ through item deletion. Items 3,1 , and 12 were removed due to negative correlation and inter-item correlation means below critical value ( $>0.200)$. These procedures increased Cronbach's alpha level $(\alpha=.694)$ at which point the inter-item correlational mean of item 11 decreased to .191 (it had previously been above .200 ). Following the critical value procedures, item 11 was deleted, which resulted in a 10 -item scale $(\alpha=.700)$. Previous studies reported similar alpha levels (14-item scale, $\alpha=$ .68, Martin, Anderson, Thweatt, 1998).

\section{Research Phase I: Relation between graduate education and applied training and mindfulness, cognitive flexibility, and communication flexibility}

Model of Mindfulness Mediation. Analysis consisted of a two-step process. First, a CFA was conducted on the latent factor, mindfulness. The aim of the CFA was to assess the relationship between the manifest variables (the subscales of CHIMES- $\beta$ ) and mindfulness as a latent factor. Two manifest variables were deleted based on mathematical and theoretical rationales, resulting in a five-factor measurement model. Second, the theoretical structural 
model was analyzed using a SEM and underwent subsequent revisions. No significant difference was indicated between the theoretical and revised structural model (based on chi square difference test). The theoretical and revised structural model are presented.

The measurement model of mindfulness. After reliability analysis, a CFA was conducted for the latent factor, mindfulness, using the SAS 9.3 CALIS procedure (Full Maximum Likelihood Estimation [FIML]) based on the variable-covariance matrix. Full Maximum Likelihood Estimation was selected because it included incomplete cases in the analysis, maximizing sample size. The initial model consisted of seven, standardized manifest variables (i.e., CHIMES- $\beta$ subscales) loading on to the latent factor, mindfulness, as suggested by previous reliability analysis of the CHIMES- $\beta$. A sample size of 200 is recommended to detect medium to large effect sizes (O'Rourke \& Hatcher, 2013). This study ( $n=185, n=159$ in SEM with 55 additional incomplete cases) does not meet this criteria, thus results should be interpreted with caution.

Two sub-scales, awareness external and act aware, reported perfect correlation, which inhibited CFA and required at least one sub-scale deletion. Both sub-scales' Cronbach's alphas were reviewed at scale and item levels. Act aware demonstrated less internal reliability ( $\alpha=$ .674) than Aware External $(\alpha=.762)$. Act aware was deleted and total scale alpha level decreased $(\alpha=.767$ from $\alpha=.769)$. Mathematically, reliability analysis suggested removal of Aware External to increase the total scale reliability $(\alpha=.800)$. Due to this outcome, items for both sub-scales were reviewed to assess if there was a theoretical rational for sub-scale deletion. Both sub-scales emphasized one's mediation of the external world, such as managing stress from external situations as opposed to managing internal thoughts, emotions, and experiences, which characterized the other five subscales. Thus, there was theoretical commonality between aware 
external and act aware sub-scales that suggested that these sub-scales were measuring a different aspect of mindfulness (managing external situations) than the majority of the sub-scales (mediation of internal experiences). Therefore, aware external was also removed and reliability analysis was conducted with a five factor solution, resulting an alpha level of "good" $(\alpha=.805)$.

Confirmatory factor analysis commenced with five variables representing the factor, renamed Internal Mindfulness (CHIMES-IM; $n=185$ ). Goodness-of-fit indices (Table 10) include the chi-square statistic $\left(\chi^{2}\right)$, Comparative Fit Index (CFI), Standardized Root Mean Square Residual (SRMSR), Root Mean Square Error of Approximation (RMSEA), 90 percent confidence limits for the RMSEA statistic, Akaike Information Criterion (AIC), and Schwarz Bayesian Criterion (BIC). The chi-square statistic indicated non-significance $\left(\chi^{2}=13.837 ; \mathrm{df}=\right.$ 5), failing to reject the null hypothesis of good model fit. Additional goodness-of-fit indices suggested ideal $(\mathrm{SRMR}=.033$; RMSEA CL $=037-.156)$, excellent $(\mathrm{CFI}=.983)$, and mediocre $($ RMSEA $=.095)$ model fit. All $t$-values were significant at the $p<.05$ level for the exogenous variables (CHIMES- $\beta$ subscales), thereby rejecting the null hypothesis that all loadings would be zero. Squared multiple correlations $\left(\mathrm{R}^{2}\right)$ ranged from 0.233 - 0.792 and standardized beta weights ranged from $0.483-0.890$ (see Table $\mathrm{X}$ for $t, \mathrm{R}^{2}$, and beta weights of each variable). Beta weights $(\beta)$ can be understood as the change in the dependent variable due to change in each independent variable and can be interpreted as strength of association, similar to correlations (i.e., zero mean with range of -1 to 1 and $\beta>0.20$ as weak effect, $\beta=.20-.40$ as moderate effect, and $\beta>0.40$ as strong) (Acock, 2006). Wald Test reported all paths significant, negating further scale modification (and use of the AIC and BIC indices). Based on these goodness of fit indices, the study used the five factor measurement model of the CHIMES$\beta$, representing Internal Mindfulness, for structural model analyses. 
The structural model. A recursive, theoretical model was posited (Figure 4) at the onset of this study and remained the same for this analysis using CHIMES-IM. Following correct model specification guidelines, bivariate correlations that were statistically significant were included in the model. However, negative, non-significant correlations were reported between applied training and each CHIMES- $\beta$ subscale. Because exploring the relation between applied training and mindfulness represented the central research purpose of this study, these variables and resulting path remained in the model. Overidentification of the model was supported ${ }^{2}$. All model variables were standardized and scales were based on mean scores.

The initial, theoretical model resulted in a poor model fit (Figure 5, Table 12) and three non-significant paths. These paths were between (a) applied training and mindfulness exposure (a covariance path, $t=-1.097$, n.s.), (b) applied training and internal mindfulness $(t=-0.025$, n.s.), and (c) mindfulness exposure and cognitive flexibility ( $t=1.188$, n.s.). Revisions based on to the theoretical proceeded in a nested fashion (O'Rouke \& Hatcher, 2013) in the order previous presented (applied training and mindfulness exposure, applied training to internal mindfulness, and mindfulness exposure to cognitive flexibility). Additionally, the path, mindfulness exposure to communication flexibility, indicated near non-significance $(t=1.99)$ and was theoretically similar to the path, mindfulness exposure to cognitive flexibility, which was deleted due to nonsignificance. A Revised Model 3 was conducted to assess if path specifications would be improved by its removal. Though the chi square statistic increased, goodness-of-fit indices diminished and a chi square difference test did not indicate significance. Thus, Revised Model 2 was selected.

\footnotetext{
${ }^{2}$ Based on the equation: Involved data points $=(p[p+1]) / 2$ where $\mathrm{p}=$ manifest variables. Total of 45 data points involved. Total of 24 parameters involved. Overidentified because data points greater than parameters.
} 
Revised model two model specifications. Revised Model Two indicated a partial mediation, in which internal mindfulness mediated the relation between mindfulness exposure and cognitive flexibility and communication flexibility, but mindfulness exposure also directly related to communication flexibility. Despite fixing one covariance parameter (to one) and deleting two paths, Revised Model Two did not differ significantly from the theoretical structural model based on chi square difference test. The chi square different test compares the change in the chi square statistic and degrees of freedom in the theoretical and revised model (i.e., the difference between $\mathrm{M}_{\mathrm{r} 2}-\mathrm{M}_{\mathrm{t}}>\Delta \mathrm{df}$ and $\chi^{2}, p<.05$ ) (O'Rouke \& Hatcher, 2013). The difference in degrees of freedom $(\Delta \mathrm{df}=2)$ and change in chi-square $\left(\Delta \chi^{2}=1.45\right)$ between the theoretical model and the revised model two did not meet the critical value for chi square distribution $\left(\chi^{2} \geq\right.$ $3.84, p>.05)$.

Cautious findings. Despite the poor fit of the revised model (and theoretical model), standardized path coefficients offered some cautious findings. All included paths were positive and statistically significant $(t$ value $\geq|1.96|)$. Contrary to what was theorized, applied training did not significantly influence for internal mindfulness and reported a negative $t$ value $(\beta=-.025$, $t=-.304$, n.s.). Instead, applied training contributed weakly to cognitive flexibility ( $\beta=.200, t=$ 3.046) and communication flexibility $(\beta=.150, t=2.251)$. Mindfulness exposure represented a small, significant correlation to internal mindfulness $(\beta=.184, t=2.307)$, as well as communication flexibility $(\beta=.142, t=1.997)$, but not cognitive flexibility $(\beta=.086, t=1.183$, n.s.). The beta weights from internal mindfulness to communication flexibility $(\beta=.318)$ and to cognitive flexibility $(\beta=.332)$ represented moderate, positive correlations within the model and were greater than the influence of applied training on communication flexibility $(\beta=.150)$ and cognitive flexibility $(\beta=.200)$. These path coefficients, though significant, still represented 
small to medium correlations. Instead the strongest correlations remained within the measurement model in which standardized beta weights ranged from .486 (aware internal) to .881 (decentering), indicating a sound CHIMES-IM.

Comparisons between professional status, graduate education, and age. Hypothesis testing was conducted to gather a more detailed view of key study variables and differences in mindfulness, cognitive flexibility, and communication flexibility. Comparisons between professional status (graduate student or professional) and type of graduate education (highest earned for professionals or currently enrolled for graduate students) were conducted using $t$-tests and an analysis of variance (ANOVA), respectively. Equal variances were assumed and supported by non-significant Levene's Test. Effect sizes provided information regarding “how much difference there is between groups and how strong the relationship is between variables" (Durlak, 2009, p. 918). Effect size calculation is recommended regardless of significance level and interpretation was based on the context, previous literature as available, and Cohen (1988) (Durlak, 2009). Due to different group sample sizes, corrected effect sizes were also calculated (i.e., $g$ ). Interpretation of Cohen's $d$ is small (0.20), medium (0.5), and large (0.8) (Cohen, 1988; Medical Research Council [MRC] Cognition and Brain Sciences Unit, 2009). Interpretation of eta square is small (0.02), medium (0.13), and large (0.26) (MRC Cognition and Brain Sciences Unit, 2009). Applied interpretation of effect sizes was aided Dulak (2009), Lakens (2013), and Magnusson (2014). All statistical analyses were conducted using SPSS (IBM Corp, 2012).

Professional status. On average, professionals reported greater cognitive flexibility $(n=$ $133, \mathrm{M}=5.243, \mathrm{SD}=0.404)$ than graduate students $(n=60, \mathrm{M}=5.055, \mathrm{SD}=0.476)$. This difference was significant with a near medium effect size $(t(191)=2.819, p<.01, g=0.438)$. Professionals also reported greater communication flexibility $(n=129, \mathrm{M}=3.910, \mathrm{SD}=.433)$ 
than graduate students $(n=58, \mathrm{M}=3.684, \mathrm{SD}=.516)$. This difference was significant with a medium effect $(t(185)=3.099, p<.01, g=0.49)$. There was no significant difference between professional status and amount of mindfulness exposure $(t(167)=.820$, n.s. $)$. However, mindfulness exposure was significantly and positively correlated with the CHIMES-IM subscales, accepting $(\mathrm{r}=.159, p<.05)$, decentering $(\mathrm{r}=.168, p<.05)$, and relative thoughts $(\mathrm{r}=$ $.166, p<.05)$, as well as communication flexibility $(\mathrm{r}=.176, p<.05)$. All sub-scales of the CHIMES-IM indicated non-significance between professional statuses, though very small effect sizes were reported for accepting ( $g=.198)$, decentering $(g=.152)$, and insight understanding ( $g$ $=.195)$. Table 13 presents all $t$-test results and effect sizes calculated through Psychometrica (Lenhard \& Lenhard, 2015).

Graduate education. Variance comparisons between type of graduate education and mindfulness, cognitive flexibility, and communication flexibility were assessed using ANOVA statistical testing. Analysis occurred separately for professionals $(n=129$, Table 14$)$ and graduate students $(\mathrm{n}=58$, Table 15$)$. Graduate education was categorized into the following groupings: (a) Ph.D. of Kinesiology, (b) Ph.D. of Counseling/Clinical Psychology, (c) Ph.D. of Sport and Exercise Psychology, (d) Master's of Counseling, and (e) Master's of Sport and Exercise Psychology, and (f) Master's in Kinesiology.

There was a significant difference between professionals' type of graduate education and their scores on cognitive flexibility $\left(F(5,119)=2.728, p<.05, \eta^{2}=0.102\right)$. Cognitive flexibility demonstrated near medium effect size, suggesting that 10.2 percent of the variance of CFS scores can be contributed to type of academic degree. Communication flexibility reported significance, but a small effect size $\left(F(5,115)=2.430, p<.05, \eta^{2}=0.095\right)$, which indicated that graduate degree accounted for 9.5 percent of variance on the COMMFS. Post hoc tests (Turkey's HSD 
and Hochberg due to unequal sample size) were conducted for cognitive flexibility and communication flexibility. Participants with a Ph.D. in Psychology reported significantly $(p<$ .05 ) higher levels of cognitive flexibility and communication flexibility than participants with a Master's in Counseling. Unlike cognitive flexibility and communication flexibility, type of graduate education did not significantly differ based on internal mindfulness. However, all CHIMES-IM sub-scales, except decentering, reported effect sizes above 0.02 and ranged from 4.5 percent (aware internal) to 5.7 percent (relatively of thoughts).

For graduate students, there was a significant difference and medium effect size between type of graduate education and cognitive flexibility $\left(F(4,52)=2.760, p<0.05, \eta^{2}=.175\right)$. Post hoc testing (Turkey's HSD and Hochberg) did not indicate which groups significantly differed. Effect size $\left(\eta^{2}\right)$ of four CHIMES-IM sub-scales, aware internal, accepting, decentering, and relative thoughts, exceeded 0.02 (i.e., small effect). The limited range of CHIMES-IM scores may account for non-significance, but presence of small effect sizes.

Age. There were no significant difference between age ranges and internal mindfulness (Table 16), cognitive flexibility $(F(7,178)=1.680, \mathrm{n} . \mathrm{s})$, or the communication flexibility $(F(7$, $177)=1.281, \mathrm{n} . \mathrm{s})$. Age range was positively correlated to cognitive flexibility $(\mathrm{r}=.229, p<.01)$ and communication flexibility $(\mathrm{r}=.180, p<.05)$, but age ranges reported a non-significant and weak negative correlation to CHIMES-IM subscales (ranged from -0.024 to -0.140 ). These results indicated that as SPCs age, internal mindfulness may slightly decrease, while cognitive flexibility and communication flexibility may tend to increase. However, this changes were not enough to demonstrate a significant difference based on age group.

Survey participants' exposure to mindfulness. Participants were surveyed regarding how they learned about mindfulness and they were able to select as many responses as 
represented their learning experience. Participants endorsed several areas of informal and formal learning. Informal, self-directed learning, such as reading research or popular literature or personal practice, was the most frequent mode of learning $(n=133)$ followed by formal learning through conference lectures and workshops $(n=122)$ and graduate school coursework $(n=118)$. Applied training experience $(n=103)$ could refer to informal or formal experiences such as clinical case or content presentations, supervision, or informal conversations with colleagues and peers. Less frequent modes of learning were from a mentor or advisor $(n=78)$ and professional development courses $(n=63)$. Every participant in the survey sample knew about the term and concept of mindfulness (i.e. no participants endorsed the item: "I have not learned about mindfulness").

\section{Research Phase II: SPCs' development of mindfulness and its influence on consultation}

Sport psychology consultants were queried about how they developed mindfulness and its role in their consultation service delivery. Unexpectedly, imbedded within interviewees' responses were interviewees' conceptualizations, definitions, and perceptions of what mindfulness is and associated terminology to express that understanding. A few participants expressed difficulty with defining mindfulness and concern about how it is currently referred to in popular culture and sport psychology. Therefore, interviewees' definitions of mindfulness are summarized and pictorial representations of each interviewee's conceptualizations are also provided (Figures 7-13). The center circle is the most salient concept and the surrounding circles are connected components. The darker the circle is shaded, the more emphasis it received within the conceptualization. Understanding how interviewees conceptualized mindfulness was important because it ultimately shaped: (a) which developmental experiences they identified and discussed and (b) how they integrated mindfulness in their consultations. Finally, four case 
exemplars are presented, which demonstrate the interactions between definition, development, and integration.

Interviewees' definitions of mindfulness. Interviewees consistently mentioned selfawareness and present moment focus in their definitions of mindfulness (all participants were given pseudonyms, Figures 7-13, Figure 14 for Bergomi et al. 2013a definition). For four participants, self-awareness was the central tenant of mindfulness. For example, participants remarked, "Mindfulness for me as a consultant is first and foremost know myself" (Sarah, Line 190) and "the first thing is self-awareness...being aware of your thoughts... and how they influence your decisions and conversations" (Jacob, Lines 5-6). Two participants identified a reflective process as the core of mindfulness (e.g., "in the moment reflective process" Jill, Line 15 ; "mindfulness is about this dynamic reflection... [that] leads to...purposeful living" (Dan, Line 96). Reflection could be considered an action that promotes self-awareness.

Self-awareness was closely connected to a present moment focus, which attended to internal and external thoughts, emotions, and experiences that were occurring. Andy considered mindfulness, "The awareness of where my attentional focus is and even more importantly, what is going on within me and what emotions are being pulled out within me" (Lines 121-122). As previously noted, Jill emphasized mindfulness as an "in the moment reflective process" (Line 15). Not only was mindfulness viewed as "awareness and being present" (Jacob, Line 74), but also there was some agency and training of that awareness. Mike explained, "The term mindfulness, really we are talking about attention control" (Line 85), which individuals could direct their attention to by "being in the present moment" (Line 67).

In addition to the components of self-awareness and present moment focus, participants shared more nuanced, personal views of mindfulness. Two participants expressed mindfulness 
as acceptance and non-judgment of thoughts and experiences (e.g., "It's just noticing your thoughts, being more accepting of your thoughts" Mike, Line 66; I've become a lot less judgmental about my skills...I am more accepting of [consulting mistakes], Amy, Line 66-68). Jill underscored how mindfulness through self-reflection "is just a good way to realize if we are being our authentic selves and acting in line with our values" (Lines 17-19). A focus on selfdevelopment was iterated by Dan, who stressed that mindfulness included "a willingness to think and challenge one's self” by "being an active learner... [and] a willingness to learn” (Lines 9394, 97-105). Sarah shared that faith framed personal and professional perspectives. Faith encouraged intentionality and purposefulness towards life, which promoted an "air of mindfulness" (Sarah, Line 8). However, Dan viewed purposeful living as an outcome of being mindful (Lines 94-96), instead of purposeful living producing mindfulness.

In general, similar resources shaped participants' definitions of mindfulness. Four participants spoke about exposure to Kabat-Zinn's books or meditation recordings and its influence on them (Andy, Amy, Jacob, and Jill). Three participants also identified reading about Acceptance Commitment Therapy (ACT) and implementing ACT principles into their consultation (Andy, Mike, and Jill). Two participants noted the eastern and western versions and history of mindfulness (Andy, Dan). Only one participant mentioned Ellen Langer's work in mindful learning (Dan).

In sum, participants expressed a few shared components of mindfulness, specifically selfawareness with a temporal, present focus on internal and external thoughts, emotions, and experiences. Participants' additional mindfulness components varied, as did the degree to which these additional components and the shared components were emphasized. Additional mindfulness components included acceptance, non-judgment toward mental events and 
experiences in the present, purposefulness, authenticity and values-driven behaviors, the influence of faith, and active, mindful approaches to learning. Participants commonly referred to work by Jon Kabat-Zinn and based on ACT as literature that first introduced them to mindfulness and mindfulness-based therapy.

Unease with the term, mindfulness. Andy, Mike, Jacob, and Dan expressed concerns and difficulties about how to translate mindfulness in consultation and terminology. It is perhaps important to note that these four participants were the most active consultants of all the participants (three full-time and one part-time) and work with either collegiate/elite athletes, business persons, or military personal. These participants expressed concern that mindfulness had become a "popular label/buzz word" (Dan, Lines 9, 82) and a "fad" (Mike, Line 111), though Andy's concerns were comforted by the long history of mindfulness within eastern traditions (Lines 141-146). Within sport psychology, Dan noted, "I know how a lot of people like to define it. In practice, you know, some awareness plus acceptance plus a few meditations skills, eh. That's just repackaging a mental skill to me" (Lines 90-92). Indeed, it seems mindfulness was absorbed into the existing, traditional mental skills of sport psychology. Participants often replaced mindfulness with "focus training" (Andy, Line 46), "attention control" (Mike, Line 85), and "awareness and being present" (Jacob, Line 74). This reframing of mindfulness reflected participants' hesitation to sound too existential to clients (Jacob, Line 5960) and to follow a specific business model that has particular key terms (Mike, Lines 83-85). In addition to reframing mindfulness, participants generally distanced themselves from the term, "meditation". Three participants emphasized that meditation can be a part of mindfulness and mindfulness practice, but that there is more to mindfulness than meditation. For example, Dan stated, "Meditation can be mindful, but it is not per se mindfulness" (Line 86) 
though this participant noted that consultants can and do use meditation with teams. Jill noted that mindfulness practice does "not necessarily involve meditation" (Line 11) and Mike worried that "mindfulness books are geared more towards just meditation a little bit and I think that can kind of give mindfulness a bad rap because people are like "Oh, it's this eastern medication like lie in lotus position for two hours" (Lines 63-65).

The decisions to reframe mindfulness demonstrated the on-going decisions on how to understand and use mindfulness in consultations. Participants acknowledged the challenge to conceptualize mindfulness (Jacob, Lines 31-35; Dan, Lines 29-31, 41-46) and integrate skills that were difficult to physically "see" changes in improvement (Andy, Lines 90-94). Nonetheless, consultants endorsed mindfulness-based interventions and explained how they integrated their understanding of mindfulness within their consultations and how it influenced them as consultants.

Case exemplars. Four participants were selected for in-depth analysis of how they developed mindfulness and the role of mindfulness within their consultation. Although it is not ideal that the selected participants were all male, they did represent the most active sport psychology consultants in terms of hours per week consulting. In addition to their consultation activity level, they represented the range of educational backgrounds and graduate programs within the interview sample. Several participants were from the same graduate programs and this selection minimized redundancy. All participants had experience working with athletes at either the college, national, or elite levels, but two also consulted with business and military clients. Though this selection does not claim to represent all SPCs' experiences with mindfulness (or even the entire sample's experience), it provides a starting point to understanding how SPC developed and integrated mindfulness. 
The retrospective nature of these research interviews suggested that participants inherently framed their developmental experiences and consultation approaches in the context of how they personally defined mindfulness. Thus, the process and actions identified by participants in both of these contexts (development and consultation integration) proceeds through and out of each interviewee's definition. The following section depicts the connections between definition, development, and consultation integration. Figures 15-18 illustrate each participants' definition (center), developmental experiences (left), and how their definition of mindfulness is implemented within the consultation (right). The solid arrows connect developmental experiences with the definitional component it formed. The dashed arrows link the definitional component to how it informed consultation. Mindfulness influenced consultation in client-directed and SPC-directed ways. Client-directed refers to ways a participant used mindfulness with a client (e.g., intervention, goals of consultation), whereas SPC-directed referred to ways in which an interviewee applied mindfulness to help himself perform as a SPC.

Andy. Self-awareness was a central tenet to Andy's conceptualization of mindfulness because it supported awareness of one's focus, which benefited the client's performance, as well as his own in a consultation (Figure 15). Self-awareness also promoted connection to his internal and external worlds. To him, the internal world consisted of thoughts and emotions that occurred in a consultation session or in his daily life. External world referred to relationships, nature, and the events occurring in his surroundings. Being attuned to both worlds allowed him to integrate his observations, reactions, and experiences into consultation and use what he noticed to support the client's processing and their relationship.

Development. Andy progressed through three developmental phases to integrate mindfulness into his personal and professional lives. First, his personality gravitated towards a 
more mindful approach toward how he lived and worked, even before learning about mindfulness. He naturally informally practiced, which consisted of "a lot of observation and introspection" (Line 37) that encouraged connecting with himself and the world by being conscious in his daily life, making time for reflection, and being with nature. In terms of personality tendencies, he noted, "I guess many people are proud of multi-tasking and I've never kind of been that way. I've always been able to focus pretty intently" (Lines 33-34).

Second, he originally learned and applied a Cognitive Behavioral Therapy (CBT) orientation to his work and found it "effective and useful, but it also didn't really fit with how I, myself, was as a person. I didn't know what, how it was different or I couldn't really put my finger on it" (Lines 12-15). A clinical peer's presentation on Acceptance Commitment Therapy (ACT) introduced him to mindfulness-based approaches and he continued to learn more through reading texts on ACT and books written by Jon Kabat-Zinn.

Last, because of these readings and growing interest in mindfulness, he began to practice more formally by meditating with audiotapes by Kabat-Zinn. He believed, "If I was going to be teaching it and encouraging other people to do it, I needed to do it myself” (Lines 26-27). He also practiced informally by taking time out of his day to reflect, do yoga, and practice lovingkindness meditation. In addition to practicing mindfulness personally, he also sought support for integrating a mindfulness-based theoretical orientation to his work more explicitly.

Collaboration with a sport psychology colleague helped him understand ways to integrate mindfulness within performance realm and their discussions further shaped his understanding of mindfulness. This colleague also prompted him to read research from Richard Davis on mindfulness and neurological markers, which helped him explain the neurological effects on 
mindfulness to clients. Andy noted that he has always wanted to receive formal training and supervision in ACT, but he had not done so.

Integration. For Andy, learning about mindfulness did not prompt a great shift in how he lived and worked per se. Instead, it fit how he was and provided a more aligned approach to consultation. In a client-direct way, mindfulness became "something that is part of my theoretical approach to both performance and clinical work" (Lines 3-4). Additionally, mindfulness meditation became a "common intervention...central to what [he did]....and is integrated with everything" (Lines 102, 114-118). Both informal and formal mindfulness meditation were implemented to fit the client. Sometimes clients did not realize he assigned informal meditation practices because these activities were referred to as "focus training" and made sport and client specific (e.g., if basketball, focusing for the time of a shot clock). The aim of these mindfulness mediation practices were to "teach focus, as well as to become more aware of focus so that [performers] can identify earlier when their focus is drifting or not where it would be most effective for their performance" (Lines 104-107). New technology, such as mindfulness apps, provided another medium to teach these skills (Line 122-123).

Mindfulness influenced Andy in SPC-directs ways. He believed that his personal informal and formal mindfulness practice "makes me a much better consultant" (Line 100) and "helps me in a lot of different ways" (Lines 56-57). In particular, it supported self-awareness of his inner processes and emotions (e.g., "what is going on within me and what emotions are being pulled out of me, Line 122, see also Line 57-59) that could inform his work with a client by either understanding how other's might experience the client (Line 123), or help the client "deepen, sit with, or better understand their experiences" (Lines 126-127). Awareness of his focus facilitated his ability to be present with a client; thereby further promoting a better 
consultee-consultant relationship and being "in tune with [himself], relationships, the environment, and everything" (Line 58-59). Thus, mindfulness was not only an approach and intervention for clients, but also something that supported his performance as a consultant.

Mike. Mindfulness was a concept and skill actively utilized by Mike in his personal life and approach to consultation (Figure 16). His definition of mindfulness reflected the readings with which he engaged as he learned about mindfulness, especially the texts about Acceptance Commitment Therapy (ACT). He explained, "I kinda like the ACT as mindfulness...it's just noticing of your thoughts and being more accepting of your thoughts and being in the present moment" (Lines 66-67). For him, the CMT Practitioner's Guide to ACT helped transition from the traditional CBT background of sport psychology where the "first thing everyone teaches, like 'when you have a negative thought, strip it away'. But, you know you can still do that, but can you use you use that in terms of just noticing thoughts and being like you know what, 'I am ok"' (Lines 45-47). For him, attentional control was the main component of mindfulness (e.g., "the term mindfulness, really we are talking about attention control," Line 85) and it influenced the ability to notice and accept thoughts, as well as perform in the present.

Development. Mike was exposed to and developed mindfulness through applied training experiences, self-initiated reading, and personal practice. He first learned about mindfulness, specifically ACT, during an internship at an Olympic training facility as a Master's level graduate student. He proceeded to read research and books, such as ACT Made Simple, CBT Practitioner's Guide to ACT, and The Psychology of Enhancing Human Performance: The Mindfulness-Acceptance-Commitment Approach. He practiced biofeedback exercises to develop attentional control and also integrated small exercises into his daily routine, such as brushing his teeth while trying to fully experience this action and its sensations instead of planning his day. 
Additionally, he practiced yoga and meditation, which generally supported the development of mindfulness. He noted that he did not learn about mindfulness within his graduate coursework, but wished he had. In general, he tried "to practice where I can as best I can" (Lines 12-13) in order to "practice what I preach" (Line 30). Though, Mike noted his mindfulness fluctuates and he did not "know whether it's gotten better or worse over the years, hopefully better" (Lines 9697).

Integration. Mike attempted to implement mindfulness consciously into consulting with the interventions he used and how he was as a consultant. The importance of attentional control, present moment focus, and noticing and accepting thoughts influenced how he perceived his role, approached his work with clients, and reflected on his own performance as a consultant. Present moment focus, as a client-directed aspect, resonated with his goal as a consultant, which was:

To get the performer to come back to the present moment because if you, um, veer from the present moment, if you worry about what just happened in the past...or are worried about what's going to happen in the future then you can't possibly be fully immersed and focused on your current performance. (Lines 75-78)

Maintaining a present moment focus demanded attentional control and training. He used a teeth brushing exercise to help clients notice thoughts and come back to the experience of teeth brushing (Lines 27-30), as well as activities and worksheets from ACT Made Simple. These activities were packaged informally and in a manner that the client did not necessarily realize they were doing mindfulness training or meditation. Biofeedback was an integral aspect of his consultation, which specifically taught and evoked attentional control. He believed that through biofeedback training: 
We are teaching [mindfulness] deliberately through biofeedback and through listening to your body, that's just mindfulness. If you're paying attention to your breathing and heart rate and seeing that on a screen and staying in that moment of keeping your breath at a certain pace, that's being mindful, you know. If you're trying to change your brain waves or the different, your blood flow within your prefrontal cortex, you have to be mindful. That's the only way to be, uh, to get better at the biofeedback games that we have. (Lines 85-90)

Not only did mindfulness influence his goals and interventions with clients, but also it shaped how he performed as a consultant (SPC-directed ways). In particular, he became more aware of noticing his thoughts about a client during his session and worked to bring his focus back to their present interaction instead of getting lost in these thoughts. Of note, though Mike included "accepting thoughts" as part of his definition, he did not explicitly integrate this aspect into his own relationship with his thoughts during a session or stress this concept when discussing his work with clients.

Jacob. Mindfulness, specifically in the form of being and cultivating self-awareness, was stressed within Jacob's consultation goals for his client and also for himself professionally (Figure 17). Self-awareness pertained to "being aware of your thoughts and then as you start to become more and more aware of those thoughts, how they influence your decisions and conversations" (Lines 5-8). He believed mindfulness (in the form of self-awareness) was always there in a consultation session, but that it was "one component of effective consulting" (Line 77) and being mindful allowed the consultant to be present and experience clarity about the client's concerns, but "it should [not] be the driving force always" (Line 78). Being present was also emphasized within his understanding and implementation of mindfulness as a consultant. Like Participant 2, he saw mindfulness as "one of those things that like you are always getting better or worse at" (Lines 13-14), but becomes "second nature" (Line 11) over time. 
Development. A combination of graduate school experiences and exploring what theories and practices shaped his personal and professional understanding and use of mindfulness. Important graduate school experienced included: (a) course readings, (b) influence of his advisor, (c) the general orientation toward mindfulness approaches within his graduate program, and (d) the coursework and experiences as part of his master's degree in counseling. Readings specifically helped him become more aware of this thoughts and actions and their effects. His doctoral advisor incorporated it into his advising and consulting, and "the way he consulted certainly impacted me and the way I consult" (Line 46). Because the graduate program as a whole adopted a mindfulness orientation, it seems to him that "when you are around it for six years...you have no choice but to adopt it. I think you kinda, it starts to just become second nature" (Lines 9-11). Additionally, "the counseling background [was] imperative when it comes to like developing that next level of mindfulness. I am able to see different things that I wouldn't be able to see without that type of education" (Line 46-51). Outside of graduate education, personal therapy supported awareness of his internal processes and related actions.

Based on his exposure to mindfulness throughout his education and personal therapy, Jacob proceeded to explore mindfulness theories and practices to which he gravitated and fit him. At first he questioned if he was practicing correctly, but came to realize that "everyone is different and everyone starts at a different place" (Line 35-36) in their developmental process and the main goal is to find "find what works for you" (Lines 21). Although he did not connect with the audiotapes by Kabat-Zinn or formal meditation and practice, he did find deliberate breathing exercises a daily practice that benefited him, especially when he noticed increase stress. When doing deliberate breathing he would "try and stay present and focused on my breath" (Lines 16-17) and after many years it became natural to do and was integrated into his 
life. Although he worked to increase his ability to be present by learning about mindfulness and deliberate breathing practices, he also believed in a trait component to this aspect of mindfulness. In other words, that individuals start at different ability levels and some individuals are better at being present than other individuals.

Integration. As Jacob's definition of mindfulness suggested, self-awareness and being present were integrated into his consultation approach and supported his work as a consultant. In terms of client-directed ways, he considered the "promotion of [clients'] self-awareness [and] self-regulation" (Lines 70-71) a priority and ever-present within consultation. Whereas improving self-awareness was his consultation goal for clients, being present supported him as a consultant to be an active listener. Active listening shaped how his responses were posed and enabled him to understand client disclosures and presenting concerns more clearly. To him, mindfulness was imperative to being an active listener because:

Your ability to be present with what the person is saying, with how they are saying it, what type of context they are saying it in, the little subtle references to people or places or things that somebody might make that if you weren't mindful and you weren't totally engaged and being an active listener you wouldn't pick up on. For me, it's how it plays out in my consulting. It allows me to be a much more active listener so I can help the client and really hear what they are saying. (Lines 62-67)

How well he listened, then, influenced his ability to conceptualize client concerns, ask thoughtful questions and responses, and facilitate the consulting relationship and clients' progress. Thus, he integrated mindfulness in the form of self-awareness as a goal for clients and considered a present focus orientation integral to being an effective consultant.

Dan. For Dan, the process of thinking and challenging one's self through "dynamic reflection," being an active learner, and developing "a level of awareness" promoted mindfulness and led to living a purposeful life (Figure 18). These four core components of his definition of mindfulness (challenge one's self, active learner, reflection, and self-awareness) are threaded 
throughout his developmental experiences and how he approached consultations and integrated mindfulness in his consultations. Though living a purposeful life was considered an outcome of mindfulness, he did not expand upon what a purposeful life entailed.

Development. Family and upbringing, educational experiences, and personal interests influenced how Dan developed his understanding of mindfulness. As a minister's son, he observed his father "[do] all his counseling around a basketball court so he was always spending his time slowing down, building collaborative relations, thinking about others. And that's how the house was" (Lines 13-14). As a child, he moved often and assisted his parents with community outreach in soup kitchen and Habitat for Humanity builds that helped him see diverse communities, have more "worldly appreciation," and see how life paths and experiences were complex, non-linear, and all have value (Lines 23-28). Because of these family influences, mindfulness felt like "part of his DNA" (Lines 10).

As an undergraduate student, his major, readings, and mentor continued to shape him. Majoring in philosophy in a liberal arts environment encouraged reflection and early classroom readings, such as Zen and the Art of Archery and his philosophy textbook, promoted further introspection and viewing one's self as an active, self-initiated learner. He connected with a sport philosophy professor who challenged his thinking and pushed him to think in a "dynamic and complicated way" (Line 41) and "nudged him into the field" (Line 35). This mentor encouraged him to meet particular practitioners within the field of sport psychology, who proceeded to further guide Dan. As a graduate student, mentoring and challenging by an advanced graduate student further spurred Dan and exposed him to the work of Ellen Langer (e.g., The Art of Mindful Learning). Today, discussions with colleagues, reading books that are 
"outside what is traditionally talked about [and] that expand the horizons and thoughtfulness" (Lines 124-125), and mentoring the next generation facilitate his learning and self-challenge.

Integration. Dan implemented his conceptualization of mindfulness in client-directed and SPC-directed manners. For clients, his approach toward consultations and their sessions together demonstrated his focus on active learning and self-reflection. He believed, "My roles are really helping athletes develop so if you are not an active learner you can't [develop] and if you're not mindful, you can't learn so teaching that to athletes from this very Westernist approach" (Lines 201-203). To support active learning and self-reflection, consultation sessions needed to be mindful experiences that provided a space for athletes to "sit with their thoughts [and] reflect on their thoughts" (Lines 213-214). In general, Dan viewed his role to be "a supporter of mindfulness" (Lines 208-209) and he believed that he played an important role in cultivating a consultation environment that promoted mindfulness. However, it was not always easy or natural to integrate mindfulness into sessions. Early in his career, it was more "paint by numbers," following activities because "you need something to grab on to" (Lines 192-194) while in session. As he became more experienced, "it becomes organic the older you get where it is not paint by numbers" (Lines 191-192).

Dan's definition of mindfulness not only affected his goals of and approaches toward consultation, but influenced him in SPC-directed ways. He believed, "The second you are not mindful, you don't per se, serve well" and as "a practitioner it is important that I remain selfreflective" (Line 194). Through self-reflection and being self-awareness he could notice what personal expectations, worldviews, and assumptions he might bring into the session and, instead, "leave my stuff at the door" (Line 229) in order to be open and accepting in the consulteeconsultant relationship. He identified ego, worldview, and anxiety as "stuff" that he might bring 
into consultation. In regards to ego, he mentioned that it was important to "be willing to not be the show...it's about them, about [the athlete] and [the athlete's] experience" (Lines 233-237). Noticing and monitoring the influence of his worldview was important because "it's tough to be open if I expect everyone to go my path" (Line 226-227). Last, recognizing "my own crap and my North American crap," which might interfere with or produce anxiety regarding client's progress, helped promote a mindful experience for both the consultant and client in a session. Dan explained:

We all have our anxiety. We all have stress and I think when we watch someone struggle a little bit there's an urge to try and solve aggressively. If you don't have the barometer for what's too quick and what's too slow on the helping give solutions, you squash mindfulness... They don't need the quick fix and they understand that. It's my own crap and it's my own North American crap perhaps that drives for the quick fix because athletes get it more that we give them credit for. (Lines 244-254)

It seems his understanding of mindfulness influenced his internal processes in order notice his personal ways of being and world views, but then shift these perspectives to the side in order to be with and connect to a client's world. His own presence helped shape a mindfully-oriented session and evoked a space for client reflection and learning. He applied mindfulness equally to how he worked with clients and how he performed as a consultant.

\section{Discussion}

Although suggested as an important area of inquiry (Davis, 2012; 2013), empirical research investigating practitioners' mindfulness in the consultation setting is scarce. Within sport psychology, there is particular interest in how (and if) SPCs develop mindfulness and integrate mindfulness in sport psychology consultations (Poczwardowski \& Sherman, 2011). Therefore, this study addressed two main purposes: (a) understanding the relation between graduate education and applied training and mindfulness, cognitive flexibility, and communication flexibility and (b) SPCs' development of mindfulness and its role in 
consultation. Through a mix-methods design, two approaches, theory confirmation and theory generation, were utilized.

\section{Research Purpose I}

It was hypothesized that mindfulness would differ between professional status and type of graduate education, and mindfulness would relate to cognitive flexibility and communication flexibility. This hypothesis was partially supported. Unexpectedly, levels of internal mindfulness did not differ between professional status and type of graduate education. This finding is consistent with Baer and colleagues (2008), who did not find a significant difference in mindfulness after a meditation intervention with a highly educated sample of mental health professionals. Perhaps, a greater range of educational levels and variety of academic degrees (especially beyond psychological disciplines) is needed to assess any differences in mindfulness. Graduate pathways, including which academic curriculums best prepare SPCs, is an important topic in sport psychology (Silva et al., 2011). These results suggested that persons in each discipline exhibited similar (or non-different) mindfulness levels. Thus, the question emerges, "Is it the academic education or the type of individuals drawn to the profession that shapes level of mindfulness?" The lack of significant difference found in this study may reflect the sample more than the differences in professional status or academic degree. Perhaps, the high mean and limited range of mindfulness scores indicated that individuals, who inherently possess a particular level of mindfulness or who are more able to develop this skill, gravitate to the profession of applied sport psychology.

Unlike internal mindfulness, levels of cognitive flexibility and communication flexibility did differ between professional status and type of graduate degree. These findings, along with the direct relation between applied training and cognitive flexibility and communication 
flexibility in Revised Model 2, may indicate that certain graduate programs, specifically those programs with more applied training requirements, may facilitate higher levels of cognitive flexibility and communication flexibility. Within Revised Model 2, there was a moderate relation between internal mindfulness and cognitive flexibility and communication flexibility. These paths were the strongest within the model. Cognitive flexibility and communication flexibility, important skills for problem solving and adaptive communication, are currently understudied in sport psychology. These findings provide initial support to a direct relation between SPCs' levels of mindfulness (either developed or dispositional) and levels of cognitive flexibility and communication flexibility. As such, improving SPCs' levels of internal mindfulness may also improve cognitive flexibility and communication flexibility. These finding support the belief of Carson and Langer (2006) that "the goal of the mindful perspective is to increase cognitive flexibility and to thereby increase behavioral flexibility and the ability to adapt to one's current environment in a meaningful manner" (p. 29). Additionally, this study's results provide some empirical support to Davis' (2013) suggestion that mindfulness might facilitate cognitive flexibility in the consultation setting. Empirically, findings from this study are consistent with Moore and Malinowski's (2009) results, who found cognitive flexibility to be positively related to levels of mindfulness. Ostafin and Kassman's (2012) findings also indicated a positive relation between trait (moderate relation) and state (strong relation) mindfulness and insight problem solving. Chiesa, Calati, and Serretti (2011) cautioned interpreting the effect of mindfulness training, specifically mindfulness meditation, on cognitive abilities (attention, working memory, and executive functions) until further studies have been completed. However, some proposed mechanisms through which mindfulness may increase cognitively creative skills, such as insight problem solving, include: (a) diminished habitual responses, (b) decentering from 
ingrained schemas, (c) improved awareness of internal, nonverbal processes, or (d) a combination of the aforementioned along with additional, unknown mechanisms (Ostafin \& kassman, 2012). Despite these propositions, at this time it is unclear which mindfulness mechanisms improve cognitive flexibility and communication flexibility.

Finally, contrary to the hypothesized, theoretical structural model, internal mindfulness did not mediate the relation between applied training and cognitive flexibility and communication flexibility. Instead, mindfulness mediated the relation between mindfulness exposure and cognitive flexibility and communication flexibility. Mindfulness exposure was also directly (though weakly) related to communication flexibility suggesting that exposure to mindfulness (content or practice) may influence SPCs' behaviors more than their cognitive processes. Thus, Revised Model 2 was partiality mediated by mindfulness with a direct relation between applied training and cognitive flexibility and communication flexibility. However, Revised Model 2 was not significantly different from the hypothesized theoretical model. The poor model fit suggested that the included variables were not salient to each other or the model was missing an important variable(s) or path(s).

Qualitative findings indicated there was more to the story than suggested by the results of the first research purpose. Although type of graduate education or applied training did not influence levels of mindfulness, graduate education and applied training experiences did introduce SPCs to mindfulness, as did personal therapy, personality tendencies, and upbringing. However, learning about mindfulness through graduate coursework was only explicitly referenced by one case exemplar. Instead, learning occurred more informally through applied training experiences and discussions with colleagues and mentors during university, graduate school, and beyond. To develop mindfulness, regardless of how introduced, SPCs engaged in 
self-directed learning by reading, practicing informally and formally, and seeking support from colleagues and mentors. Overall, the inclusion of mindfulness in graduate curriculum may be program dependent instead of standard practice (such as, lessons on psychological skills training). However, this implication was based on a very small sample and further graduate curriculum and applied training program reviews are needed.

In this study, the discrepancy between confirmative (quantitative) and generative (qualitative) findings may be due to measurement. In Revised Model 2, applied training is a composite of hours and years of graduate level applied experience. However, SPCs did not refer to the length of time they engaged in consultation, but identified multiple moments of exposure to mindfulness content and practice, which prompted learning, practice, and implementation into their consultation. Even in the survey, informal modes of learning were endorsed most frequently. This developmental narrative suggests that learning and integrating mindfulness is a cyclical, repetitive process characterized by moments of exposure (i.e., episodes) followed by self-directed learning, which is then incorporated into personal and professional practice.

Mindfulness development through self-directed learning. This cyclical process and long-term developmental narrative suggests that SPCs, who decided to pursue mindfulness after exposure, are continuous learners throughout their professional careers. Self-directed learning is considered an essential process of skill development across undergraduate education, graduate education and training, and professional development (Towle \& Cottrell, 1996) that facilitates critical thinking and meaning-making in ambiguous and complex settings and disciplines (Garrison, 1997). Self-directed learners are "motivated to assume personal responsibility and collaborative control of the cognitive (self-monitoring) and contextual (self-management) processes in constructing and confirming meaningful and worthwhile learning outcomes" 
(Garrison, 1997, p. 18). Garrison (1997) offered a comprehensive model of self-directed learning from which to understand SPCs' development and integration of mindfulness into their consultation approaches. This model considers self-directed learning to be shaped by the interrelated components of self-management, self-monitoring, and motivation.

Self-management is the ability to select and pursue tasks, which is facilitated by possessing some knowledge or skill proficiency from which to expand, accessing resources to facilitate learning, and comparing learning to a standard of knowledge and norms (Garrison, 1997). In this study, SPCs demonstrated self-management when they described choosing to learn more about mindfulness after initial (or subsequent) exposure to the concept. Their ability to learn more about mindfulness and apply it to themselves and their work may suggest that they possessed a certain level of proficiency in mindfulness, which may stem from educational, applied training, social (i.e., upbringing) experiences or personality traits. Having clinical peers, colleagues, and resources (i.e., readings, meditation tapes) available seemed to facilitate that learning. Lastly, although defining and applying mindfulness in Western psychology is an ongoing discussion, there are some guidelines (e.g., Kaufman, Glass, \& Arnkoff, 2009; Teasdale, Segal\& Williams, 2003; Gardner \& Moore, 2007) from which SPCs can critique and compare their understanding of mindfulness and how to consult using mindfulness-based approach and interventions.

Self-monitoring is the responsibility to be aware of learning, to self-check learning through self and other's feedback, and incorporate new knowledge into existing schemas in a meaningful manner (Garrison, 1997). Interviewed SPCs strongly emphasized self-awareness, reflection, and active learning as processes they valued personally and in order to 'do good work'. These processes support the meta-cognitive aspects of self-monitoring. Additionally, 
mentors, who challenged SPCs' thinking, collaborated and shared how to integrate mindfulness into consultation, and role modeled a mindful orientation, helped SPCs refine their thinking and understanding of mindfulness through feedback, modeling, and advice giving.

Motivation is the both the decision to begin learning a task (i.e., mindfulness) and to sustain learning over time. Garrison (1997) explained that attraction to valued, learning goals produces a preferred affective state, which motivates learners to initiate, sustain, and complete learning goals. For SPCs in this study, mindfulness presented an additional or complementary approach to consultation, which was valued. Although this study did not investigate why SPCs value mindfulness or the affective states mindfulness learning and practice produces, their description of the benefits of mindfulness in their consultation might provide a starting point.

\section{Research Purpose II}

Integrating mindfulness into service delivery reportedly influenced consultation in clientdirected and SPC-directed ways. Both categories are inter-connected and changes in practitioner mindfulness tend to transfer into the 'look and feel' of sessions (Bruce, Shapiro, Constantino, \& Manber, 2010; Campbell \& Christopher, 2012). The differentiation between client-directed and SPC-directed influence of mindfulness may provide a better understanding of this process. Although other research on impact of mindfulness on SPCs' consultation is unavailable, research on the influence of mindfulness training on mental health practitioners' work and well-being is referenced. Findings on mental health practitioners were not differentiated by client-directed and practitioner-directed, which may suggest a unique influence of mindfulness on SPCs' consultation. It may also reflect the influence of sampling as research on mindfulness-based interventions for mental health practitioners tends to focus on the how mindfulness may improve trainees' skill development. 
Client-directed integration of mindfulness. In regards to client-directed ways, SPCs identified that their mindfulness learning and practice influenced the goals of consultation and types of interventions. Goals for clients included increasing awareness, present focus abilities, self-regulation, and ability to be an active learner. Previous research has not overtly discussed how practitioners' conceptualization of and exposure to mindfulness shapes client goal formation. It is unclear why, but perhaps the emphasis of previous research on trainees (who may have less experience and personalized intervention styles) and their skill development may not have been able to assess the influence of mindfulness on broader intervention goals or techniques. The type of interventions SPCs used with clients, such as informal or formal meditation, biofeedback, and generally cultivating the session to be a mindful experience, did echo previous research in this area. In-session mindfulness training may help clients' decrease ruminative thinking and improve their awareness, as well as self-compassion (Dunn, Callahan \& Swift, 2013a). Counselor trainees, who were exposed to a mindfulness-based self-care course, indicated interest in integrating the content and activities learned as interventions with clients (Schure, Christopher, \& Christopher, 2008). Outside of mental health, educational research has advocated for mindful classroom environments to promote dispositional mindfulness in students (Ritchhart \& Perkins, 2000) and resiliency in teachers and students (Meiklejohn et al., 2012).

SPC-directed integration of mindfulness. Within consultation, SPC-directed influences of mindfulness were improved awareness of one's self, as well as client presentation, present focus, active listening, and patience. Mindfulness training has been found to increase self-awareness and acceptance (in session, Aggs \& Bambling, 2010; in general, Moore, 2008; Schure et al., 2008) by supporting self-kindness and self-observation and diminishing evaluation of observed thoughts and emotions (Moore, 2008). Although not specifically client awareness, 
research has demonstrated that empathy toward clients can be improved with mindfulness training (Greason \& Cashwell, 2009; Leppma, 2012; Moore, 2008; Schure et al., 2008). Improved attention, present focus and engagement throughout a session has been reported as a consistent byproduct of brief mindfulness training (Dunn, Callahan, Swift, \& Ivanovic, 2013b; Greason \& Cashwell, 2009; Moore, 2008; Schure et al., 2008; Zeidan, Johnson, Diamond, David, \& Goolkasian, 2010). Likewise, engagement in a session can improve practitioners' ability to respond appropriately and use counseling skills effectively, such as active listening (Buser et al., 2012). Clients have reported experiencing more effective sessions when practitioners completed a five-minute centering exercise before session and displayed high focus during the sessions (Dunn et al., 2013b). Improved patience with the counseling process after mindfulness training reverberates across various studies. Findings have emphasized a diminished need to problem solve (McAuliffe \& Lovell, 2006), to control sessions (Schure et al., 2008), and to teach (Christopher \& Maris, 2010), as well as an increased ability to slow down, to be with the process, and to explore with clients (Buser et al, 2012; Campbell \& Christopher, 2012; Schure et al., 2008).

In this study, it seemed SPCs' experience with mindfulness supported attunement to the thoughts and emotions within themselves, as expressed by the client, and interpersonally with the client. These three levels of attunement (self, other, and interpersonal) facilitate the counseling relationship and process (Bruce et al., 2010) and can be elicited through mindfulness practice (Schure et al., 2008; Siegal, 2010). In sum, mindfulness has been shown to support a broad range generic (e.g., relationship building) and specific skills (i.e., way respond to client) (Buser et al., 2002) that can assist SPCs' ability to connect with clients and facilitate the consultation process. 
Surprisingly, SPCs did not emphasize mindfulness use for self-care or clients' care, which are applications that have been well-documented in the literature (Christopher \& Maris, 2010; Keng, Smoski, \& Robins, 2011). SPCs noted the importance of maintaining a personal practice and identified ways in which their informal practice helped them manage stress and become more centered. Nevertheless, they did not directly link mindfulness as a self-care strategy to manage professional pressures or to use as an intervention with clients. Given SPCs high work engagement and potential burnout (MacIntyre et al., 2015), mindfulness training might offer one mechanism to maintain quality work and diminish burnout. Its absence as a selfcare strategy may reflect how SPCs were exposed to mindfulness, defined it, and conceptualized the purpose of mindfulness.

\section{Defining and "Blending" Mindfulness}

An unexpected finding from this study's interviews was the personalized conceptualizations of mindfulness stated by SPCs. Normally, how a conceptual term is operationally defined within a research study is derived from research immersed in the area. Yet, holding the interviewee-driven definition and research-driven definitions side by side provided a chance to take stock of how mindfulness is being understood by SPCs and by researchers. Conversations among researchers (including clinical practitioners) about conceptual clarity, distinctiveness, operational definitions, and measurement have been on-going in Western psychology (see Baer, Smith, Hopkins, Krietemeyer, \& Toney, 2006; Bergomi, Tschacher, Kupper, 2013b; Grossman, 2011; Holas \& Jankowski, 2013; Russell, 2011), but it appears that this conversation is important for SPCs as well.

Sport psychology consultants shared components, such as present focus and (self) awareness, but also revealed a variety of emphasis (e.g., active learner, connection to internal 
and external world, noticing and accepting thoughts). The similarity and consistency of some core components suggested some consensual understanding across researchers and SPCs of what mindfulness is believed to be. Indeed, many of the interviewees mentioned the work of KabatZinn, who is considered one of the pioneers in Western mindfulness, and their definitions were influenced by his work. Interviewees' common components, present focus and awareness, reflected the first half of the Kabat-Zinn's definition of mindfulness, "the awareness that emerges through paying attention on purpose, in the present moment" (2003, p. 145). However, the definitions in this study did not emphasize the second half “ ....and nonjudgmentally to the unfolding of experience moment by moment" (2003, p. 145). Thus, SPCs conceptualizations of mindfulness focused predominantly on where one's attention was directed and less on the orientation toward what was attended. It is this orientation that separates mindfulness from simply "focusing" and other traditional western psychological theories used in sport psychology, such as cognitive behavioral therapy.

In addition to an over-emphasis of present focus and awareness without the infusion of a mindful orientation, only two main resources for understanding mindfulness (Kabat-Zinn and ACT, with one reference to Langer's work on mindful learning) were referenced by SPCs. Thus, those SPCs who said that they integrate mindfulness-based approaches into their work, derive their knowledge of mindfulness from a narrow (albeit rich) body of knowledge. This tendency may indicate that SPCs are less familiar with other understandings of mindfulness, the extent to which therapeutic approaches (like ACT) are or are not mindfulness-based, and the current research. For example, this study and the mindfulness scale used, CHIMES- $\beta$, were based on the Bishop and colleagues (2004) definition, which was not referenced by any interviewees. Like Kabat-Zinn's conceptualization, Bishop and colleagues emphasized mindfulness as a mode of 
attention toward "internal stimuli" (p. 6) in order to "bring a quality of non-elaborative awareness to current experience and a quality of relating to that experience with an orientation of curiosity, experiential openness, and acceptance" (p. 5) with the intention to gain insight through de-centering (see also Safran \& Segal, 1990; Bishop et al., 2004). Interviewees used the term 'awareness' often to describe mindfulness, which makes sense as it is a key term in the KabatZinn definition. The term 'reflection' was also utilized, though less frequently, and it is unclear from this study if the interviewees perceived any conceptual difference between awareness and reflection. However, Bishop and colleagues considered self-awareness distinct from mindfulness and from reflection. Reflection and introspection, in which one simply observes thoughts, is more aligned with mindfulness than self-awareness, in which the meanings and relationships of observed thoughts are being interpreted and actively connected. These slight, yet important, variants in terminology and definitions have implications for what mindfulness is or is not, as well how it is taught in graduate education and integrated into consultation. It also may illustrate a need for broader and deeper discussions about mindfulness in the field of sport psychology.

Although SPCs discussed mindfulness openly within the study interviews, SPCs hesitated to use the term, "mindfulness," when working with clients. Instead they preferred "focus training," "attentional control," and "self-regulation". Both the variety of definitions and the tendency to re-term mindfulness may further indicate conceptual confusion among SPCs, or also a desire to adapt the term to meet the clientele and a blending of traditional mental skills with mindfulness. It is reasonable and good practice to tailor interventions to clients and settings, but the rationales and implications of re-labeling mindfulness is also worthy of attention. While beyond the scope of this study, it raises the question, "Is it the client or SPCs who do not feel comfortable using the term and why?" 
The re-labeling seems to be indicative of blending traditional mental skills with mindfulness approach. This blend may produce many benefits. Birrer and colleagues (2012) presented a model of high performance requirements, skills, and techniques that included mindfulness among traditional psychological and personal development skills for athletes. In this model, Birrer and colleagues differentiated between dispositional mindfulness (the tendency to be mindful in daily life) and mindfulness practice (characterized by "intention, attention, and attitude" p. 235), and also suggested mechanisms through which mindfulness may support athletes' skillful, high quality performance. Although this theoretical model may offer a great resource and direction for SPCs integrating (client-directed) mindfulness-based approaches into consultation, it is important to maintain clarity for SPCs and clients what are mindfulness practices (and theory) and what is a blended version of mindfulness and traditional psychological skills.

Overall, SPCs in this study revealed some conceptual confusion, but mentioned seeking advice from colleagues and mentors or engaging in informal reading in order to advance their understanding and ability to integrate it into consultation. However, none of the interviewees said they had received formal training and/or supervision in mindfulness-based approaches. Thus, it is unclear how well mindfulness is understood among other SPCs. Although wellintentioned, these learning process may or may not be advancing understanding and integration of mindfulness. Sport psychology consultants are not alone in their search to understand mindfulness, as Western researchers continue to question how to operationally define it, measure it, and assess it. As such, it may be that this conversation - how to define and understand mindfulness - may be co-occurring at separate, 'horizontal levels" (i.e., practitioners and researchers). It is unknown how much vertical discussion between researchers and practitioners 
is happening. Vertical conversations are important so that there is sharing of multiple perspectives, agreement in conceptualization, and establishment of accurate and similar applications by practitioners and researchers. Potentially, graduate education is one mechanism in which to connect the horizontal and vertical discussions. Based on this study's findings, it appears that minimal information about mindfulness is discussed in the graduate level curriculum (based on the time-frame the interviewees attended). Thus, there is opportunity to begin to bridge research and applied conversations through graduate education. Without open discussions across these important sectors within sport psychology, miscommunication, inaccurate findings, and improper implementation may occur.

\section{An Adjusted, Preliminary Composite Conceptualization}

This study's findings, taken together, cautiously suggested a relation between mindfulness exposure and behavioral changes within SPCs that influence how they approached and conducted their consultation. As Figure 19 depicts, exposure to mindfulness may initiate greater communication flexibility and self-directed learning, which results in behavior changes. In turn, behavior changes are integrated into SPCs' personal practice and consultation in clientdirected and SPC-directed ways based on their conceptualization of mindfulness (as influenced by their exposure). This cycle continues as the SPC receives feedback from personal and professional experiences, as well as engages in further exposure and learning. 


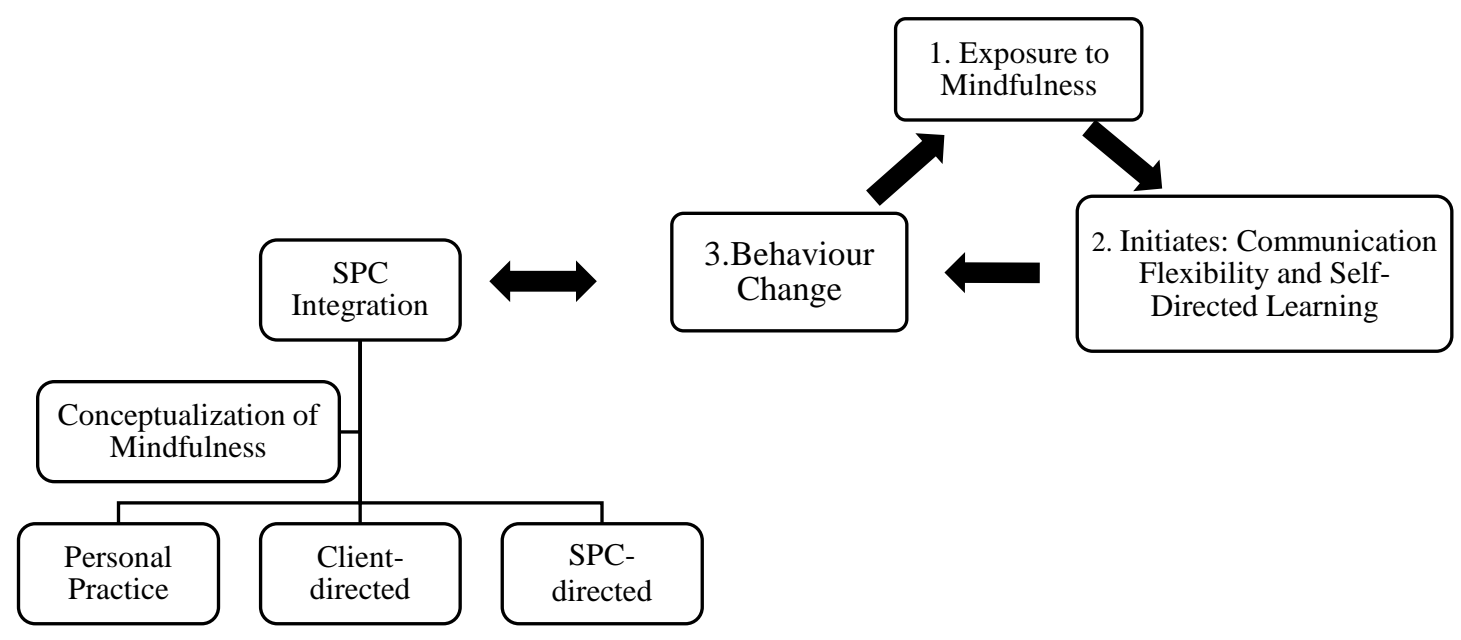

Figure 19. Preliminary composite conceptualization of mindfulness development and role in sport psychology consultation. Process continues across time and multiple exposure moments and integrations.

\section{Limitations}

As mentioned throughout the discussion, there were several clear limitations to this study. First, there were several measurement issues. In regards to the CHIMES- $\beta$, there were four items omitted from the scale participants completed. Thus, comparisons to the original CHIMES- $\beta$ cannot be made. Additionally, CHIMES- $\beta$ underwent significant scale modification. As a new scale (and used for the first time on a North American sample), these changes are part of the developmental process, but difficult to contextualize within the literature at this time. The resulting CHIMES-IM focused on one aspect of mindfulness (internal mindfulness), which may limit comparisons of results across studies that measure different aspects of mindfulness. Because there are several mindfulness self-report scales, it is unclear how similar or distinct these scales are from each other. Thus, any cross-study comparisons made should be heeded with caution. All of the scales used in this study were self-report and, thus, liable to bias due to social desirability. Survey participants were not told the study's main variables (i.e., 
mindfulness, cognitive flexibility, and communication flexibility) until the end of the survey in order to diminish this bias. Last, mean scores were above the average on the Likert scale, which might indicate poor discriminatory properties of the CHIMES- $\beta$ and CHIMES-IM. Further research using these scales might help clarify this concern.

The sample size attained was sizable for the SPC population, but did not meet the acceptable range for SEM. Thus, results should be interpreted with caution. Additionally, the results of the SEM require further confirmation on new samples to provide verification. Given the poor model fit (though approaching adequate model fit), adjustments based on this study's findings, further review of literature, and future studies would need to be made. The case exemplars consisted of only male SPCs. This decision was made consciously due to other benefits this cross-section provided, but at the cost of hearing a female perspective that may or may not differ.

Overall, this study was correlational and no causal effects can be stated. Additionally, the client-directed and SPC-directed ways in which mindfulness was integrated cannot be directly connected to cognitive flexibility, communication flexibility, problem solving, or communication. However, the data generated can ground future studies that specifically examine these relations.

\section{Strengths}

This study's mix-methods design was a primary strength because it provided an opportunity for divergent, complex findings to arise out of the data. In so doing, a more nuanced view evolved, which suggested how mindfulness developed, how it related to a priori variables, and how it influenced emergent processes and actions within sport psychology consultations. The conceptualizations derived out of these data are at their early stages, but provide 
groundwork for researchers to adjust and advance. In this way, the data can be viewed as theory generative not only for this study, but many more studies to come.

The in-depth interviews provided a glimpse into how SPCs understand and do their work from a mindfulness approach. This exploratory focus is advocated by PJDM research in order to better understand "why practitioners are doing what they are doing" (Martindale \& Collins, 2007, p. 467). Traditionally, research on mindfulness and practitioners consisted of brief interventions with follow-up assessment. Although such intervention research has its benefits, it cannot show the developmental narrative that retrospective interviews can present.

Retrospective interviews highlight what was meaningful and interpreted as additive and participants can explain multiple stages of development along with its antecedents and effects. It is acknowledge that identified experiences may not necessarily be what elicited change and development, but nonetheless resonated with interviewees' development of mindfulness.

\section{Future Directions}

Because mindfulness within consultation is a developing research area, there are several future directions this study might support. First, the model in this study provided some findings, but was generally a poor fit statistically. Therefore, further exploration into the variables and paths that should make up a developmental model (and how these variables might be measured) should be pursued. This study begins this process by presenting a revised, preliminarily conceptualization built from the result and discussion sections. Additional interviews, observations, and large survey-responses might refine this conceptualization and develop it into a measureable model.

Second, early career professionals constituted the survey and interview participants, which is different from previous research that focused on veteran SPCs (Poczwardowski \& 
Sherman, 2011). However, to more closely compare graduate education and applied training experiences, a mix-method cohort study might be an effective research design. Cohorts could be divided into current master's and doctoral graduate students, and then professionals every five or ten years after graduate school.

Third, this study was situated within PJDM research and explored how SPCs 'do what they do' in regards to developing and integrating mindfulness. To capture the behavioral aspects of these retrospective interviews and see mindfulness-based approaches come to life, SPCs conceptualization, problem solving, and action process might be investigated through the use of think aloud protocol (written or video scenario) or in real time through the use of video capturing SPCs' perspective. Adapted from Luna (2013), this small video would be adorned on SPCs and could capture in the moment thinking by allowing SPCs to push a record button (thereby saving the previous minute of recording) when SPCs noted an important event, made an observation, or would intervene. Recordings could then be reviewed by SPCs and the researcher to understand the thought process during 'real time' consultation.

\section{Conclusion}

It was conceptualized at the onset of this study that problem solving and communication were two fundamental consultant tasks and that mindfulness, cognitive flexibility, and communication flexibility might promote these tasks. Additionally, it was thought that graduate education and applied training might foster mindfulness, cognitive flexibility, and communication flexibility. So, did it? As with most things, it depends and there is more to learn.

It seems that most learning about mindfulness occurred informally and in self-directed ways rather than in the classroom. Some of these informal modes were in graduate school, such as collaboration with colleagues, mentoring, or at applied training sites. The survey indicated 
that graduate coursework was the third most frequent mode of learning about mindfulness. However, based on interview participants $(2-25$ years post graduate school), mindfulness concepts or application to consultation were mostly not structured into graduate education coursework. Thus, there remains some discrepancy about how often and in what manner mindfulness is integrated into the graduate curriculum.

Applied training did not account for mindfulness as was predicted, though it seemed to be an important way SPCs were exposed to mindfulness and tried out mindfulness-based approaches. Both mindfulness and applied training appeared to relate to levels of cognitive flexibility and communication flexibility, offering initial support that mindfulness might facilitate skills which are important for problem solving (cognitive flexibility) and communication (communication flexibility). The important role of the quantity of applied training experiences, particularly paired with individual and group supervision, is further encouraged by its relation to cognitive flexibility and communication flexibility.

The accounts of how mindfulness influenced sport psychology consultations in clientdirected and SPC-directed ways indicated some connection to problem solving and communication tasks. SPCs in this study used mindfulness-based interventions or included mindfulness approaches in their interventions in order to help their clients solve their presenting concerns and gain a skill set. Thus, the intervention approach, how SPCs conceptualized that approach, and the goals of consultation seemed to be shaped by their understanding of mindfulness. SPC-directed influences, such as patience, also facilitated problem solving by approaching consultation in a slower, more open manner, instead of rushing to 'do' and 'fix' right away. Additionally, how SPCs in this study integrated mindfulness into their own behaviors affected the way they interacted with clients, including how they communicated. A 
SPC, who is an engaged, present focused, and active listener, is likely more able to respond appropriately a client's presentation (i.e., content and affect). Further examination is needed to understand these potential relations more clearly and the mechanisms through which mindfulness supports problem solving and communication in sport psychology consultation setting.

Finally, it is hoped that these findings provided some initial information to graduate programs to support the development of future SPCs. As the entry way into the professional world of sport psychology, graduate education and applied training provide a foundation and exposure to core knowledge, skills, and abilities that develop competent SPCs. Because of the range of ways mindfulness contributed to SPCs' consultation within this study (including potential blending with traditional psychological skills training), as well as early indication that it may relate to higher levels of cognitive flexibility and communication flexibility, graduate programs are encouraged to incorporate mindfulness content into their coursework and applied training curriculums. 


\section{References}

Acock, A. C. (2006). A gentle introduction to Stata. ( $2^{\text {nd }}$ Ed). College Station, TX: Stata Press.

Aggs, C., \& Bambling, C. (2010). Teaching mindfulness to psychotherapists in clinical practice: The Mindful Therapy Programme. Counselling and Psychotherapy Research, 10(4), 278286. doi: $10.1080 / 14733145.2010 .485690$

Ahn, A. J., Kim, B. S. K., \& Park, Y. S. (2009). Asian cultural values gap, cognitive flexibility, coping strategies, and parent-child conflicts among Korean Americans. Asian American Journal of Psychology, S(1). 29-44. doi: 10.1037/1948-1985.S.1.29

Andersen, M. B. (2000). Beginnings: Intakes and the initiation of relationships. In M. B. Andersen (Ed.), Doing sport psychology (pp. 3-16). Champaign, IL: Human Kinetics.

Andersen, M. B., \& Tod, D. (2011). Professional pathways and territories in sport psychology. In T. Morris \& P. Terry (Eds.), The new sport and exercise psychology companion (pp.403423). Morgantown, WV: Fitness Information Technology.

Association for Applied Sport Psychology. (2013a). About Applied Sport and Exercise Psychology. Retrieved from http://www.appliedsportpsych.org/about/about-appliedsport-and-exercise-psychology/

Association for Applied Sport Psychology. (2013b). Become a Certified Consultant. http://www.appliedsportpsych.org/certified- consultants/become-a-certified-consultant/ Association for Applied Sport Psychology. (2013c). Ethics code: AASP ethical principles and standards. Retrieved from http://www.appliedsportpsych.org/about/ethics/ethics-code/

Baer, R. A., Smith, G. T., Hopkins, J., Krietemeyer, J., \& Toney, L. (2006). Using self-report assessment methods to explore facets of mindfulness. Assessment, 13(1), 27-45. doi: $10.1177 / 1073191105283504$ 
Baer, R. A., Smith, G. T., Lykins, E., Button, D., Krietemeyer, J., Sauer, S., ...Williams, M. G. (2008). Construct validity of the Five Facet Mindfulness Questionnaire in meditating and nonmeditating samples. Assessment, 15(3), 329-342. doi: 10.11771073191107313003

Barry, C. (2002). Multiple realities in a study of medical consultations. Qualitative Health Research, 12(8), 1093-1111.

Bergomi, C., Tschacher, W., \& Kupper, Z. (2013a). Measuring mindfulness: First steps toward the development of a Comprehensive Mindfulness Scale. Mindfulness, 4, 18-32. doi:10.1007/s12671-012-0102-9

Bergomi, C., Tschacher, W., \& Kupper, Z. (2013b). The assessment of mindfulness with selfreport measures: Existing scales and open issues. Mindfulness, 4(3), 191-202.

Birrer, D., Rüthlin, P., \& Morgan, G. (2012). Mindfulness to enhance athletic performance: Theoretical considerations and possible impact mechanisms. Mindfulness. doi:10.1007/s12671-012-0109-2

Bishop, S. R., Lau, M., Shapiro, S., Carlson, L., Anderson, N., Carmody, J., ...Devins, G. (2004). Mindfulness: A proposed operational definition. Clinical Psychology: Science and Practice, 11(3), 230-241. doi: 10.1093.clipsy/bph077

Bochner, A. P. \& Kelly, C. W. (1974). Interpersonal competence rational, philosophy, and implementation of a conceptual framework. The Speech Teacher, 23(4), 279-301.

Bodhi, B. (2011). What does mindfulness really mean? A canonical perspective. Contemporary Buddhism, 12(1), 19-39. doi:10.1080/1469947.2011.564813

Booth-Butterfield, M. (1998). Measurement of communication flexibility: Working adults vs. college students. Communication Research Reports, 15(4), 365-369. 
British Psychological Society. (2012). Accreditation through partnership handbook: Guidance for sport and exercise psychology programmes. Retrieved from www.bps.org.uk/partnership

Bruce, N. G., Shapiro, S. L., Constantino, M. J., \& Manber, R. (2010). Psychotherapist mindfulness and the psychotherapy process. Psychotherapy Theory: Research, Practice, Training, 47(1), 83-97.

Buser, T. J., Buser, J. K., Peterson, C. H., Seraydarian, D. G. (2012). Influence of mindfulness practice on counseling skills development. Journal of Counselor Preparation and Supervision, 4(1), 20-36.

Campbell, J. C., \& Christopher, J. C. (2012). Teaching mindfulness to create effective counselors. Journal of Mental Health Counseling, 34(3), 213-226.

Cañas, J. J., Quesada, J. F., Antolí, A., \& Fajardo, I. (2003). Cognitive flexibility and adaptability to environmental changes in dynamic complex problem-solving tasks. Ergonomics, 46(5), 482-501. doi: 10.1080/0014013031000061640

Carson, S. H., \& Langer, E. J. (2006). Mindfulness and self-acceptance. Journal of RationalEmotive \& Cognitive Behavior Therapy, 24(1), 29-43. doi: 10.1007/s10942-006-002-5

Charmaz, K. (2014). Construction grounded theory. ( $2^{\text {nd }}$ ed.). Thousand Oaks, CA: SAGE Publications.

Chiesa, A., Calati, R., \& Serretti, A. (2011). Does mindfulness trainings improve cognitive abilities? A systematic review of neuropsychological findings. Clinical Psychology Review, 31, 449-464. doi: 10.1016/j.cpr.2010.11.003 
Christopher, J. C., \& Maris, J.A. (2010). Integrating mindfulnessas self-care into counselling and psychotherapy training. Counselling and Psychotherapy Research, 10(2), 114-125. doi: $10.1080 / 14733141003750285$

Cohen, J. (1998). Statistical power analysis for the behavioral sciences. ( $2^{\text {nd }}$ ed.). Hillsdate, NJ: Erlbaum.

Creswell, J. W. (2009). Research design: Qualitative, quantitative, and mixed methods approach ( $3^{\text {rd }}$ Ed.). Thousand Oaks, CA: SAGE Publications.

Davis, T. S. (2011). Evidence base for mindfulness and Mindfulness Based Conversations. Retrieved from www.mindful-conversations.com/index.php?evidence-base/

Davis. T. S. (2012). Mindfulness-based approaches and their potential for educational psychology practice. Educational Psychology in Practice: Theory, research and practice in educational psychology, 28(1), 31-46.

Davis, T. S. (2013). A literature review exploring the potential of mindfulness as a tool for developing skills and qualities for effective consultation. Mindfulness. doi: $10.1007 / \mathrm{s} 12671-013-0219-5$

DeCoster, J., \& Iselin, A. (2005). Effect size corrections. Retrieved from www.stat-help.com Dillman, D. A. (2000). Mail and internet surveys: The tailored design method ( $2^{\text {nd }}$ ed.). New York, NY: John Wiley \& Sons, Inc.

Doyle, W. L. \& Conklin, R. C. (1970). Counselor effectiveness: A changing emphasis. Counseller Canadien, 4(4), 269-276.

Dreyfus, G. (2011). Is mindfulness present-centered and non-judgmental? A discussion of the cognitive dimensions of mindfulness. Contemporary Buddhism, 12(1), 41-54. doi: 10.1080/14639947.2011.564815 
Dunn, R., Callahan, J. L., \& Swift, J. K. (2013a). Mindfulness as a transtheoretical clinical process. Psychotherapy, 50(3), 312-315. doi:10.1037/a0032153

Dunn, R., Callahan, J. L., Swift, J. K., \& Ivanovic, M. (2013b). Effects of pre-session centering for therapists on session presence and effectiveness. Psychotherapy Research, 23(1), 78 85.

Duran, R. L. (1992). Communication adaptability: A review of conceptualization and measurement. Communication Quarterly, 40(3), 253-268.

Durlak, J. A. (2009). How to select, calculate, and interpret effect sizes. Journal of Pediatric Psychology, 34(9), 917-928.

Epstein, R. M. \& Hundert, E.M. (2002). Defining and assessing professional competence. JAMA: Journal of the American Medical Association, 287, 226-235. doi: 10.1001/jama. 287.2.226

Etzel, E. F., \& Watson, J. W., II. (2011). Ethics. In T. Morris \& P. Terry (Eds.), The new sport and exercise psychology companion (pp. 425-440), Morgantown, WV: Fitness Information Technology.

Facetime. (2015). Apple Inc. Retrieved from https://www.apple.com/mac/facetime/ Factor analysis using PROC FACTOR. (2015). UCLA: Statistical Consulting Group. From http://www.ats.ucla.edu/stat/sas/library/factor_ut.htm.

Fletcher, D., \& Maher, J. (2013). Toward a competency-based understanding of the training and development of applied sport psychologists. Sport, Exercise, and Performance Psychology. doi: 10.1037/a0031976 
Flett, M. R., Gould, D., \& Lauer, L. (2012). A study of underserved youth sports program using the Youth Program Quality Assessment. Journal of Applied Sport Psychology, 24, 275289. doi: $10.1080 / 10413200.2011 .641061$

Fosnot, C. T. (2005). Preface. In C. T. Fosnot (Ed.), Constructivism: Theory, perspective, and practice ( $2^{\text {nd }}$ ed.) (pp.ix-xii), New York: Teachers College Press.

Gardner, F. L., \& Moore, Z. E. (2007). The psychology of enhancing human performance: The Mindfulness-Acceptance Commitment (MAC) approach. New York: Springer Publishing Co.

Garrison, D. R. (1997). Self-direct learning: Toward a comprehensive model. Adult Education Quarterly, 48(1), 18-33.

Greason, P. B., \& Cashwell, C. S. (2009). Mindfulness and counseling self-efficacy: The mediating role of attention and empathy. Counselor Education and Supervision, 49, 219.

Grossman, P. (2011). Defining mindfulness by how poorly I think I pay attention during everyday awareness and other intractable problems for psychology's (re)invention of mindfulness; Comment on Brown et al. (2011). Psychological Assessment, 23(4), 10341040.

Holas, P., \& Jankowski, T. (2013). A cognitive perspective on mindfulness. International Journal of Psychology, 48(3), 232-243. doi: 10.1080/00207594.2012.658056

IBM Corp. (Released 2012). IBM SPSS Statistics for Windows, Version 21.0. Armonk, NY: IBM Corp.

Kabat-Zinn, J. (2003). Mindfulness-based interventions in context: Past, present, and future. Clinical Psychology: Science and Practice, 10(2), 144-156. doi:10.1093/clipsy/bpg016 
Kaufman, K. A., Glass, C. A., \& Arnkoff, D. B. (2009). Evaluation of mindful sport performance enhancement (MSPE): A new approach to promote flow in athletes. Journal of Clinical Sports Psychology, 4, 334-356.

Keng, S., Smoski, M., \& Robins, C. J. (2011). Effects of mindfulness on psychological health: A review of empirical studies. Clinical Psychology Review, 31, 1041-1056. doi:

10.1016/j.cpr.2011.04.006

Lakens, D. (2013). Calculating and reporting effect sizes to facilitate cumulative science: A practical primer for $t$-tests and ANOVAs. Frontiers in Psychology, 4, 863. doi:

10.3389/fpsyg.2013.00863

Langer, E. J., Russell, T., \& Eisenkraft, N. (2009). Orchestral performance and the footprint of mindfulness. Psychology of Music, 37, 125-136. doi: 10.1177/0305735607086053

Lenhard, W., \& Lenhard, A. (2015). Calculation of effect sizes. Available http://www.psychometrica.de/effect_size.html. Bibergau, Germany: Psychometrica.

Leppma, M. (2011). The effect of loving-kindness meditation on empathy, perceived social support, and problem solving appraisal in counseling students. (Doctoral dissertation, University of Central Florida). Retrieved from http://etd.fcla.edu/CF/CFE0003656/ Leppma_Monica_201105_PhD.pdf

Leppma, M. (2012). Loving kindness meditation and counseling. Journal of Mental Health Counseling, 34(3), 197-205.

Luna, M. J. (2013). Investigating elementary teachers' thinking about and learning to notice students' science ideas. (Doctoral dissertation, Northwestern University). Retrieved from http://search.proquest.com/docview/1328169309?pq-origsite=summon 
Lubker, J. R., Watson, J. C., II., Visek, A. J., \& Geer, J. R. (2008). Physical appearance and the perceived effectiveness of performance enhancement consultants. The Sport Psychologist, 19, 446-458.

MacIntyre, T., Van Raalte, J., Brewer, B., Lavallee, D., Mahoney, C., McCormack, H., ... Campbell, M. (2015). Practicing what we preach: An investigation of well-being and work engagement among applied sport psychology consultants (AASP Seed Grant Report: Practitioner Self-Care). Association for Applied Sport Psychology.

Magnusson, K. (2014). Interpreting Cohen's $d$ effect size: an interactive visualization. The $\mathrm{R}$ Psychologist. Retrieved from http://rpsychologist.com/d3/cohend/

Maher, C. (2013, June 22). A systems approach for professional practice of sport psychology: Conceptualizing, organizing, and focusing the task. Paper presented at the $14^{\text {th }}$ Annual Workshop in Applied Sport Psychology conducted by Dr. Jack Lesyk, Middlebury Heights, $\mathrm{OH}$.

Martin, M. M., \& Anderson, C. M. (1998). The Cognitive Flexibility Scale: Three validity studies. Communication Reports, 11(1), 1-9.

Martin, M. M., \& Anderson, C. M., \& Thweatt, K. S. (1998). Aggressive communication traits and their relationships with the Cognitive Flexibility Scale and the Communication Flexibility Scale. Journal of Social Behavior and Personality, 13(3), 531-540.

Martin, M. M., \& Rubin, R. B. (1990, November). The development of a Communication Flexibility Scale. Paper presented at the Speech Communication Association Annual Meeting, Chicago, IL.

Martin, M. M., \& Rubin, R. B. (1994). Development of a communication flexibility measure. The Southern Communication Journal, 59, 171-178. 
Martin, M. M., \& Rubin, R. B. (1995). A new measure of cognitive flexibility. Psychological Reports, 76, 623-626.

Martindale, A., \& Collins, D. (2005). Professional judgment and decision making: The role of intention for impact. The Sport Psychologist, 19(3), 303-317.

Martindale, A., \& Collins, D. (2007). Enhancing the evaluation of effectiveness with professional judgment and decision making. The Sport Psychologist, 21, 458-474.

Martindale, A., \& Collins, D. (2012). A professional judgment and decision making case study: Reflection-in-action research. The Sport Psychologist, 26, 500-518.

McAuliffe, G., \& Lovell, C. (2006). The influence of counselor epistemology on the helping interview: A qualitative study. Journal of Counseling \& Development, 84, 308-316.

McCarthy, P., \& Jones, M. (Eds.). (2013). Becoming a sport psychologist. New York: Routledge. Medical Research Council (MRC) Cognition and Brain Sciences Unit, (2009). Rules of thumb on magnitude of effect sizes. Retrieved from http://imaging.mrccbu.cam.ac.uk/statswiki/FAQ/effectSize

Meiklejohn, J., Phillips, C., Freedman, M. L., Griffin, M. L., Biegel, G., Roach, A., ...Saltzman, A. (2012). Integrating mindfulness training into K-12 education: Fostering the resilience of teachers and students. Mindfulness. doi: 10.1007/s12671-012-0094-5

Meyers, J. (2002). A 30 year perspective on best practices for consultation training. Journal of Education and Psychological Consultation. 13(1\&2), 35-54.

Meyers, A. W., Coleman, J. K., Whelan, J. P., \& Mehlenbeck, R. S. (2001). Examining careers in sport psychology: Who is working and who is making money?. Professional Psychology: Research and Practice, 32, 5-11. 
Moore, P. (2008). Introducing mindfulness to clinical psychologists in training: An experiential course in brief exercises. Journal of Clinical Psychology in Medical Settings, 15, 331337. doi: 10.1007/s10880-008-9134-7

Moore, A., \& Malinowski, P. (2009). Meditation, mindfulness, and cognitive flexibility. Consciousness and Cognition, 18, 176-186. doi: 10.1016/j.concog.2008.12.008

Moran, A. (2004). Sport and exercise psychology: A critical introduction. New York: Routledge.

O’Rourke, N., \& Hatcher, L. (2013). A step-by-step approach to using SAS for factor analysis and structural equation modeling. ( $2^{\text {nd }}$ ed.). Cary, NC: SAS.

Ostafin, B. D., \& Kassman, K. T. (2012). Stepping out of history: Mindfulness improves insight problem solving. Consciousness and Cognition, 21, 1031-1036. doi: 10.1016/j.concog.2012.014

Palmberger, M., \& Gingich, A. (2014). Qualitative comparative practices: Dimensions, cases, and strategies. In U. Flick (Ed.), The SAGE handbook of qualitative data analysis. Washington, DC: SAGE Publications, Ltd.

Parsons, R. D., \& Meyers, J. (1984). Developing consultation skills. Washington, DC: JosseyBass, Inc. Publishers.

Passon, W. R., \& Olsen, L. C. (1969). Relationship of counselor characteristics and empathic sensitivity. Journal of Counseling Psychology, 16(5), 440-445.

Patten, M. L. (2000). Understanding research methods: An overview of the essentials ( $2^{\text {nd }}$ ed.). Los Angeles, CA: Pyrczak Publishing.

Poczwardowski, A., \& Sherman, C. P. (2011). Revisions to the Sport Psychology Services Delivery (SPSD) heuristic: Explorations with experienced consultants. The Sport Psychologist, 25, 511-531. 
Poczwardowski, A., Sherman, C. P., \& Ravizza, K. (2004). Professional philosophy in the sport psychology service delivery: Building on theory and practice. The Sport Psychologist, 18, $445-463$.

Polit, D. F. \& Beck, C. T. (2008). Nursing research: Generating and assessing evidence for nursing practice ( (th $^{\text {ed }}$ e). Philadelphia, PA: Lippincott Williams \& Williams.

Portenga, S., Aoyagi, M., Balague, G., Cohen, A., \& Harmison, B. (2012). Defining the practice of sport and performance psychology. Division 47 (Exercise and Sport Psychology) of the American Psychological Association. Retrieved from http://www.apadivisions.org/division-47/about/resources/defining.pdf

Qualtrics Research Suite. (2014). Qualtrics. Qualtrics and all other Qualtrics products or service names are registered trademarks of Qualtrics, Provo, UT, USA. http://wvu.qualtrics.com

Raykov, T. \& Marcoulides, G. A. (2006). A first course in structural equation modeling ( $2^{\text {nd }}$ ed.). Mahwah, NJ: Lawrence Erlbaum Associates, Publishers

Reder, L. M., \& Schunn, C. D. (1999). Bringing together the psychometric and strategy worlds: Predicting adaptability in a dynamic task. In D. Gopher \& A. Koriat (Eds.), Cognitive regulation of performance: Interaction of theory and application. Attention and Performance XVII, pp. 315-342.

Richhart, R. \& Perkins, D. N. (2000). Life in the mindful classroom: Nurturing the disposition of mindfulness. Journal of Social Issues, 56(1), 27-47.

Ritter, S. M., Damian, R. I., Simonton, D. K., van Baaren, R. B., Strick, M., Derks, J., \& Dijksterhuis, A. (2012). Diversifying experiences enhance cognitive flexibility. Journal of Experimental Social Psychology, 48, 961-964. doi: 10.1016/j.esp.2012.02.009 
Russell, J. V. (2011). The effect of mindfulness-based stress reduction on quality of life: A metaanalysis. (Doctoral dissertation, University of Edinburgh). Retrieved from https://www.era.lib.ed.ac.uk/bitstream/handle/1842/6301/Russell2011.pdf;jsessionid=587 A7B03E8DF8DFC6582C2E43700AFD7?sequence $=1$

Rybak, C. (2012). Nurturing positive mental health: Mindfulness for wellbeing in counseling. International Journal for the Advancement of Counselling, 35(2), 110-119. doi: $10.1007 / \mathrm{s} 10447-012-9171-7$

Safran, J. D. \& Segal, Z. V. (1990). Interpersonal processes in cognitive therapy. New York: Basic Books.

Saldaña, J. (2013). The coding manual for qualitative researchers $\left(2^{\mathrm{nd}}\right.$ ed.). Thousand Oaks, CA: SAGE Publications.

Schure, M. B., Christopher, J., \& Christopher, S. (2008, Winter). Mind-body medicine and the art of self-care: Teaching mindfulness to counseling students through yoga, meditation, and qigong. Journal of Counseling \& Development, 86, 47-56.

Sears, R., Rudisill, J., \& Mason-Sears, C. (2006). Consultation skills for mental health professionals. Hoboken, NJ: John Wiley \& Sons, Inc.

Sharp, L. A. \& Hodge, K. (2011). Sport psychology consulting effectiveness: The sport psychology consultant's perspective. Journal of Applied Sport Psychology, 25, 360-376. doi: 10.1080/10413200.2011.583619

Shibl, G. W. (2010). The relationship among White counselors' cognitive flexibility, racial identity statuses, and perceived multicultural counseling competence. (Doctoral dissertation, California School of Professional Psychology at Alliant International University, San Diego). 
Siegal, D. J. (2010). The mindful therapist: A clinician's guide to mindsight and neural integration. New York: W.W. Norton \& Co.

Silva, J. M., III. (2013). Coalition for the advancement of graduate training in the practice of sport psychology: A report and discussion. Symposium conducted at the meeting of Association of Applied Sport Psychology, New Orleans, LA.

Silva, J. M., III., Conroy, D. E., \& Zizzi, S. J. (1999). Critical issues confronting the advancement of applied sport psychology. Journal of Applied Sport Psychology, 11(2), 298-320. doi: 10.1080/10413209908404206

Silva, J. M., III., Metzler, J. N. Lerner, B. (2011). Training professionals in the practice of sport psychology ( $2^{\text {nd }}$ ed.). Morgantown, WV: Fitness Information Technology.

Skype. (2015). Microsoft/Skype. Retrieved from http://www.skype.com/en/

Spiro, R. J., Coulson, R. L., Feltovich, P. J., \& Anderson, D. K. (1988). Cognitive flexibility theory: Advanced knowledge acquisition in ill-structured domains. (Report No. 441). Program of the Tenth Annual Cognitive Science Society. Hillsdale, NJ: Lawrence Erlbaum Associates, Inc. Retrieved from http://files.eric.ed.gov/fulltext/ED302821.pdf

Spitzberg, B. H., \& Cupach, W. R. (1984). Interpersonal communication competence. Beverly Hills, CA: Sage Publications.

Teasdale, J. D., Segal, Z. V. \& Williams, J. M. (2003). Mindfulness training and problem formation. Clinical Psychology: Science and Practice, 10(2), 157-160. doi: 10.1093/clipsy/bpg017

Teddlie, C., \& Tashakkori, A. (2009). Foundations of mixed methods research: Integrating quantitative and qualitative approaches in the social and behavioral sciences. Thousand Oaks, CA: Sage Publications. 
Tenenbaum, G., Papaianou, A., \& Samulski, D. (2003). Competencies (occupational standards, knowledge, and practice), and their accomplishment (learning specification; essential knowledge and skills) in sport and exercise psychology: An ISSP position stand. International Journal of Sport and Exercise Psychology, 1(2), 155-166. doi:10.1080/1612197X.2003.9671709

Tod, D. (2010). Training and professional development in applied sport psychology. In S. J. Hanrahan \& M. B. Andersen (Eds.), Routledge handbook of applied sport psychology (pp. 21-29). New York: Routledge.

Towele, A., \& Cottrell, D. (1996). Self directed learning. Medication Education, 74, 357-359. Wagner, P. (2000). Consultation: Developing a comprehensive approach to service delivery. Educational Psychology in Practice, 16(1), 9-18.

Ward, D. G., Sandstedt, S. D., Cox, R. H., \& Beck, N. C. (2005). Athlete-counseling competencies for U.S psychologists working with athletes. The Sport Psychologist, 19, $318-334$.

Weinberg, R. S., \& Gould, D. (2011). Foundations of sport and exercise psychology (5th ed.). Champaign, IL: Human Kinetics.

Whiteley, J. M., Sprinthall, N. A., Mosher, R. L., \& Donaghy, R. T. (1967). Selection and evaluation of counselor effectiveness. Journal of Counseling Psychology, 14(3), 226234.

Zeidan, F., Johnson, S. K., Diamond, B. J., David, Z., \& Goolkasian, P. Mindfulness meditation improved cognition: Evidence of brief mental training. Consciousness and Cognition, (2010), doi: 10.1016/j.concog.2010.03.014 
Figure 2: Hypothesized, theoretical, recursive structural model (all coefficients positive)

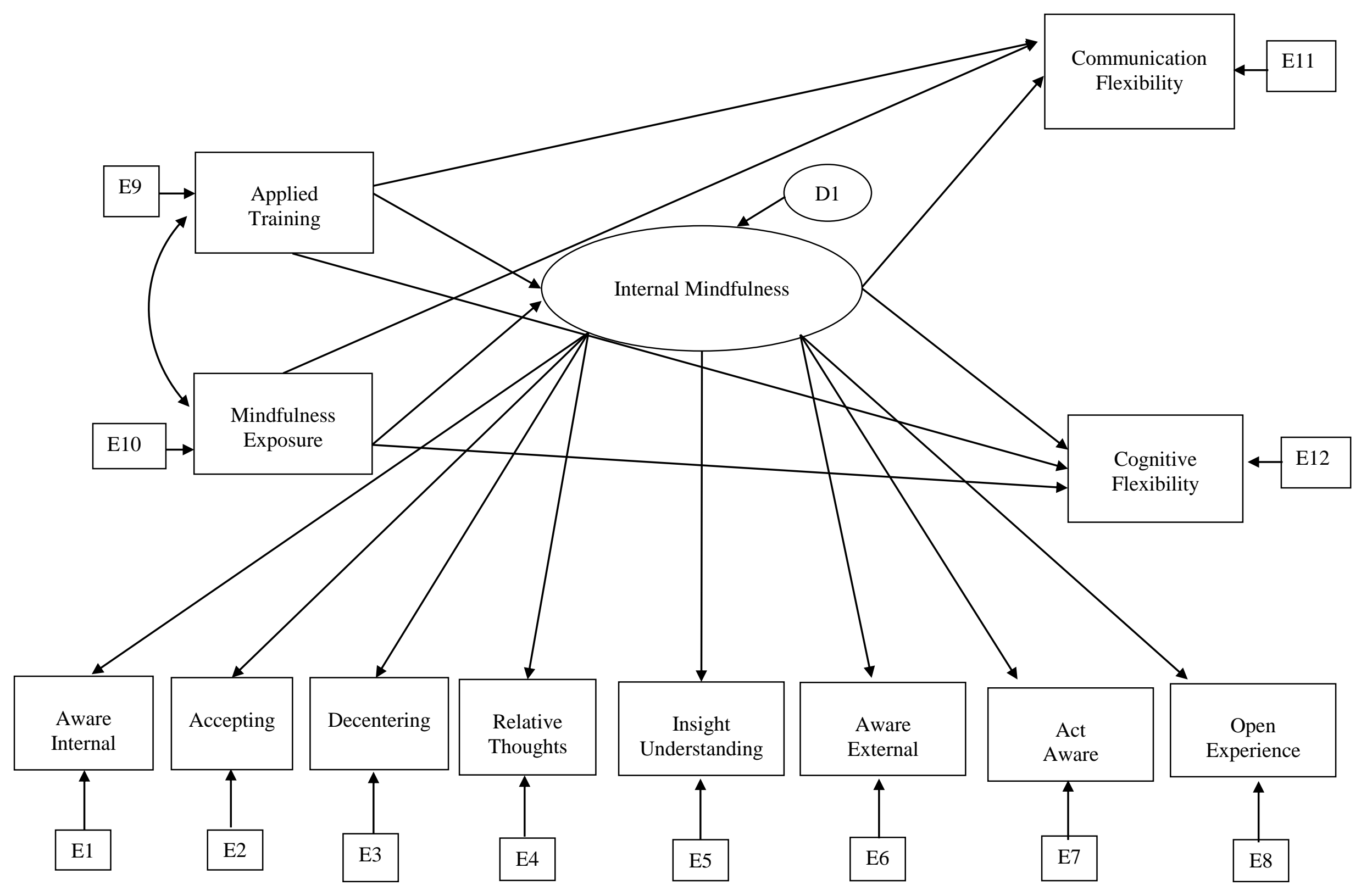


Figure 4: Initial, Theoretical Model (with CFA adjustments)

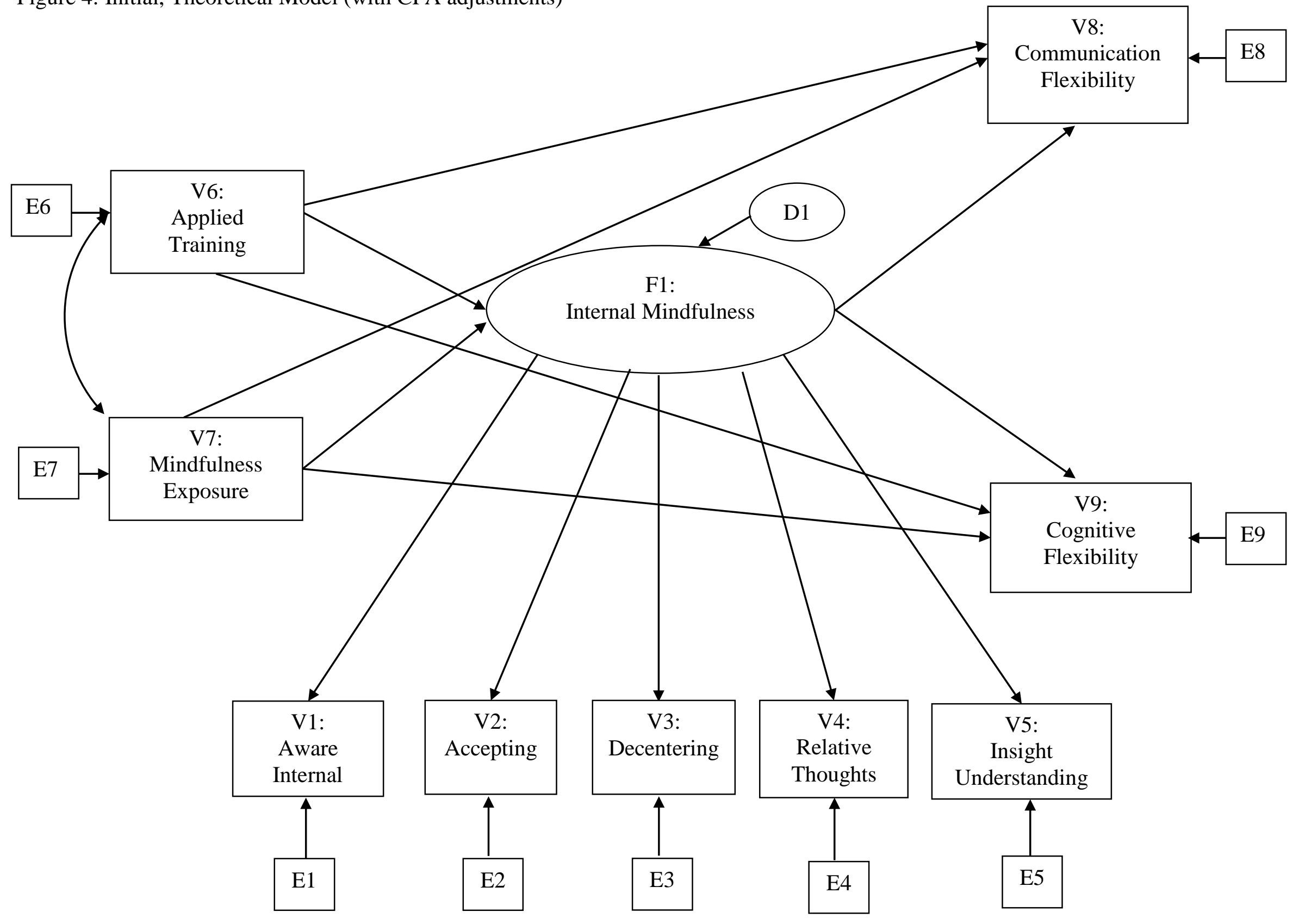


Figure 5: Standardized Results for Initial Model

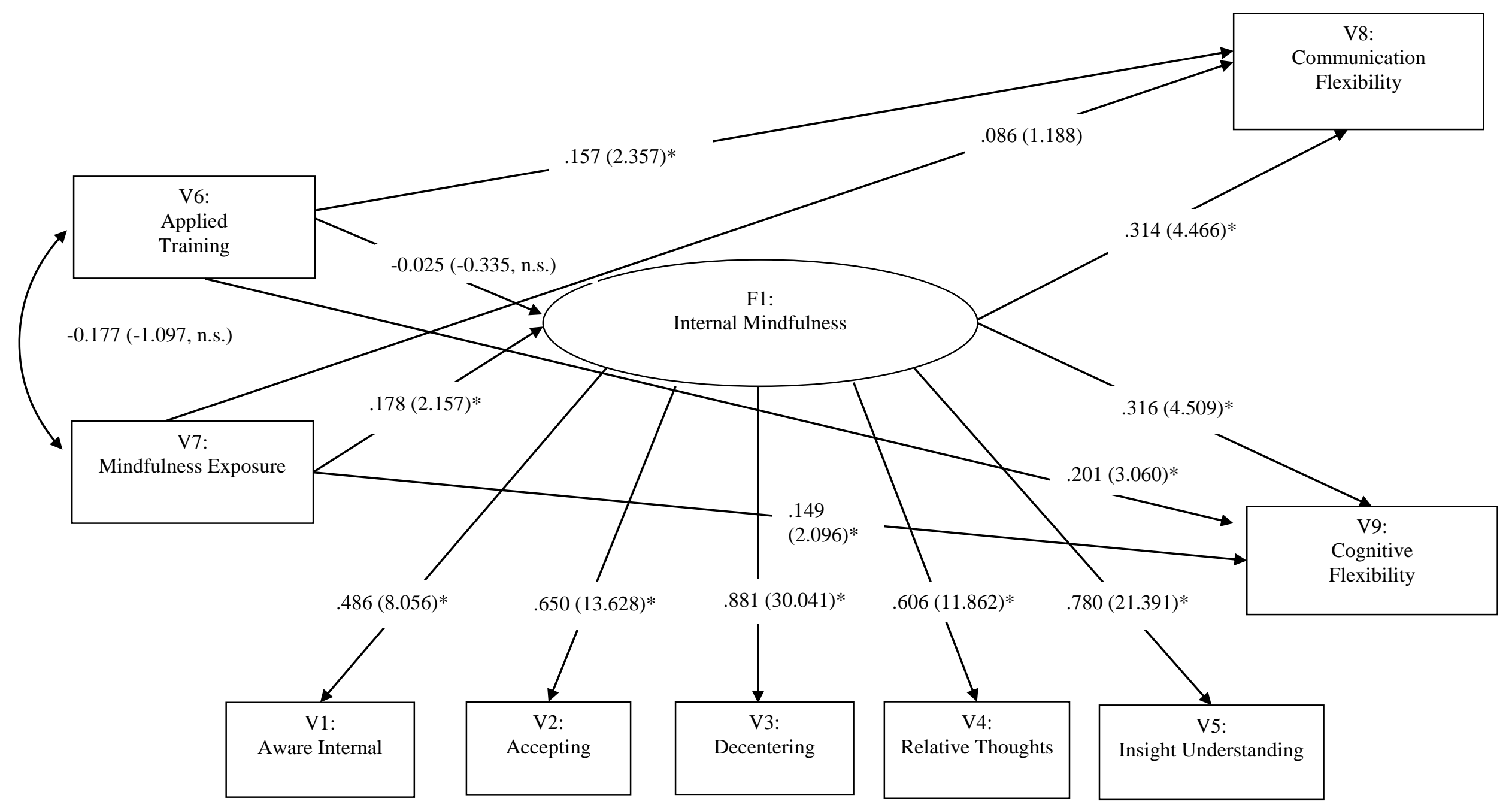

Note. Path parameters express standardized solution from full information maximum likelihood. $\mathrm{t}$ values in parentheses (statistically significant t values $>|1.96|, p<.05)$. 
Figure 6: Revised Model 2

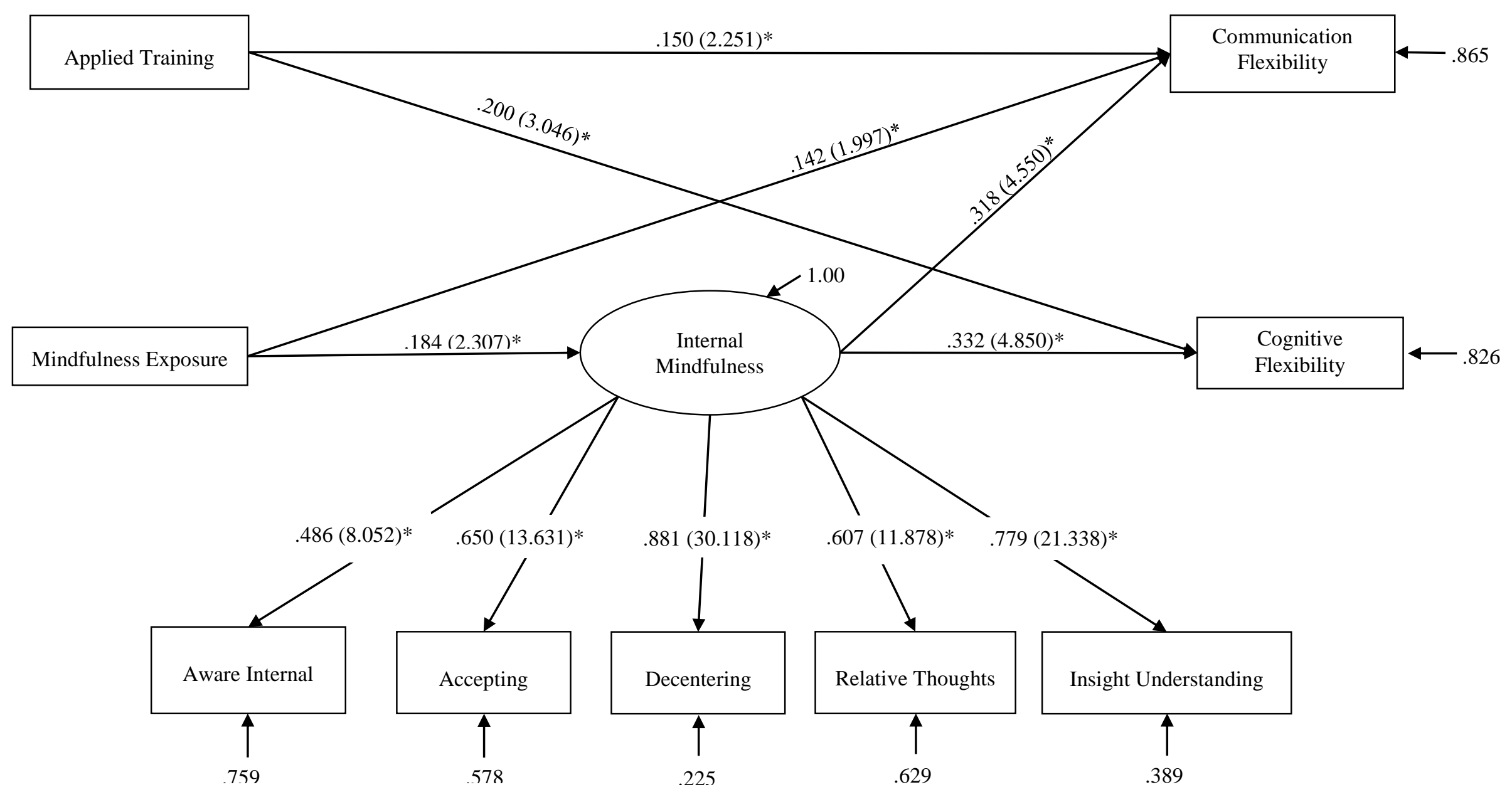

Note. Path parameters express standardized solution from full information maximum likelihood. Accompanying $t$ values in parentheses (statistically significant $\mathrm{t}$ values $>|1.96|, p<.05)$. $(*)$ signifies $p \leq .05 . \mathrm{R}^{2}=(1-$ error variances $)$. 
Figure 7: Andy's Conceptualization of Mindfulness

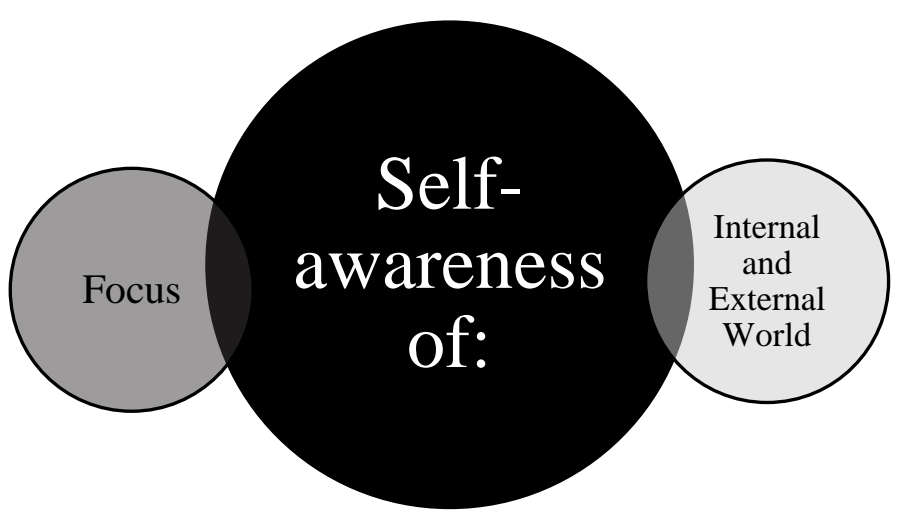

Based on the following quotes either directly exposing a mindfulness conceptualization or compiled from references within transcript.

\begin{tabular}{|c|c|c|}
\hline SS/Lines & Main topics & Statement \\
\hline $47 / 121$ & $\begin{array}{l}\text { Self-awareness of } \\
\text { focus }\end{array}$ & the awareness of where my attentional focus is \\
\hline $48 / 122$ & $\begin{array}{l}\text { Self-awareness of } \\
\text { internal } \\
\text { process/emotions }\end{array}$ & $\begin{array}{l}\text { even more importantly, what is going on within me and what } \\
\text { emotions are being pulled out within me }\end{array}$ \\
\hline $29 / 58-59$ & $\begin{array}{l}\text { Helps me be "in } \\
\text { tune within and } \\
\text { around me" }\end{array}$ & $\begin{array}{l}\text { to be more I guess just in tune with what's going on both } \\
\text { within me and around me, relationships, and the } \\
\text { environment, and everything }\end{array}$ \\
\hline $\begin{array}{l}45 / \\
116-118\end{array}$ & $\begin{array}{l}\text { "Focus training" } \\
\text { is "central to } \\
\text { what I do" }\end{array}$ & $\begin{array}{l}\text { they would never know were meditation or mindfulness } \\
\text { training but we would just call it focus training or something } \\
\text { like that. So it's pretty integrated with everything that I do. }\end{array}$ \\
\hline
\end{tabular}


Figure 8: Mike's Conceptualization of Mindfulness

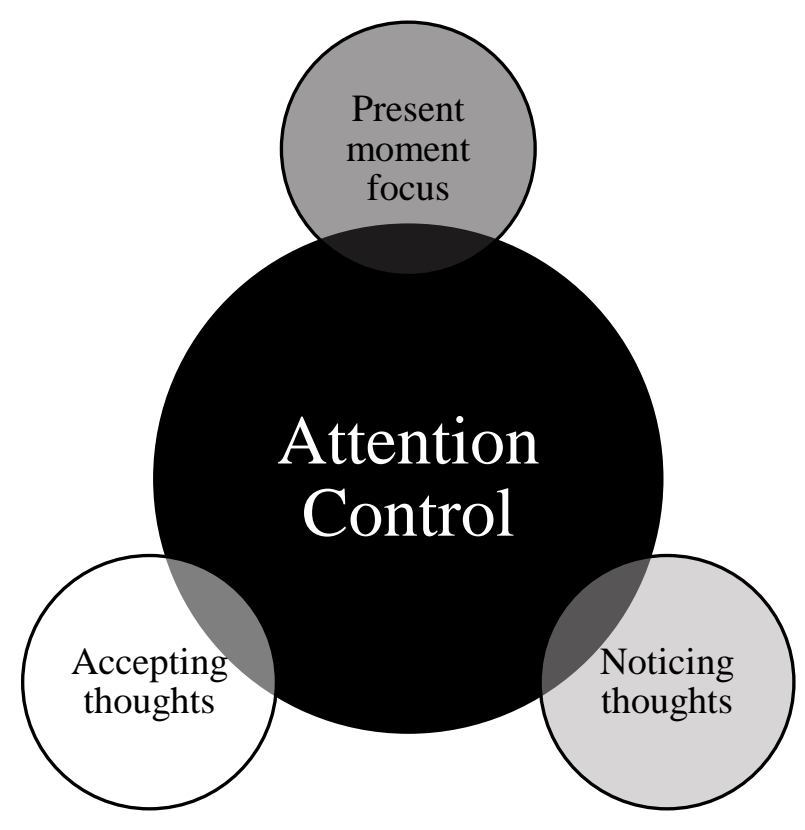

Based on the following quotes either directly exposing a mindfulness conceptualization or compiled from references within transcript.

\begin{tabular}{|c|c|c|}
\hline SS/Lines & Main topics & Statement \\
\hline $20 / 85$ & $\begin{array}{l}\text { Attentional } \\
\text { Control }\end{array}$ & $\begin{array}{l}\text { the term mindfulness, really we are talking about attention } \\
\text { control. }\end{array}$ \\
\hline $17 / 66$ & $\begin{array}{l}\text { Notice and } \\
\text { accept thoughts }\end{array}$ & $\begin{array}{l}\text { and it's just noticing of your thoughts, being more accepting of } \\
\text { your thoughts, }\end{array}$ \\
\hline $17 / 67-68$ & Present focus & $\begin{array}{l}\text { being in the present moment, present moment focus which is } \\
\text { what we are trying to do as practitioners is get athletes or } \\
\text { performers in general to come back to the moment. }\end{array}$ \\
\hline
\end{tabular}


Figure 9: Amy's Conceptualization of Mindfulness

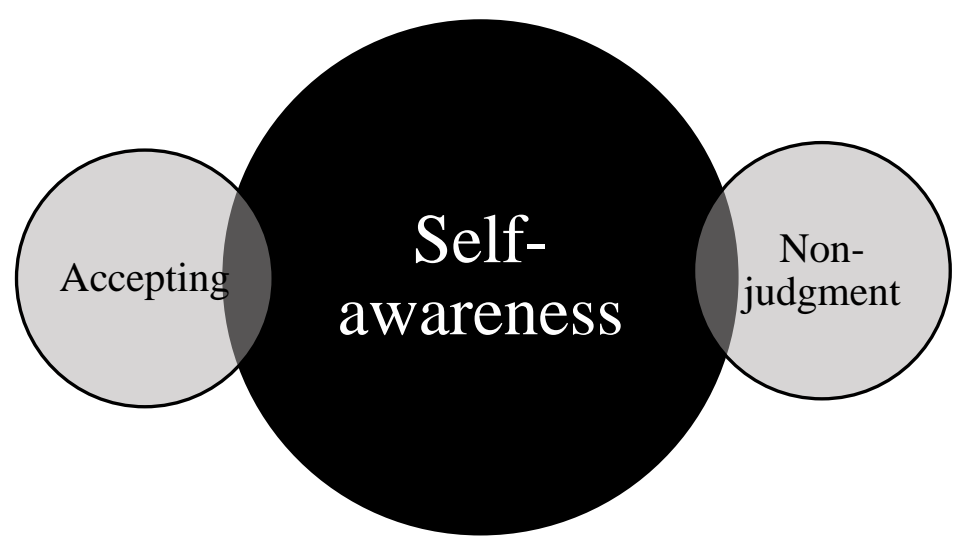

Based on the following quotes either directly exposing a mindfulness conceptualization or compiled from references within transcript.

\begin{tabular}{|c|c|c|}
\hline SS/Lines & Main topics & Statement \\
\hline $4 / 6-8$ & $\begin{array}{l}\text { Brings } \\
\text { awareness and } \\
\text { non-judgment }\end{array}$ & $\begin{array}{l}\text { I think mindfulness is appropriate in any setting just from } \\
\text { bringing a bit more of awareness and nonjudgmental } \\
\text { approach }\end{array}$ \\
\hline $15 / 66-67$ & Less judgmental & $\begin{array}{l}\text { I think I've become a lot less judgmental about my skills um } \\
\text { and you know I still make mistakes, obviously, a make a lot of } \\
\text { mistakes }\end{array}$ \\
\hline $16 / 67-68$ & Accepting & I am more accepting of that [consulting mistakes] \\
\hline 31/92-96 & $\begin{array}{l}\text { Awareness of } \\
\text { thoughts and } \\
\text { non-judgment } \\
\text { of others }\end{array}$ & $\begin{array}{l}\text { I think a little bit of the mindfulness and I am probably using } \\
\text { that incorrectly, more of an awareness thing, but I think there } \\
\text { is also the "ok I'm not going to judge them, but going to notice } \\
\text { some of those thoughts." }\end{array}$ \\
\hline 28/86 & $\begin{array}{l}\text { Mindfulness } \\
\text { practice: Self- } \\
\text { awareness }\end{array}$ & I think it's just the self-awareness thing \\
\hline
\end{tabular}


Figure 10: Jacob's Conceptualization of Mindfulness

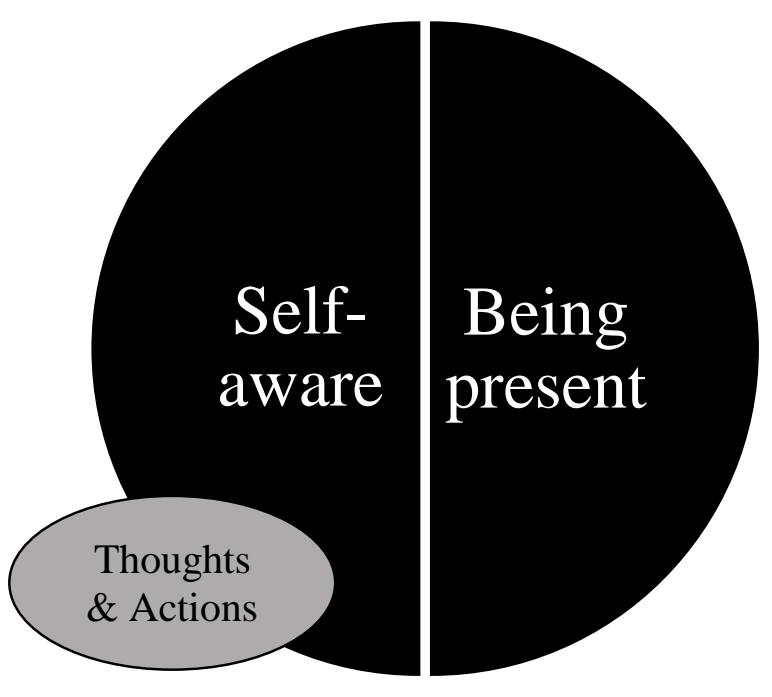

Based on the following quotes either directly exposing a mindfulness conceptualization or compiled from references within transcript.

\begin{tabular}{|c|c|c|}
\hline SS/Lines & Main topics & Statement \\
\hline $36 / 73-74$ & $\begin{array}{l}\text { Awareness and Being } \\
\text { present }\end{array}$ & $\begin{array}{l}\text { I think I just would more reference it [mindfulness] as } \\
\text { like awareness and being present }\end{array}$ \\
\hline $2 / 5-6$ & $\begin{array}{l}\text { Self-awareness of } \\
\text { thoughts }\end{array}$ & $\begin{array}{l}\text { I think the first thing is self-awareness and that comes } \\
\text { with just being aware of your thoughts }\end{array}$ \\
\hline $3 / 5-6$ & $\begin{array}{l}\text { Self-awareness of } \\
\text { thoughts influences } \\
\text { decisions/conversations }\end{array}$ & $\begin{array}{l}\text { and then as you start to do that you start to become more } \\
\text { and more aware of those thoughts, how they influence } \\
\text { your decisions and conversations. }\end{array}$ \\
\hline
\end{tabular}


Figure 11: Sarah's Conceptualization of Mindfulness

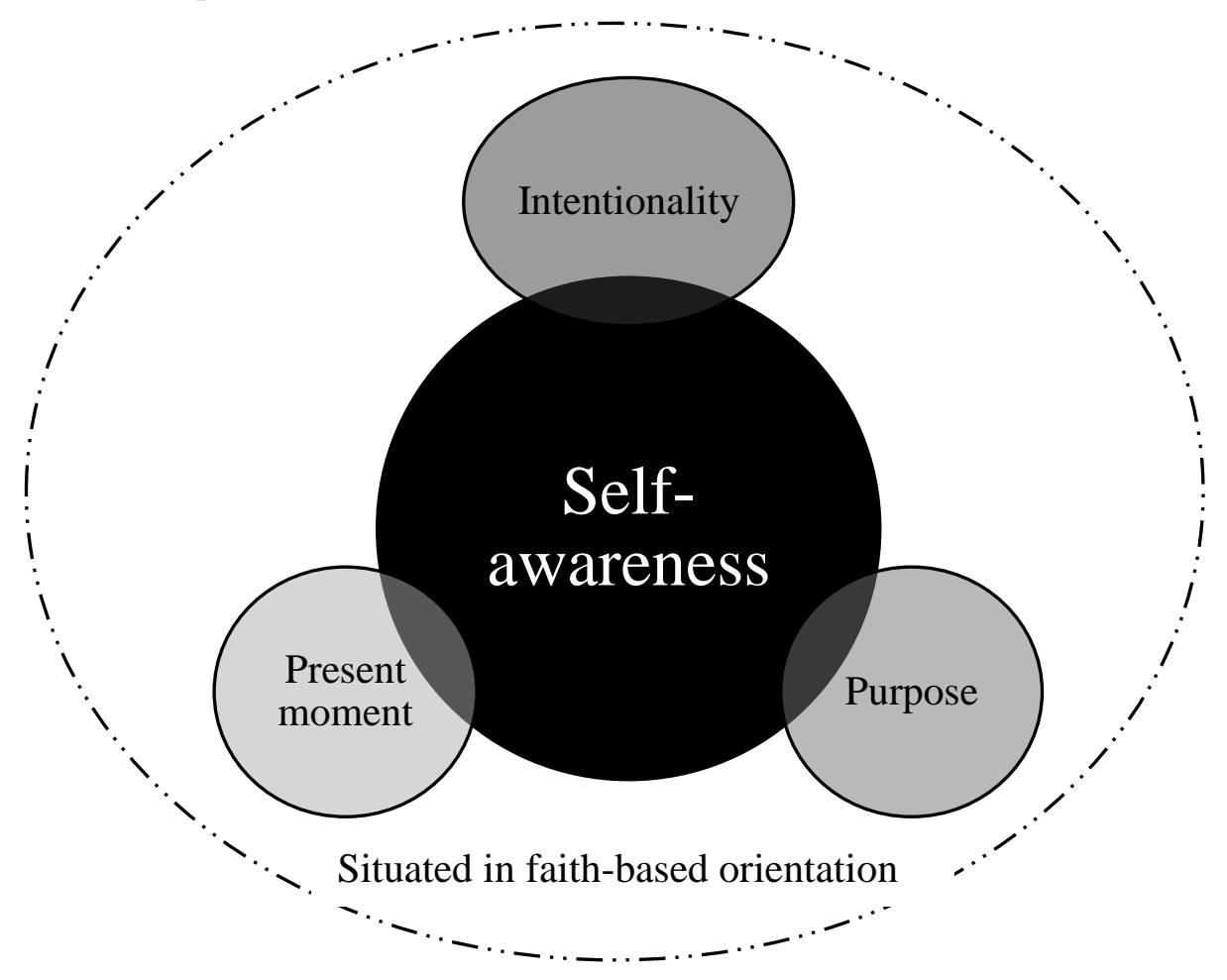

Based on the following quotes either directly exposing a mindfulness conceptualization or compiled from references within transcript.

\begin{tabular}{|c|c|c|}
\hline SS/Lines & Main topics & Statement \\
\hline $2-3$ & $\begin{array}{l}\text { Mindfulness } \\
\text { through faith }\end{array}$ & $\begin{array}{l}\text { I have not like pursued mindfulness, I guess, as it's written } \\
\text { about or kind of how we learn about it academically per se, } \\
\text { but for me my faith is the most important thing in my life }\end{array}$ \\
\hline $7 / 7-8$ & Intentionality & $\begin{array}{l}\text { being really intentional and deliberate about how I go about } \\
\text { conducting my life is important to me and I think with that } \\
\text { inherently comes an air of "mindfulness" if you will, }\end{array}$ \\
\hline $8 / 8-13$ & $\begin{array}{l}\text { Present, } \\
\text { essences of life }\end{array}$ & $\begin{array}{l}\text { I have a lot of energy and am obsessed with life in general and } \\
\text { so like maximizing life and experiences and interactions with } \\
\text { people is really important to me and I don't think you can do } \\
\text { that unless you are just really present and experiencing the } \\
\text { intricate essences of life on a constant, ongoing basis. }\end{array}$ \\
\hline $\begin{array}{l}52 / 190- \\
192\end{array}$ & $\begin{array}{l}\text { Self-awareness, } \\
\text { Purpose, Help } \\
\text { others }\end{array}$ & $\begin{array}{l}\text { mindfulness for me as a consultant is first and foremost know } \\
\text { myself, secondly know my purpose, and then finally, help } \\
\text { others see and connect theirs through our work together. }\end{array}$ \\
\hline $\begin{array}{l}29 / 117- \\
119\end{array}$ & $\begin{array}{l}\text { Intentionality } \\
\text { leads to purpose } \\
\text { and engagement }\end{array}$ & $\begin{array}{l}\text { So, it is just this essence of it drives that sense of purpose and } \\
\text { engagement through your days if you have that sort of } \\
\text { intentionality. }\end{array}$ \\
\hline
\end{tabular}


Figure 12: Jill's Conceptualization of Mindfulness

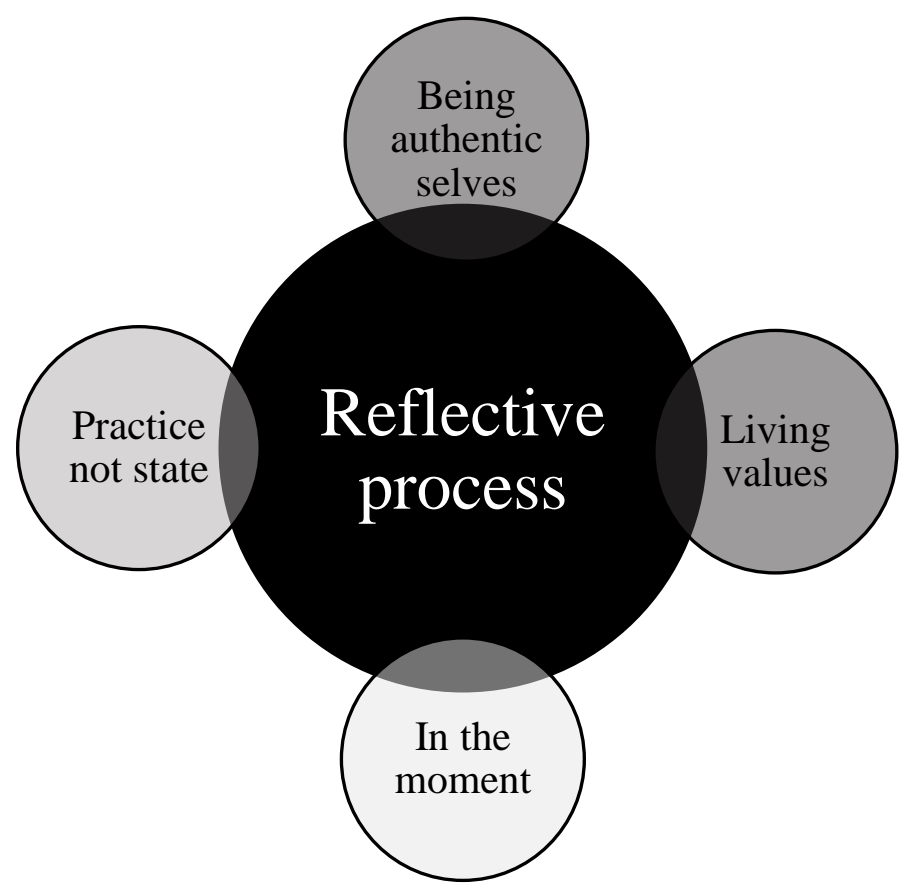

Based on the following quotes either directly exposing a mindfulness conceptualization or compiled from references within transcript.

\begin{tabular}{lll}
\hline SS/Lines & Main topics & Statement \\
\hline $3 / 10-11$ & $\begin{array}{l}\text { Practice not a } \\
\text { state }\end{array}$ & $\begin{array}{l}\text { started looking at mindfulness as more of a practice as opposed } \\
\text { to a state }\end{array}$ \\
Active Self- & $\begin{array}{l}\text { something that kinda like } \text { a self-check for me. So, I look at it } \\
\text { more from an active perspective where "oh I am } \\
\text { communicating with you in the moment, how am I reacting } \\
\text { physically? Is this helping? Is this hurting? What do I want out } \\
\text { of this interaction? How do I change it? How do I not?" And } \\
\text { so it became really more of an in the moment reflective proces } \\
\text { for me }\end{array}$ \\
& & $\begin{array}{l}\text { I think it is just a good way to realize if we are being our } \\
\text { authentic selves and acting in line with our values because we }\end{array}$ \\
& $\begin{array}{l}\text { Realize } \\
\text { authentic } \\
\text { selves and } \\
\text { living values }\end{array}$ & $\begin{array}{l}\text { anything like that is impacting us without that check um every } \\
\text { once in a while. So, that's kinda how I view it. }\end{array}$ \\
&
\end{tabular}


Figure 13: Dan's Conceptualization

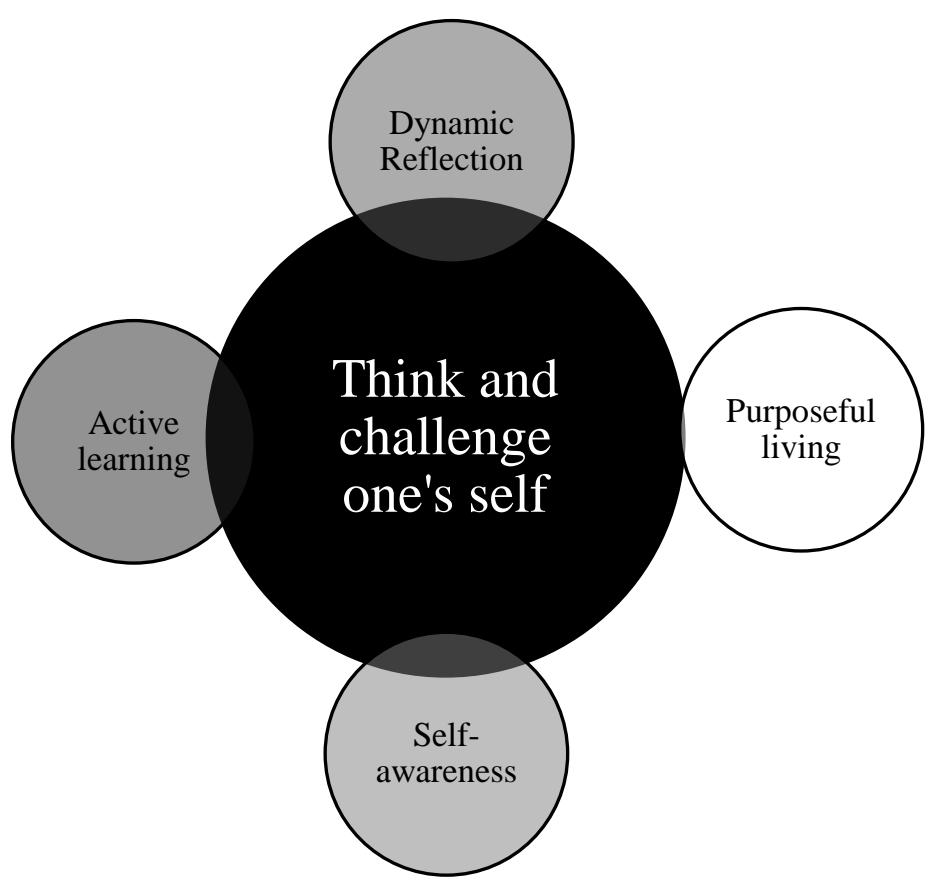

Based on the following quotes either directly exposing a mindfulness conceptualization or compiled from references within transcript.

\begin{tabular}{|c|c|c|}
\hline SS/Lines & Main topics & Statement \\
\hline $93-94$ & $\begin{array}{l}\text { Think and } \\
\text { challenge self }\end{array}$ & $\begin{array}{l}\text { I'm probably going to give a non-academic definition. Mindfulness is } \\
\text { um willingness to think and challenge one's self. }\end{array}$ \\
\hline $94-96$ & $\begin{array}{l}\text { Dynamic } \\
\text { reflection leads } \\
\text { to } \\
\text { purposefulness, }\end{array}$ & $\begin{array}{l}\text { um having a level of awareness that leads to a level of purpose you } \\
\text { know and I think that's where I try to blend in eastern a bit because } \\
\text { there is a level of purposefulness so I think mindfulness is about this } \\
\text { dynamic reflection that's not just reflection by itself but it leads to } \\
\text { some sort of purposeful living }\end{array}$ \\
\hline $97-105$ & $\begin{array}{l}\text { Being an } \\
\text { active/mindful } \\
\text { learner }\end{array}$ & $\begin{array}{l}\text { And then you know it's circular, you know, especially in sports, you } \\
\text { do this, you try on for size, you re-reflect, you do it, you try it for size, } \\
\text { um maybe a way for me to phrase it is about being an active learner, } \\
\text { you know. It's really, and again, I'm a Western guy so maybe I } \\
\text { overly westernize it, right. Um where so I had a client on the phone } \\
\text { last night who's relatively new to working with me and I said, "You } \\
\text { know what I'm always gonna ask? I'm gonna ask you what'd you } \\
\text { learn and what's going to be different about you in two months". [R: } \\
\text { Yea] There you go. What'd you learn? You I think that to me is } \\
\text { mindfulness, a willingness to learn but also a willingness not to get } \\
\text { caught up in that wrong times in sport. There is a time to learn and } \\
\text { there is a time to play. There is a time to reflect. }\end{array}$ \\
\hline
\end{tabular}


Figure 14: Bishop and colleagues (2004) definition

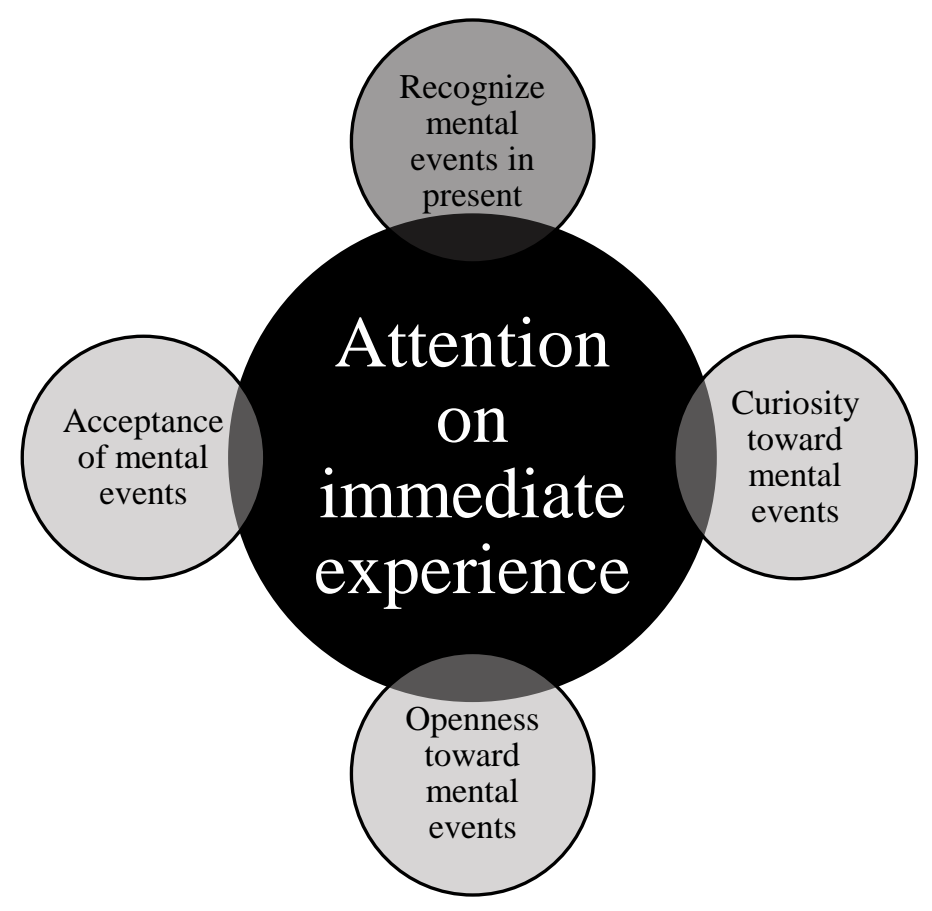

Bishop and colleagues (2004) definition and discussion within the article:

The first component is the self-regulation of attention so that it is maintained on immediate experience, thereby allowing for increased recognition of mental events in the present moment. The second component involves adopting a particular orientation toward one's experiences in the present moment, an orientation that is characterized by curiosity, openness, and acceptance. (p. 232) 
Figure 15: Andy's Developmental and Integration Process

\section{Developmental Actions and Processes}

\begin{tabular}{|c|c|c|}
\hline Phase & Experience & Actions \\
\hline \multirow[t]{2}{*}{ First } & $\begin{array}{l}\text { Informal } \\
\text { practice }\end{array}$ & $\begin{array}{l}\text { Observation of world, } \\
\text { Introspection, Living } \\
\text { consciously, connecting } \\
\text { to world through nature }\end{array}$ \\
\hline & Personality & $\begin{array}{l}\text { Single task focus, focus } \\
\text { intently }\end{array}$ \\
\hline Second & $\begin{array}{l}\text { Learn about } \\
\text { ACT and } \\
\text { mindfulness }\end{array}$ & $\begin{array}{l}\text { Searching for theoretical } \\
\text { "fit," Clinical peer } \\
\text { presented on ACT, } \\
\text { Read about mindfulness } \\
\text { (Jon Kabat-Zinn) and } \\
\text { ACT }\end{array}$ \\
\hline \multirow[t]{2}{*}{ Third } & $\begin{array}{l}\text { Practice } \\
\text { formally and } \\
\text { informally }\end{array}$ & $\begin{array}{l}\text { Kabat-Zinn meditation } \\
\text { tapes, Yoga, Reconnect } \\
\text { through daily meditation, } \\
\text { Practice loving-kindness } \\
\text { meditation }\end{array}$ \\
\hline & $\begin{array}{l}\text { Integrate into } \\
\text { consultation }\end{array}$ & $\begin{array}{l}\text { Collaborate and receive } \\
\text { mentoring from } \\
\text { colleague, Read research, } \\
\text { Adopt as theoretical } \\
\text { orientation }\end{array}$ \\
\hline
\end{tabular}

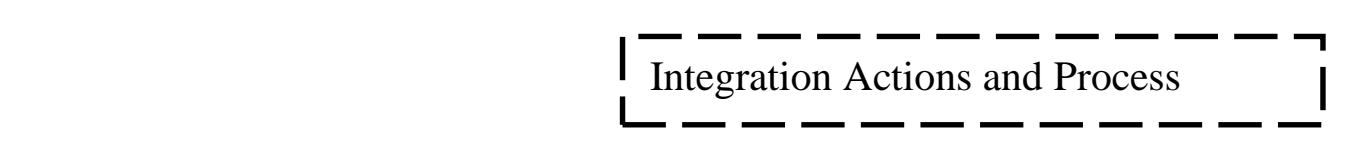

SPC directed: Awareness of attentional focus facilitates being present and aware with client

Client directed: Focus training teaches focus and awareness of focus. Clients do informal or formal mindfulness meditation, including mobile applications (i.e., "apps)
SPC directed: Helps connect to thoughts and emotions that are:

- "Going on" within self

- "Being pulled out" of self

- Used to inform work with client

- Be more connected and patient with client 
Figure 16: Mike's Developmental and Integration Processes

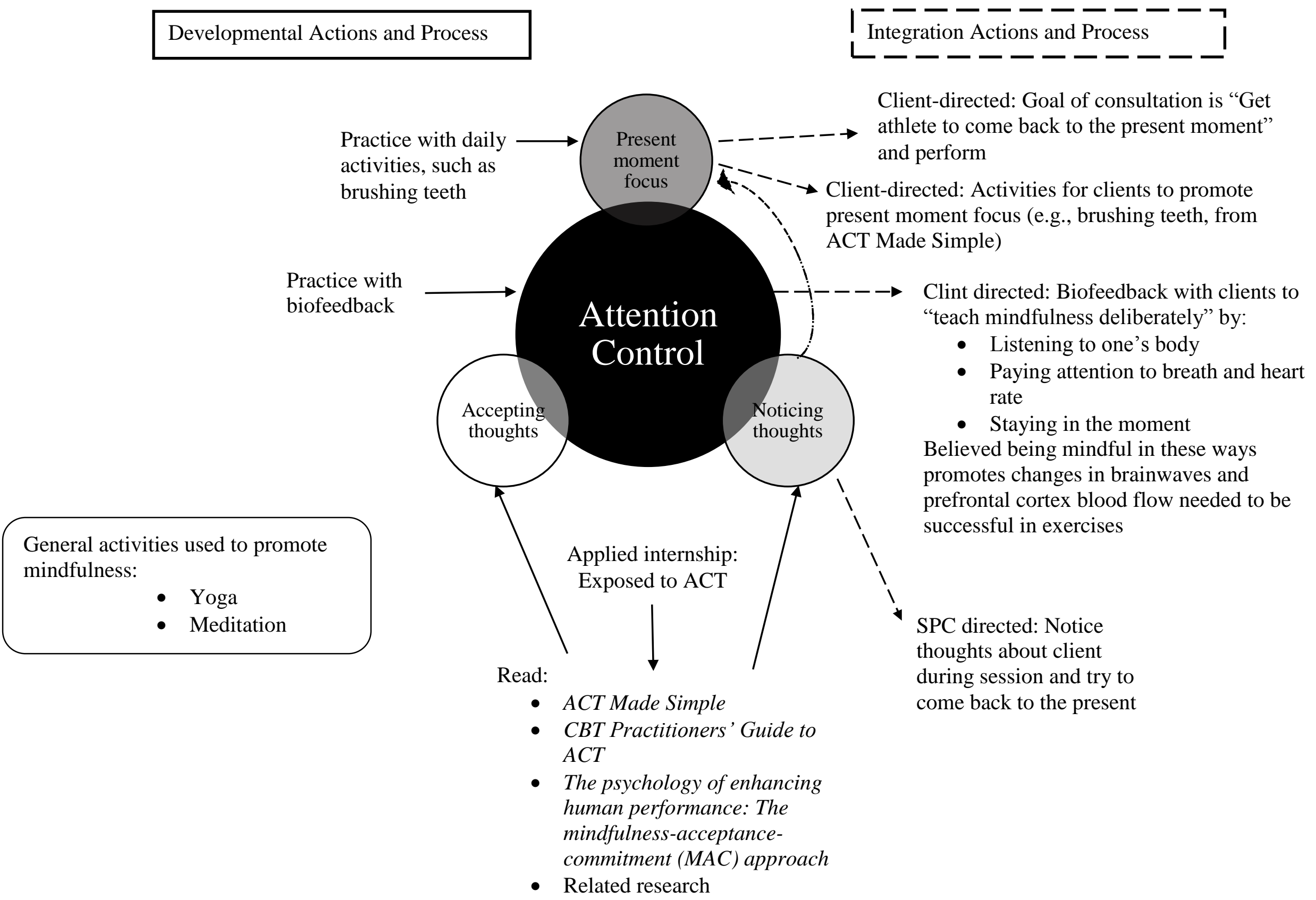


Figure 17: Jacob's Developmental and Integration Actions

Some people are better

Developmental Actions and Process

Graduate School

Experiences:

- Influence of advisor

- Orientation of graduate program

- Master's degree in counseling
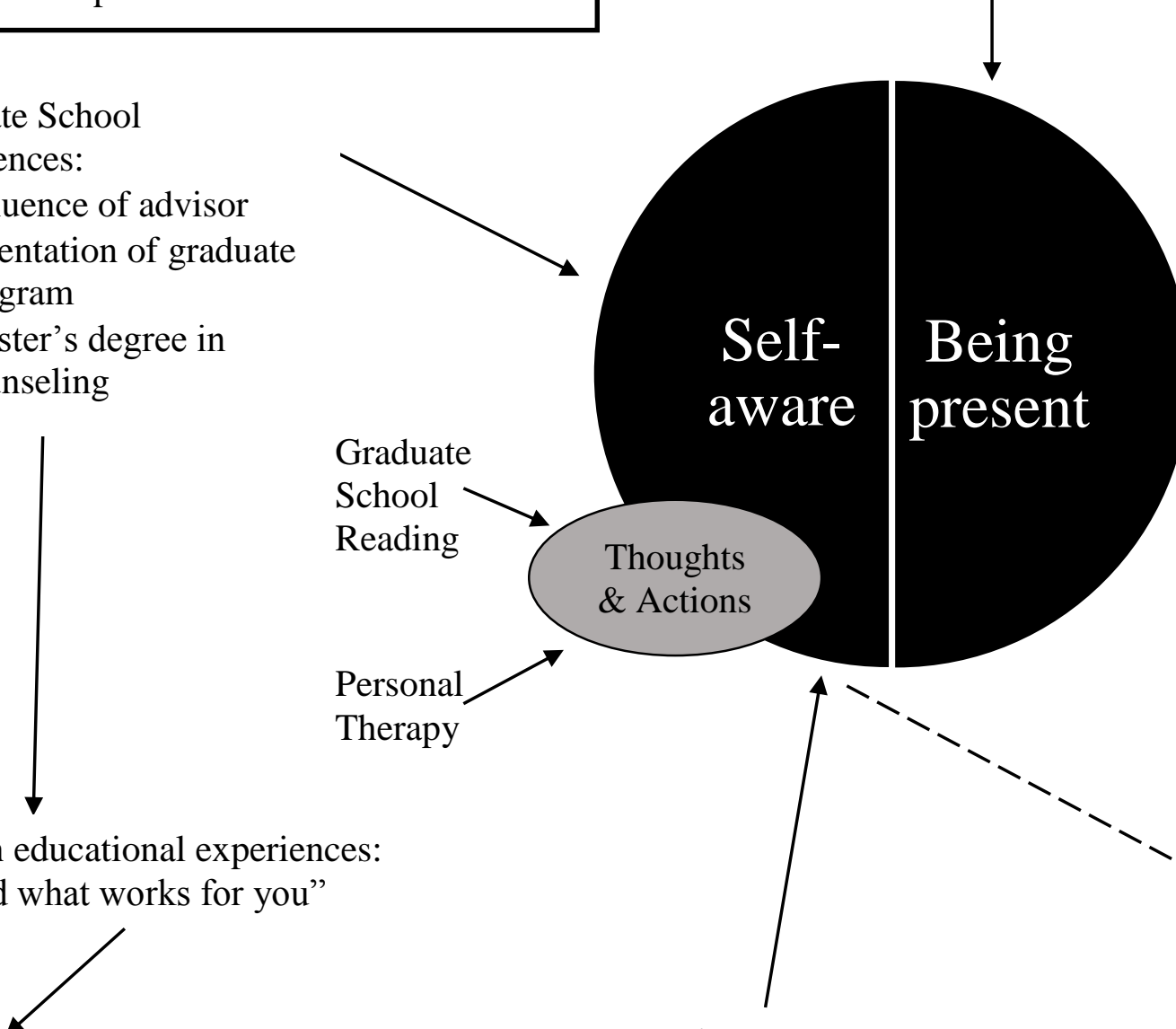

at being present

"Second nature"

"It just becomes part of your existence,

"Grapple" with mindfulness

"Am I doing this right?"

(e.g., trying different

mindfulness activities from graduate school)

just the self-awareness piece"

(e.g., deep breathing when stressed, aware of surroundings and thoughts)

Client directed: Promoting selfawareness and regulation in consulting

SPC directed: Facilitates being an active listener:

- Present with what, how, and context of what client saying

- Shapes "the way I ask questions"

- Provides clarity to "see" client concerns and help

ased on educational experiences:

"Find what works for you"
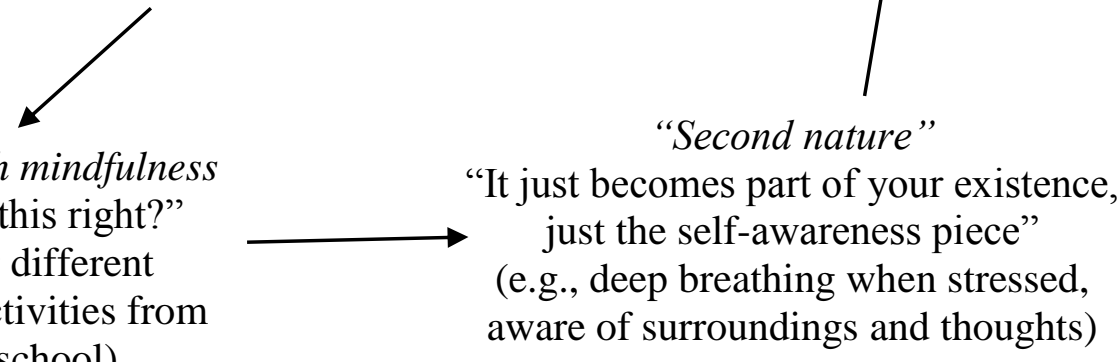
Figure 18: Dan's Developmental and Integration Processes

$$
\text { Developmental Actions and Process }
$$

Family and Childhood Experiences:

"In my dna"

- Influence from social-familial system

- Integrated into way of being over time and with practice*

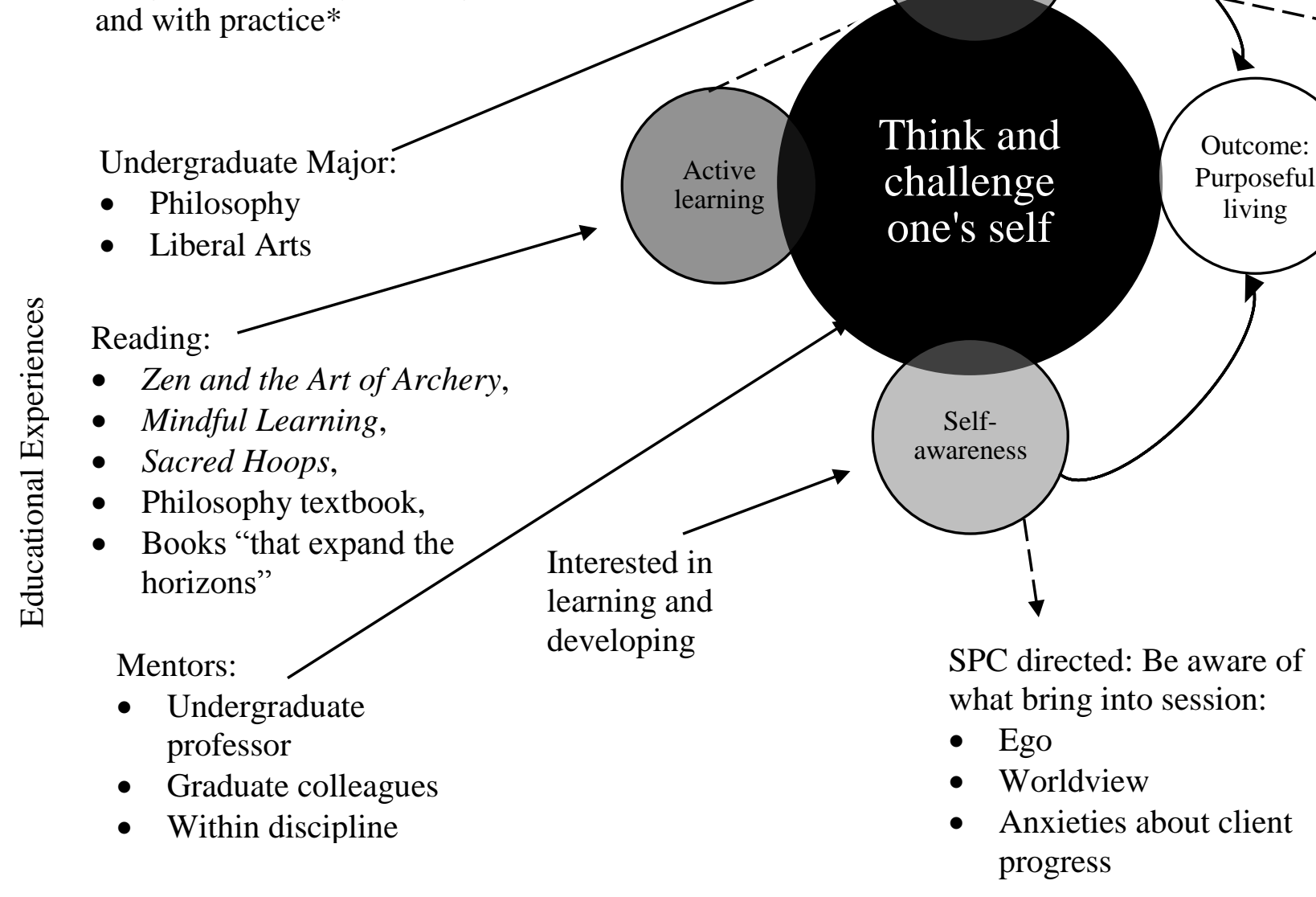

Integration Actions and Process
$\square---\square$

Client directed: Develop as an active learner

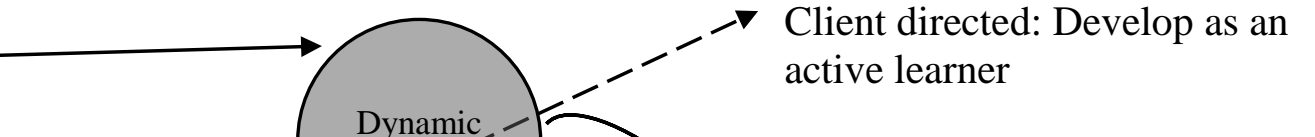


Table 1

Demographic categories with frequency and valid percentage

\begin{tabular}{|c|c|c|}
\hline Demographic Category & Frequency $^{1}$ & Valid Percentage \\
\hline \multicolumn{3}{|l|}{ Professional status } \\
\hline Graduate student & 72 & $31.4 \%$ \\
\hline Professional (post-graduate school) & 157 & $68.56 \%$ \\
\hline \multicolumn{3}{|l|}{ Identified gender } \\
\hline Female & 81 & $43.5 \%$ \\
\hline Male & 104 & $55.91 \%$ \\
\hline No response & 1 & $.00537 \%$ \\
\hline \multicolumn{3}{|l|}{ Age range } \\
\hline $21-25$ & 22 & $11.76 \%$ \\
\hline $26-30$ & 54 & $44.92 \%$ \\
\hline $31-35$ & 38 & $20.32 \%$ \\
\hline $36-40$ & 24 & $12.83 \%$ \\
\hline $41-45$ & 16 & $8.56 \%$ \\
\hline $46-50$ & 5 & $2.67 \%$ \\
\hline $50-60$ & 17 & $9.09 \%$ \\
\hline $61-70$ & 10 & $5.35 \%$ \\
\hline 71 and older & 1 & $.53 \%$ \\
\hline \multicolumn{3}{|l|}{ Identified racial/ethnic backgrounds } \\
\hline Caucasian, non-Hispanic & 175 & $89.3 \%$ \\
\hline Black, African-American & 6 & $3.06 \%$ \\
\hline Hispanic, Latino & 5 & $2.5 \%$ \\
\hline No response & 4 & $2.04 \%$ \\
\hline Asian & 3 & $1.53 \%$ \\
\hline American Indian, Alaskan Native & 1 & $.51 \%$ \\
\hline Bi-racial & 1 & $.51 \%$ \\
\hline Other & 1 & $.51 \%$ \\
\hline Native Hawaiian, Pacific Islander & 0 & $0 \%$ \\
\hline \multicolumn{3}{|l|}{ Country of Origin } \\
\hline United States of America & 150 & $80.21 \%$ \\
\hline Other $^{2}$ & 13 & $9.6 \%$ \\
\hline Canada & 8 & $4.28 \%$ \\
\hline No response & 5 & $2.67 \%$ \\
\hline Great Britain & 4 & $2.14 \%$ \\
\hline Israel & 3 & \\
\hline Ireland & 2 & \\
\hline
\end{tabular}

Note. ${ }^{1}$ Response totals: Identified gender and age range $(n=187)$, professional status $(n=229)$ and racial/ethnic backgrounds $(n=196) .{ }^{2}$ Other countries $(n=1)$ : Australia, Brazil, Colombia, Czech Republic, Estonia, Expatriate/Third Culture Kid, Germany, Greece, France, Italy, Nigeria, South Africa, Ukraine 
Table 2

Graduate students' current academic programs in descending order

\begin{tabular}{lcc}
\hline Graduate programs & Frequency & Valid Percentage \\
\hline Current program & \\
Ph.D./Ed.D. in Sport and Exercise & 27 & $37.5 \%$ \\
Psychology & & $13.88 \%$ \\
Ph.D. in Kinesiology & 10 & $13.88 \%$ \\
Ph.D. in Clinical/Counseling Psychology & 8 & $1.93 \%$ \\
Master's in Kinesiology & 8 & $1.93 \%$ \\
Master's in Counseling & 3 & $4.16 \%$ \\
Master's in Sport and Exercise Psychology & 2 & $2.77 \%$ \\
Master's in Sport and Performance & & \\
Psychology & 2 & $2.77 \%$ \\
Ph.D. in Sport Studies (socio-cultural & & $1.38 \%$ \\
emphasis) & 1 & $1.38 \%$ \\
Ph.D. in Education (sport psychology focus) & 1 & \\
Psy.D. in Sport and Performance Psychology & & \\
& & \\
Additional degree & 29 & \\
Master's in Kinesiology & 9 & \\
Master's in Sport and Performance & & \\
Psychology & 7 & \\
Master's in Counseling & 6 & \\
Master's in Sport and Exercise psychology & 3 & \\
Master's in Clinical Psychology & 1 & \\
Master's in Industrial and Organizational & & \\
Psychology & 1 & \\
Master's in statistics & 0 & \\
Master's in Social Work & 56 & \\
Total of additional degrees earned & 'Pegrages
\end{tabular}

Note: ${ }^{1}$ Percentages calculated from total number of participants who endorsed themselves as graduate students ( 72 participants). Four participants selected more than one option for this question resulting in 76 responses.

${ }^{2}$ Participants may have endorsed more than one additional degree deterring a calculation of percentage of graduate student participants with additional degree. 
Table 3

Highest and additional degrees earned by professional participants

Degree type

\begin{tabular}{lcc}
\hline Highest Degree $^{1}$ & Frequency & Percentage \\
\hline Ph.D./Ed.D. in Sport and Exercise & 43 & $25.9 \%$ \\
Psychology & 36 & $21.68 \%$ \\
Ph.D. in Kinesiology & 28 & $16.87 \%$ \\
Ph.D. in Clinical/Counseling Psychology & 23 & $13.85 \%$ \\
Master's in Kinesiology & 9 & $5.4 \%$ \\
Master's in Counseling & 8 & $4.82 \%$ \\
Master's in Sport and Performance & & $3.61 \%$ \\
Psychology & 6 & $1.81 \%$ \\
Master's in Sport Psychology & 3 & $.6 \%$ \\
Master's in Social Work & 1 & $.6 \%$ \\
Ed.D. Sport Counseling & 1 & $.6 \%$ \\
Ed.D. (unknown area) & 1 & $.6 \%$ \\
Ed.D. Counseling Psychology with sport & & $.6 \%$ \\
psychology emphasis & 1 & $.6 \%$ \\
Master's in Psychology & 1 & $.6 \%$ \\
MSc in Performance Psychology & 1 & $.6 \%$ \\
Ph.D. in Personality/Social Psychology with & & $.6 \%$ \\
clinical minor & 1 & \\
Ph.D. in Education & 1 & \\
Ph.D. in Curriculum and Instruction & 1 & \\
Ph.D. in Experiential Psychology & $\mathbf{1 6 5}$ &
\end{tabular}

Additional degree (s) earned ${ }^{2}$

Master's in Kinesiology $\quad 66$

Master's in Counseling $\quad 35$

Master's in Psychology 5

Master's in Social Work $\quad 4$

Master's in Sport and Exercise Psychology 4

Master's in Clinical Psychology 3

Master's in Experiential Psychology 2

BSc Psychology / B.A. English \& History 1

Ed.D. in Counseling 1

Master's in Child Development $\quad 1$

Master's in Personality/Social Psychology 1

Master's in Education 1

Master's in Fine Arts 1

Master's in Athletic Coaching/Sport 1

Meditation

Master's in Social Psychology 1

Post doctorate in Counseling Psychology 1

Total degrees earned 128

Note: ${ }^{1}$ One hundred and sixty-six participants responded. Participants may have endorsed more than one additional degree deterring a calculation of percentage of graduate student participants with additional degree. 
Table 4

Cross tabulation of years and hours per week of applied training (consulting) reported by graduate students and professionals

\begin{tabular}{|c|c|c|c|c|c|c|c|}
\hline Years/Hours & $0-5$ & $6-10$ & $11-15$ & $16-20$ & $21+$ & Total & Percentage \\
\hline \multicolumn{8}{|l|}{$\begin{array}{l}\text { Graduate } \\
\text { students }\end{array}$} \\
\hline 1 & 7 & 6 & 1 & 1 & 1 & 16 & $25.81 \%$ \\
\hline 2 & 3 & 6 & 5 & 2 & 1 & 17 & $27.42 \%$ \\
\hline 3 & 4 & 6 & 1 & 0 & 1 & 12 & $19.35 \%$ \\
\hline 4 & 1 & 7 & 1 & 0 & 0 & 9 & $14.52 \%$ \\
\hline $5+$ & 3 & 5 & 0 & 0 & 0 & 8 & $12.90 \%$ \\
\hline Total & 18 & 30 & 8 & 3 & 3 & 62 & \\
\hline Percentage $^{1}$ & $29.03 \%$ & $48.39 \%$ & $12.90 \%$ & $4.83 \%$ & $4.83 \%$ & & \\
\hline \multicolumn{8}{|l|}{ Professionals } \\
\hline 0 & 6 & 0 & 0 & 0 & 0 & 6 & $4.8 \%$ \\
\hline 1 & 4 & 8 & 2 & 2 & 4 & 20 & $16 \%$ \\
\hline 2 & 4 & 9 & 2 & 5 & 0 & 20 & $16 \%$ \\
\hline 3 & 5 & 9 & 2 & 0 & 1 & 17 & $13.6 \%$ \\
\hline 4 & 4 & 5 & 3 & 3 & 1 & 16 & $12.8 \%$ \\
\hline 5 & 10 & 15 & 13 & 5 & 3 & 46 & $36.8 \%$ \\
\hline Total & 33 & 46 & 22 & 15 & 9 & 125 & \\
\hline Percentage $^{2}$ & $26.4 \%$ & $36.8 \%$ & $17.6 \%$ & $12 \%$ & $7.2 \%$ & & \\
\hline
\end{tabular}

Note: ${ }^{1}$ Calculated from 62 participants who responded to "years" and "hours per week" items.

${ }^{2}$ Calculated from 125 participants who responded to "years" and "hours per week" items. 
Table 5

Demographics of interview participants ${ }^{1}$

\begin{tabular}{|c|c|c|c|c|c|}
\hline Participant & Gender & $\mathrm{Age}^{2}$ & Profession & Highest Earned Degree & Additional Degrees \\
\hline Andy & $\mathrm{M}$ & 37 & $\begin{array}{l}\text { Associate Professor, Director of } \\
\text { consulting organization }\end{array}$ & $\begin{array}{l}\text { Ph.D. Counseling Psychology, } \\
\text { emphasis in sport psychology }\end{array}$ & $\begin{array}{l}\text { M.S. Kinesiology emphasis in } \\
\text { sport psychology }\end{array}$ \\
\hline Mike & M & 27 & $\begin{array}{l}\text { Full-time sport psychology } \\
\text { consultant }\end{array}$ & $\begin{array}{l}\text { M.S. Exercise Sciences with an } \\
\text { emphasis in sport psychology }\end{array}$ & - \\
\hline Amy* & $\mathrm{F}$ & 33 & $\begin{array}{l}\text { Doctoral student in Clinical } \\
\text { Psychology with emphasis in } \\
\text { health psychology; Sport coach; } \\
\text { Private consultant }\end{array}$ & $\begin{array}{l}\text { M.A. Sport and Performance } \\
\text { Psychology }\end{array}$ & - \\
\hline Jacob & M & 30 & Master Resilience Trainer & $\begin{array}{l}\text { Ph.D. Sport and Exercise } \\
\text { Psychology }\end{array}$ & $\begin{array}{l}\text { M.A. Community Counseling; } \\
\text { M.S. Exercise Science with } \\
\text { emphasis in sport psychology }\end{array}$ \\
\hline Sarah* & $\mathrm{F}$ & 27 & $\begin{array}{l}\text { Doctoral Student; Private } \\
\text { Consultant }\end{array}$ & $\begin{array}{l}\text { M.A. Sport and Performance } \\
\text { Psychology }\end{array}$ & - \\
\hline Jill* & $\mathrm{F}$ & 26 & $\begin{array}{l}\text { Grant coordinator and supervisor } \\
\text { for applied sport psychology non- } \\
\text { profit }\end{array}$ & $\begin{array}{l}\text { M.A. Sport and Performance } \\
\text { Psychology }\end{array}$ & - \\
\hline Dan & M & 40 & $\begin{array}{l}\text { Professor; Full-time sport } \\
\text { psychology consultant }\end{array}$ & $\begin{array}{l}\text { Ed.D. Counseling Psychology } \\
\text { emphasis in sport psychology }\end{array}$ & M.A. Counseling \\
\hline
\end{tabular}

Note. ${ }^{1}$ All participants identified as Caucasian, non-Hispanic and the United States of America as their country of origin. ${ }^{2}$ Descriptive statistics for age: $\mathrm{M}=31.43$ years, range $=14$ years, $\mathrm{SD}=5.44, \min =26, \max =40$. $(*)$ denotes excluded from case exemplar analysis. 
Table 6

Interview participants' current consulting experience and focus

\begin{tabular}{|c|c|c|c|c|c|}
\hline Participant & Consult Focus & Consult Population & $\begin{array}{l}\text { Direct } \\
\text { hours per week }^{1}\end{array}$ & Years & $\begin{array}{l}\text { Certificatic } \\
\text { Licensure }\end{array}$ \\
\hline Andy & Performance and Clinical & Athletic, Elite & 10 & 15 & $\begin{array}{l}\text { CC-AASP } \\
\text { Licensed } \\
\text { Psychologi }\end{array}$ \\
\hline Mike & Performance & Athletic \& Business & Full time, $25-30$ & 7 & - \\
\hline Amy * & Performance and Clinical & $\begin{array}{l}\text { Athletic, Youth, High school, } \\
\text { Collegiate }\end{array}$ & 5 & 5 & CC-AASP \\
\hline Jacob & Performance & Military, previously athletic & Full time, $25-30$ & 8 & CC-AASP \\
\hline Sarah * & Performance & Athletic, High school & 3 & 4 & - \\
\hline Jill * & $\begin{array}{l}\text { Performance, emphasis well- } \\
\text { being }\end{array}$ & $\begin{array}{l}\text { Athletics, High school, People } \\
\text { with physical disability, and } \\
\text { Eating disorders }\end{array}$ & $20^{2}$ & 3 & - \\
\hline
\end{tabular}

$\begin{array}{llrrr}\text { Dan } & \text { Performance, Organizational } & \text { Athletic, Elite } & 25-30 & 19\end{array}$

Note. ${ }^{1}$ Hours per week varied for many participants depending on sport season and profession engagements. The hours listed reflect current hours per week. Previous years' hours may have been higher or lower.

${ }^{2}$ These hours refer to direct supervision. No direct consulting at this time, but previous experience a full time clinician and consulting. Descriptive statistics: Years $(M=8.714, \mathrm{SD}=6.02, \min =3$, $\max =19)$, Hours $(\mathrm{M}=18.64, \mathrm{SD}=13.04, \min =0, \max =30)$.

(*) denotes excluded from case exemplar analysis. 
Table 7

Spearman's rho correlational matrix for variables included in CFA and SEM

\begin{tabular}{|c|c|c|c|c|c|c|c|c|c|c|c|}
\hline Applied & $\begin{array}{c}\text { Applied } \\
\text { Training } \\
1.00\end{array}$ & $\begin{array}{c}\text { Aware } \\
\text { Internal }\end{array}$ & $\begin{array}{c}\text { Aware } \\
\text { External }\end{array}$ & $\begin{array}{c}\text { Act } \\
\text { Aware }\end{array}$ & $\begin{array}{l}\text { Accept } \\
\text {-ing }\end{array}$ & $\begin{array}{l}\text { Decenter- } \\
\quad \text { ing }\end{array}$ & $\begin{array}{l}\text { Relative } \\
\text { Thoughts }\end{array}$ & $\begin{array}{c}\text { Insight } \\
\text { Understand }\end{array}$ & $\begin{array}{l}\text { Mind } \\
\text { Expo }\end{array}$ & CFS & $\mathrm{COMMFS}^{1}$ \\
\hline Training & & & & & & & & & & & \\
\hline $\begin{array}{l}\text { Aware } \\
\text { Internal }\end{array}$ & -.039 & 1.00 & & & & & & & & & \\
\hline $\begin{array}{l}\text { Aware } \\
\text { External }\end{array}$ & -.031 & $.402 * *$ & 1.00 & & & & & & & & \\
\hline Act Aware & -.055 & $.413 * *$ & $1.00 * *$ & 1.00 & & & & & & & \\
\hline Accepting & -.090 & $.202 * *$ & .012 & .022 & 1.00 & & & & & & \\
\hline Decentering & -.024 & $.453 * *$ & $.181 *$ & $.189 * *$ & $.617 * *$ & 1.00 & & & & & \\
\hline $\begin{array}{l}\text { Relative } \\
\text { Thoughts }\end{array}$ & -.071 & $.320 * *$ & $.149 *$ & .140 & $.409 * *$ & $.513 * *$ & 1.00 & & & & \\
\hline $\begin{array}{l}\text { Insight } \\
\text { Understand }\end{array}$ & -.057 & $.414^{* *}$ & .131 & .128 & $.493 * *$ & $.687 * *$ & $.498 * *$ & 1.00 & & & \\
\hline Age & .126 & -.118 & -.035 & -.054 & -.024 & -.095 & -.140 & -.059 & & & \\
\hline Mind Expo & -.061 & .051 & $.182 *$ & $.200 * *$ & $.159 *$ & $.168 *$ & $.166 *$ & .066 & 1.00 & & \\
\hline CFS & .122 & .139 & .051 & .045 & .141 & $.259 * *$ & $.282 * *$ & $.216^{* *}$ & .107 & 1.00 & \\
\hline COMMF & $.145^{*}$ & $.164 *$ & .016 & .014 & .128 & $.302 * *$ & $.214 * *$ & $.261 * *$ & $.176^{*}$ & $.548 * *$ & 1.00 \\
\hline Mean & .000 & 4.795 & 4.67 & 4.691 & 3.754 & 4.313 & 4.168 & 4.453 & .026 & 5.184 & 3.840 \\
\hline Mode & .81 & 5.00 & 5.00 & 5.00 & 3.67 & 4.00 & 4.00 & 4.67 & 1.15 & 5.33 & 3.70 \\
\hline SD & 1.377 & .712 & .768 & .761 & .953 & .766 & .792 & .860 & 1.537 & .435 & .470 \\
\hline Range & 6.16 & 3.33 & 3.75 & 3.75 & 4.00 & 3.80 & 3.67 & 4.00 & 7.73 & 1.92 & 2.20 \\
\hline Skewness & .027 & -.221 & -.407 & -.421 & -.057 & -.444 & -.093 & -.422 & .488 & -.088 & -.269 \\
\hline Kurtosis & -.507 & -.431 & -.027 & .033 & -.656 & .124 & -.288 & .016 & .175 & -.737 & -.381 \\
\hline$n$ & 213 & 194 & 196 & 193 & 194 & 191 & 196 & 194 & 169 & 193 & 187 \\
\hline
\end{tabular}

Note. Valid $n$ listwise $=157$. Applied Training, Age, and Mind Expo are standardized. Likert scale ranges are CHIMES- $\beta$ : 1 (almost never) to 6 (almost always), CFS: 1 (strongly disagree) to 6 (strongly agree), and COMMF: 1 (not at all like you) to 5 (a lot like you). Effect size for correlations are small (0.1), medium (0.3), and large (0.5) (MRC Cognition and Brain Sciences Unit, 2009).

${ }^{1}$ COMMFS 10 item 
Table 8

Cronbach's alpha scores for scales and subscales ${ }^{1}$

\begin{tabular}{|c|c|c|c|c|}
\hline $\begin{array}{c}\text { Scale/ } \\
\text { Subscale Name }\end{array}$ & $\begin{array}{l}\text { Cronbach's } \\
\text { Alpha }\end{array}$ & Qualitative Label & $\begin{array}{l}\text { Number } \\
\text { of Items }\end{array}$ & $\begin{array}{c}\text { Total Number } \\
\text { of Cases }^{2}\end{array}$ \\
\hline $\begin{array}{l}\text { Comprehensive } \\
\text { Inventory of } \\
\text { Mindfulness } \\
\text { Experiences - } \mathrm{IM}^{4} \\
\text { Subscales }\end{array}$ & $.805^{3}$ & Good & 17 & 183 \\
\hline Aware Internal & .581 & Poor & 3 & 194 \\
\hline Aware External & .762 & Good & 4 & 193 \\
\hline Act Aware & .674 & Acceptable & 4 & 194 \\
\hline Accepting & .744 & Good & 3 & 194 \\
\hline Decentering & .802 & Good & 5 & 191 \\
\hline $\begin{array}{l}\text { Relative } \\
\text { Thoughts }\end{array}$ & .430 & Unacceptable & 3 & 196 \\
\hline $\begin{array}{l}\text { Insight } \\
\text { Understanding }\end{array}$ & .745 & Good & 3 & 193 \\
\hline $\begin{array}{l}\text { Cognitive } \\
\text { Flexibility Scale }\end{array}$ & 0.777 & Good & 12 & 190 \\
\hline $\begin{array}{l}\text { Communication } \\
\text { Flexibility Scale }\end{array}$ & 0.700 & Good & 10 & 181 \\
\hline \multicolumn{5}{|c|}{$\begin{array}{l}\text { Notes. }{ }^{1} \text { Cronbach's Alpha Score Qualitative Labels determined based on the following } \\
\text { assumptions: Excellent }(\alpha \leq 0.9) \text {, Good }(0.7 \leq \alpha<0.9) \text {, Acceptable }(0.6 \leq \alpha<0.7) \text {, Poor }(0.5 \leq \alpha \\
<0.6) \text {, Unacceptable }(\alpha<0.5) \text {. } \\
{ }^{2} \text { Cases based on listwise deletion. } \\
{ }^{3} \text { Based on five factor model. } \\
{ }^{4} \text { The original CHIMES- } \beta \text { has } 37 \text { items. Four items were omitted unintentionally. Each missing } \\
\text { item contributed to a different factor. All factors (prior to psychometric analysis) had four or } \\
\text { five items, except relativity of thoughts, which had three items. }\end{array}$} \\
\hline
\end{tabular}


Table 9

CHIMES- $\beta$ psychometric properties: Subscale and item reliability and deletion process

\begin{tabular}{|c|c|c|c|c|c|c|}
\hline \multirow[b]{2}{*}{ Subscale } & \multicolumn{2}{|c|}{ Initial } & \multirow[b]{2}{*}{ Rationale } & \multicolumn{2}{|c|}{ Corrected } & \multirow[b]{2}{*}{$\begin{array}{l}\text { Total } \\
\text { items }\end{array}$} \\
\hline & Alpha & $\begin{array}{c}\text { Inter-item } \\
\text { mean }\end{array}$ & & Alpha & $\begin{array}{c}\text { Inter-item } \\
\text { mean }\end{array}$ & \\
\hline 1. Aware Internal & .299 & & 1. Item 29 negatively correlated to all other items. & .581 & & 3 \\
\hline a. Item 1 & & .302 & 2. Could drop one more item to increase alpha to & & .407 & \\
\hline b. Item 5 & & .175 & .600, but then subscale would consist of 2 items. & & .333 & \\
\hline c. Item 14 & & .230 & & & .456 & \\
\hline d. Item $29^{*}$ & & .019 & & & - & \\
\hline 2. Aware External & .762 & & No modifications. & .762 & & 4 \\
\hline e. Item 9 & & .449 & & & .449 & \\
\hline f. Item 18 & & .522 & & & .522 & \\
\hline g. Item 21 & & .663 & & & .663 & \\
\hline h. Item 27 & & .624 & & & .624 & \\
\hline 3. Act Aware & .674 & & No modifications. & .674 & & 4 \\
\hline i. Item 10 & & .357 & & & .357 & \\
\hline j. Item 12 & & .507 & & & .507 & \\
\hline k. Item 17 & & .466 & & & .466 & \\
\hline 1. Item 26 & & .507 & & & .507 & \\
\hline 4. Accepting & .455 & & 1. Item 32 negatively correlated to items. & .744 & & 3 \\
\hline m. Item 2 & & .393 & & & .546 & \\
\hline n. Item 7 & & .469 & & & .525 & \\
\hline o. Item 11 & & .505 & & & 659 & \\
\hline p. Item $32 *$ & & -.168 & & & - & \\
\hline 5. Decentering & .765 & & 1. Item 28 deletion increases alpha sizably. & .802 & & 5 \\
\hline q. Item 8 & & .586 & 2. Subscale has double the amount of items of & & .642 & \\
\hline r. Item 13 & & .621 & other subscales and deletion would diminish & & .618 & \\
\hline s. Item 16 & & .498 & difference. & & .507 & \\
\hline t. Item 20 & & .498 & & & .500 & \\
\hline u. Item 25 & & .675 & & & .671 & \\
\hline
\end{tabular}


v. Item $28^{*}$

\section{Relative}

\section{Thoughts}

w. Item 4

x. Item 23

y. Item 31

7. Open

Experience*

aa.Item 19

bb. Item 22

cc. Item 30

dd. Item 33
.209

.430

.324

.300

.163

.228

.182

.216

.017

.026

1. Considered dropping item 31 to improve alpha
to .494 , but two item factor discouraged ${ }^{1}$.

\author{
to .494 , but two item factor discouraged ${ }^{1}$
}

1. Negative correlations between items.
2. Highest alpha with dropping items was .291.
3. Exploratory factor analysis of items indicated
that items factored on two different factors (two
per factor).
4. Reviewed items to assess if made sense
theoretically. The items could be captured by
other factors and focused on how managed pain
and distraction and did not seem to 'get at' open
to experience. Additionally, all items reverse
scored (only subscale captured this way).

\begin{tabular}{|c|c|c|c|}
\hline 8. Insight & .715 & 1. Item 6 removal increased alpha. & .745 \\
\hline $\begin{array}{l}\text { Understanding } \\
\text { ee. Item } 3\end{array}$ & .444 & & .499 \\
\hline ff. Item $6^{*}$ & .369 & & .575 \\
\hline gg. Item 15 & .573 & & 649 \\
\hline hh. Item 24 & .664 & & - \\
\hline
\end{tabular}

Note. Full subscale names: Awareness toward internal experience, awareness towards external experiences, Acting with awareness, Accepting and non-judgmental orientation, Decentering and nonreactivity, Openness to experience, Relativity of thoughts, Insight understanding.

* Denotes deletion (item or subscale) 
Table 10

Goodness of fit results for confirmatory factor analysis of CHIMES- $\beta(n=185)$

\begin{tabular}{|lcccccccc|}
\hline Model & $\chi^{2}$ & df & CFI & SRMSR & RMSEA & (RMSEA CL90) & AIC & BIC \\
\hline F1: Mindfulness & 13.837 & 5 & .983 & .033 & .095 & $(.037-.156)$ & 2453.426 & 2502.598 \\
\hline
\end{tabular}

Note. $\chi^{2}=$ chi-square; $\mathrm{df}=$ degrees of freedom; CFI = Comparative Fit Index; SRMR = Standardized Root Mean Square Residual; RMSEA = Root Mean Square Error of Approximation; RMSEA CL $90=$ RMSEA 90\% Confidence Limits, AIC = Akaike Information Criterion, BIC $=$ Schwarz Bayesian Criterion. Goodness of fit criteria for indices: CFI (ideal > .94), SRMSR (excellent $<.055$ ), RMSEA (poor $>.10$, mediocre $=.08-.10$, fair $=.055-.08$, ideal $<.055)$, RMSEA CL 90 (ideal $=.054 \geq$ RMSEA CL90 $\geq .000)$. AIC and $\mathrm{BIC}$ are used as comparisons between models to assess fit (represented by a decrease in value). According to Wald Test, all paths significant and models were not compared. Criteria based on O'Rouke and Hatcher (2013). 
Table 11

Manifest variable loadings of the latent factor, Internal Mindfulness, from confirmatory factor analysis

\begin{tabular}{lcccc}
\hline \multicolumn{1}{c}{ Variable } & $\mathrm{t}$ Value & Beta weight & Std. Err. & $\mathrm{R}^{2}$ \\
\hline Aware Internal & 7.972 & .483 & .060 & .233 \\
Accepting & 13.987 & .659 & 047 & .434 \\
Decentering & 29.496 & .890 & .030 & .792 \\
$\begin{array}{l}\text { Relative } \\
\text { Thoughts }\end{array}$ & 11.225 & .590 & .052 & .348 \\
$\begin{array}{l}\text { Insight } \\
\text { Understanding }\end{array}$ & 20.747 & .776 & .037 & .603 \\
\hline
\end{tabular}

Note. $n=185$, Criteria for significant $\mathrm{t}$ value is greater than \pm 1.96 . 
Table 12

Goodness-of-Fit indices for various models $(n=159)$

\begin{tabular}{|c|c|c|c|c|c|c|c|c|c|c|}
\hline Model & $\chi^{2}$ & df & $\Delta \chi^{2}$ & $\Delta \mathrm{df}$ & CFI & SRMR & RMSEA & $\begin{array}{c}\text { (RMSEA } \\
\text { CL }\end{array}$ & AIC & BIC \\
\hline $\begin{array}{l}\text { Theoretical } \\
\text { Model } \\
\text { (initial) }\end{array}$ & 77.611 & 23 & & & .869 & .0654 & .1053 & $.080-.131$ & 4869.578 & 4976.923 \\
\hline $\begin{array}{l}\text { Revised } \\
\text { Model } 1\end{array}$ & 77.727 & 24 & .116 & 1 & .871 & .065 & .1023 & $.077-.128$ & 4867.693 & 4968.673 \\
\hline $\begin{array}{l}\text { Revised } \\
\text { Model } 2\end{array}$ & 79.061 & 25 & 1.45 & 2 & .871 & .067 & .1005 & $.076-.125$ & 4867.028 & 4964.641 \\
\hline $\begin{array}{l}\text { Revised } \\
\text { Model } 3\end{array}$ & 82.868 & 26 & 5.25 & 3 & .864 & .069 & .1011 & $.077-.125$ & 4868.835 & 4963.082 \\
\hline
\end{tabular}

Note. Incomplete observations $(n=55)$ included in FIML method. Revised Model 2 selected. $\chi^{2}=$ chi-square; df $=$ degrees of freedom; CFI = Comparative Fit Index; SRMR = Standardized Root Mean Square Residual; RMSEA = Root Mean Square Error of Approximation; RMSEA CL90 $=$ RMSEA 90\% Confidence Limits, AIC = Akaike Information Criterion, BIC $=$ Schwarz Bayesian Criterion. Goodness of fit criteria for indices: CFI (ideal > .94), SRMSR (excellent <.055), RMSEA (poor > .10, mediocre $=.08-.10$, fair $=.055-.08$, ideal $<.055)$, RMSEA CL 90 (ideal $=.054 \geq$ RMSEA CL90 $\geq .000$ ). AIC and BIC are used as comparisons between models to assess fit (represented by a decrease in value). Criteria based on O'Rouke and Hatcher (2013). 
Table 13

Mean comparisons of graduate students and professionals and mindfulness (CHIMES-IM), cognitive flexibility (CFS), and communication flexibility (COMMFS)

\begin{tabular}{|c|c|c|c|c|c|c|c|c|c|}
\hline \multirow[b]{2}{*}{ Variable } & \multicolumn{2}{|r|}{$n$} & \multicolumn{2}{|c|}{$M(\mathrm{SD})$} & \multirow[b]{2}{*}{$t$} & \multirow[b]{2}{*}{ df } & \multirow[b]{2}{*}{$\begin{array}{c}\text { Sig. } \\
(p<.05)\end{array}$} & \multirow{2}{*}{$\begin{array}{c}\text { Corrected } \\
\text { effect size } \\
(g)\end{array}$} & \multirow[b]{2}{*}{$\begin{array}{c}\text { Converted } \\
d \text { from } g\end{array}$} \\
\hline & $\begin{array}{l}\text { Graduate } \\
\text { students }\end{array}$ & Professionals & $\begin{array}{l}\text { Graduate } \\
\text { Students }\end{array}$ & Professionals & & & & & \\
\hline \multicolumn{10}{|l|}{ CHIMES- $\beta$} \\
\hline Aware Internal & 59 & 135 & $4.802(0.763)$ & $0.692(4.792)$ & .087 & 192 & .931 & -0.014 & -0.013 \\
\hline Accepting & 59 & 134 & $0.914(3.621)$ & $0.970(3.810)$ & 1.271 & 191 & .205 & 0.198 & 0.197 \\
\hline Decentering & 55 & 135 & $0.705(4.229)$ & $0.792(4.346)$ & .956 & 188 & .340 & 0.152 & 0.151 \\
\hline $\begin{array}{l}\text { Relative } \\
\text { Thoughts }\end{array}$ & 59 & 136 & $0.802(4.124)$ & $0.790(4.181)$ & .461 & 193 & .645 & 0.072 & 0.071 \\
\hline $\begin{array}{l}\text { Insight } \\
\text { Understanding }\end{array}$ & 59 & 134 & $0.961(4.339)$ & $0.813(4.507)$ & 1.252 & 191 & .212 & 0.195 & 0.194 \\
\hline
\end{tabular}


Table 14

Variance comparisons of professionals' graduate education and mindfulness (CHIMES-IM), cognitive flexibility (CFS), and communication flexibility (COMMFS)

\begin{tabular}{|c|c|c|c|c|c|c|c|}
\hline Variable & $\mathrm{SS}_{\mathrm{M}}$ & $\mathrm{SS}_{\mathrm{T}}$ & $\mathrm{df}$ & $\mathrm{F}$ & Sig. & $\begin{array}{l}\text { Effect size } \\
\qquad\left(\eta^{2}\right)^{1}\end{array}$ & $\begin{array}{c}\text { ES } \\
\text { Qualitative }\end{array}$ \\
\hline \multicolumn{8}{|l|}{ CHIMES- $\beta$} \\
\hline Aware Internal & 2.671 & 58.301 & 5 & 1.162 & .332 & .045 & small \\
\hline Accepting & 5.829 & 118.381 & 5 & 1.243 & .293 & .049 & small \\
\hline Decentering & 1.319 & 77.499 & 5 & .419 & .835 & .017 & n.s. \\
\hline $\begin{array}{l}\text { Relative } \\
\text { Thoughts }\end{array}$ & 4.652 & 80.694 & 5 & 1.493 & .197 & .057 & small \\
\hline $\begin{array}{l}\text { Insight } \\
\text { Understanding }\end{array}$ & 4.036 & 78.346 & 5 & 1.304 & .267 & .051 & small \\
\hline CFS & 2.118 & 20.589 & 5 & 2.728 & $.023 *$ & .102 & $\begin{array}{l}\text { nearing } \\
\text { medium }\end{array}$ \\
\hline COMMFS & 2.197 & 22.986 & 5 & 2.430 & $.039 *$ & .095 & small \\
\hline
\end{tabular}

Note. Effect size $\left(\eta^{2}\right)$ calculated by $\sqrt{\mathrm{SS}_{\mathrm{m}}} / \mathrm{SS}_{\mathrm{T}}$ (Field, 2009). Eta squared interpretation: 0.02 (small), 0.13 (medium), and 0.26 (large) (MRC Cognition and Brain Sciences Unit, 2009). 
Table 15

Variance comparisons of graduate students' graduate education and mindfulness (CHIMES-IM), cognitive flexibility (CFS), and communication flexibility (COMMFS)

\begin{tabular}{|c|c|c|c|c|c|c|c|}
\hline Variable & $\mathrm{SS}_{\mathrm{M}}$ & $\mathrm{SS}_{\mathrm{T}}$ & df & $\mathrm{F}$ & Sig. & $\begin{array}{l}\text { Effect size } \\
\quad\left(\eta^{2}\right)\end{array}$ & $\begin{array}{c}\text { ES } \\
\text { Qualitative }\end{array}$ \\
\hline \multicolumn{8}{|l|}{ CHIMES- $\beta$} \\
\hline Aware Internal & 1.090 & 31.429 & 4 & .458 & .766 & .034 & small \\
\hline Accepting & 2.276 & 46.760 & 4 & .652 & .628 & .048 & small \\
\hline Decentering & 2.357 & 24.193 & 4 & 1.268 & .296 & .097 & small \\
\hline $\begin{array}{l}\text { Relative } \\
\text { Thoughts }\end{array}$ & 1.796 & 33.665 & 4 & .719 & .583 & .053 & small \\
\hline $\begin{array}{l}\text { Insight } \\
\text { Understanding }\end{array}$ & .509 & 51.484 & 4 & .127 & .972 & .009 & n.s. \\
\hline CFS & 2.165 & 12.366 & 4 & 2.760 & $.037 *$ & .175 & medium \\
\hline COMMFS & .483 & 14.047 & 4 & .445 & .776 & .034 & small \\
\hline
\end{tabular}

Note. The group 'Master's in Counseling” had only one case and was deleted in order to conduct analyses, which is why df $=4$, not 5 as in Table 14. Effect size $\left(\eta^{2}\right)$ calculated by $\sqrt{ } \mathrm{SS}_{\mathrm{m}} / \mathrm{SS}_{\mathrm{T}}$ (Field, 2009). Eta squared interpretation: 0.02 (small), 0.13 (medium), and 0.26 (large) (MRC Cognition and Brain Sciences Unit, 2009). 
Table 16

Results for ANOVA between CHIMES-IM and age range

\begin{tabular}{|c|c|}
\hline Factor & Result \\
\hline $\begin{array}{l}\text { Aware } \\
\text { Internal }\end{array}$ & $F(7,176)=1.118$, n.s. \\
\hline Accepting & $F(7,176)=.887$, n.s. \\
\hline Decentering & $F(7,172)=.614$, n.s. \\
\hline $\begin{array}{l}\text { Relative } \\
\text { Thoughts }\end{array}$ & $F(7,177)=.619$, n.s. \\
\hline $\begin{array}{l}\text { Insight } \\
\text { Understanding }\end{array}$ & $F(7,175)=1.132$, n.s. \\
\hline
\end{tabular}




\section{APPENDIX A \\ Extended Review of Literature}

The following review of literature discusses the components of sport psychology consultation within the field of sport psychology as conceptualized for the present study (Figure 1). The three sport psychology consultation variables outlined in the proposed study were: (a) educatuional background, (b) consultant skills, and (c) consultant performance tasks. Educational background referred to a SPCs' graduate education and graduate applied training that form the foundation for how SPCs' approach and conduct consultation. The consultant skills of mindfulness, cognitive flexibility, and communication flexibility were three skills that have not received previous attention with sport psychology, but have potential influence on consultant performance tasks. Consultant performance tasks consisted of problem solving and communication Meyers, 2002).

The purpose of the study was to examine the relationship between educational background (graduate education and graduate applied training) and consultant skills (mindfulness, cognitive flexibility, and communication flexibility). It was important to explore how professional backgrounds may relate to SPCs' mindfulness, cognitive flexibility, and communication flexibility because this knowledge may identify professional experiences that impact these skills and, in turn, inform professional development programming in graduate school and beyond. Such programming may enhance the quality of SPCs' service delivery. This review of literature was divided into two major sections. Section I introduced and described all the components involved in the proposed study and represented in Figure 1. These components include: (a) consultation, (b) sport psychology consultation, (c) consultant performance tasks, (d) consultant skills, and (e) SPCs' educational/professional background. Section II discussed 
relationships between the components of sport psychology consultation based on previous research findings.

The topics of consultation, educational background (graduate education and graduate applied training), and consultant skills (mindfulness, cognitive flexibility, and communication flexibility) have attracted noteworthy attention across multiple disciplines. Given the breadth and depth of these topics, this review limited itself to these concepts within sport psychology and allied disciplines' literature when appropriate. Significant research that is outside the scope of this review was referenced for the reader's information.

\section{Section I: Overview of Study Conceptualization}

\section{Consultation}

Consultation is considered a professional activity (Akin-Little, Little, \& Delligatti, 2004) of which a professional may engage in addition to other professional roles and activities (e.g., professor, counselor). A consultation often involves three participants: (a) the consultant, who offers expertise in a collaborate manner to the consultee, (b) the consultee, who seeks services and is responsible for implementation (or lack of implementation) of action items, and (c) the client, who benefits from the consultation (Caplan \& Caplan, 1993; Sears Rudisill, \& MasonSears, 2006). Several definitions of consultation exist. The broadest definition of a consultant is "a person with special knowledge, skills, and talent, who makes needed expertise available to a client for a fee" (Sears et al., 2006, p. 4). A conceptualization based on the mental health model asserts that consultation is:

The process of interaction between two professional persons - the consultant, who is a specialist, and the consultee, who invokes the consultant's help in regard to a current work problem with which the latter is having some difficulty, and which he has decided is within the former's area of specialized competence. (Caplan \& Caplan, 1993, p. 11). 
Generally, a consultant is both an organizational and a topical specialist (O'Roark, 2007). Four essential components of consultation include:

(a) indirect delivery of services, (b) the upgrading of skills and understanding of [consultees] with a primary prevention orientation, (c) a collaborative peer-professional relationship between consultant and consultee, and (d) the fact that consultation is consultee initiated with the consultee having the freedom to accept or reject the services of the consultant. (Akin-Little et al., 2004, p. 156)

Consultations may focus on systemic, group, or organizational change, instead of individual change, though systemic change may be initiated through change within one individual consultee (Davis, 2011; Meyers, 2002). Change requires a problem solving process, which consultants are hired to facilitate (Sears et al., 2006). Consultants approach problem solving collaboratively in order to enhance consultees' problem-solving abilities. The consultant and consultee engage in a systematic problem solving process, which progresses in the following order: "(a) define the problem, (b) identify alternative solutions, (c) weigh the consequences of alternative solutions, (d) implement the decision, (e) evaluate the consequences of the decision, (f) redefine the problem and restart the problem-solving sequence" (Sears et al., 2006, p. 21). In short, consultants are problem-solving helpers who collaborate with consultees' to achieve the purpose of consultation (Sears et al., 2006).

Because many consultants engage in several professional activities, it is important to differentiate consultation from other similar, but nevertheless unique, relationships. For example, the supervisory relationship differs from consultant-consultee relationship in that it is an obligatory, superior-subordinate relationship with a senior professional in the same discipline in which the supervisor exerts some amount of power over the supervisee (Caplan \& Caplan, 1993). Ultimately, the supervisor is responsible for the supervisees work, whereas the consultant does not accept any professional responsibility for the consultees' actions and decision making 
of the client. Lastly, the supervisory relationship is often continual instead of limited to a specific time frame or case (Caplan \& Caplan, 1993).

In addition to the supervisory relationship, consultation relationships differ from clientcounselor relationships. Researchers have distinguished between counseling and consulting in several areas. Often, counseling occurs over a longer time frame than a consultation (HenningStout \& Conoley, 1987). Furthermore, whereas counseling is a direct service focused of exploring and restructuring clients' cognitions, behaviors, and personality, consulting is often an indirect service focused on using the consultee as he or she is to solve the problem presented (Henning-Stout \& Conoley, 1987).

Consulting requires tailored training because it is a specialized field within the helping professions (Brown, 1993; Meyers, 2002). Despite calls for specific training in mental health consultation, limited progress has occurred within graduate level curriculums (Brown, 1993). However, professional development opportunities are available through APA Division 13: Society of Consulting Psychology and a proliferation of practitioner research on consulting models within community and school mental health environments (Akin-Little et al., 2004; Caplan \& Caplan, 1993; Meyers, Meyers, Graybill, Proctor, \& Huddleston, 2012; Wagner, 2000). Similarly, the discipline of sport psychology continues to advance its understanding of consultation, identify necessary skills and competencies, and develop professional and graduate level programming to accomplish sport psychology consultation performance tasks.

\section{Sport Psychology Consultation}

Various definitions of sport psychology exist; based on differing world perspectives and types of research and practice (for review see Quartiroli \& Zizzi, 2011). From the North American perspective, sport psychology is considered one sub-field within performance 
psychology that applies performance psychology knowledge, principles, and interventions into the domain of competitive sport (Portenga, Aoyagi, Balague, Cohen, \& Harmison, 2012). Applied sport psychology refers to professional practitioners whose professional identity is the practice of sport psychology (Portenga et al., 2012). Sport psychology consultants, as applied practitioners, "help athletes prepare psychologically for the demands of competition and training" (British Psychological Society, 2013) and "facilitate optimal involvement, performance, and enjoyment in sport and exercise" (AASP, 2013a). Facilitating life skills development and overall well-being through sport are considered complimentary components of SPCs' work and philosophy (see Conley, Danish, \& Pasquariello, 2010; Friesen \& Orlick, 2010; McCarthy \& Jones, 2013; Poczwardowki, Sherman, Ravizza, 2004). Although sport psychology consultants may have clinical training and licensure, the main purpose of sport psychology consultation is "helping people reach their potential rather than about ameliorating mental health issues" (Portenga, 2012, p. 14). In short, SPCs help consultees improve in the area they wish to better (Andersen, 2000) through specific actions the SPC carries out (Maher, 2013).

Two definitions may clarify the professional identity and qualifications of a SPC, as well as, what the practice of applied sport psychology consultation encompasses. First, regarding professional identity and competencies, Portenga and colleagues (2012) stated:

Applied sport psychologists/[consultants] are uniquely trained and specialized to engage in a broad range of activities including the identification, development, and execution of the mental and emotional knowledge, skills, and abilities required for excellence in athletic domains; the understanding, diagnosing, and preventing of the psychological, cognitive, emotional, behavioral, and psychophysiological inhibitors of consistent, excellent performance; and the improvement of athletic contexts to facilitate more efficient development, consistent execution, and positive experiences in athletes. (p. 9-10) 
Contrary to previous definitions used to explain sport psychology and its practice (Weinberg \&

Gould, 2011; William \& Straub, 2006), this definition alleviates conceptual confusion caused by the inclusion of sport and exercise domains into one definition and describing what sport psychology studies, but not how it is done. Such conceptual confusions have plagued sport psychology and made it challenging to progress professionally and market its services to consumers accurately (Portenga et al., 2012; Silva, Metzler, \& Lerner, 2011). Nevertheless, the definition by Portenga and colleagues (2012) is an initial step toward professional clarity that will inform education, training, and competencies for ethical practice. The ramifications of this definition in terms of education, training, and work experience will be discussed in subsequent sections.

Although Portenga and colleagues (2012) identified SPCs' professional role and competencies, the process of sport psychology consultation remained undefined. Therefore, Maher (2013) presented a formal definition of professional practice in sport psychology:

The process by which a qualified practitioner organizes for and provides services to clients, such as athletes and coaches, and, whereby, the practitioner is duly compensated for their services, while being responsible for the quality and outcomes of their work. (p. 1)

This definition emphasized the essential elements (organization, service delivery, compensation, and responsibility) needed to conduct ethical and thorough sport psychology consultations (Maher, 2013). Together, both definitions provide a comprehensive view of the purpose, professional competencies, and process of applied sport psychology practice.

\section{Educational Background}

Educational background refers to SPCs' graduate education and graduate applied training in sport psychology. Sport psychology consultants originate from a variety of professional or educational backgrounds with potentially distinct exposure to sport psychology knowledge and 
practice. The most common educational backgrounds are sport sciences and psychology.

Regardless of education or professional backgrounds, SPCs have access to professional development programming of which training competent SPCs is a central concern (see Fletcher \& Maher, 2013; Keegan, 2010; Quartiroli \& Zizzi, 2011; Taylor, 1994; Tod, 2007). Epstein and Hundert (2002) defined professional competency as "the habitual and judicious use of communication, knowledge, technical skills, clinical reasoning, emotions, values, and reflection in daily practice for the benefit of the individual and community being served" (p. 226; see also: Fletcher \& Maher, 2013; Tenenbaum, Papaianou, \& Samulski, 2005).

Competency-based training is important because the development of competencies has been tied to the progress and legitimacy of a discipline (Ward, Sandstedt, Cox, \& Beck, 2005). With sport psychology, the central role of competency is highlighted by Principle A of the AASP Ethical Code (2013c):

AASP members maintain the highest standards of competence in their work...recognize the boundaries of their professional competencies and the limitations of their expertise... maintain knowledge related to the services they render, and they recognize the need for ongoing education...AASP members are cognizant of the fact that the competencies required in serving, teaching, and/or studying groups of people vary with the distinctive characteristics of those groups.

Despite the significance of competencies, specifics of sport psychology competencies remain undefined (Fletcher \& Maher, 2013) even though efforts to codify specific knowledge and skills of SPCs though certification (AASP, 2012b), self-assessment checklists (APA; American Psychological Association, 2005; Gordon, 2013), review of expert perspectives (Ward et al., 2005) and position stands (Tenenbaum et al., 2003) have occurred.

The endorsement of sport psychology as proficiency within psychology by APA, further distinguished sport psychology as a specialized discipline that requires attainment of a particular set of competencies to practice (Portenga et al., 2012). The following section will describe the 
education, applied training, and work experiences of SPCs that contribute to SPCs' professional development. Silva and colleagues (2011), Silva, Conroy, and Zizzi (1999), and Andersen and Tod (2011) are recommended for an extended treatise of professional issues in sport psychology.

Graduate education. Applied sport psychology is an interdisciplinary discipline that draws its understanding of performance from sport science and psychology disciplines (Moran, 2004; Silva et al., 2011; Weinberg \& Gould, 2011). Its interdisciplinary nature benefits the knowledge and effectiveness of SPCs, but also contributes to the difficulty and complexity of designing educational curriculums. Individuals interested in sport psychology pursue three major career areas (research, teaching, and applied practice). The area a student wishes to pursue determines the educational path taken; though there is overlap between all three areas and professionals often work in more than one area. Individuals, who desire to teach and conduct research in the sport sciences, as well as, consult with athletes, traditionally purse a doctorate degree in the sport sciences (Meyers, Coleman, Whelan, \& Mehlenbeck, 2001). Individuals, who wish to teach and conduct research in psychology, and also work with athletes, usually complete a doctorate in clinical or counseling psychology with supplemental training in sport sciences (Meyers et al., 2001).

Meyers and colleagues (2001) also examined who works as a SPC and to its role in their career and personal livelihood. Of respondents $(n=433), 45$ percent of the sample was trained in clinical psychology, 28 percent in sport or exercise science, 18 percent trained in counseling psychology, and 9 percent is other psychology fields/psychiatry, or physical therapy. Potentially, the higher response rate from members of APA Division 47 than AASP membership shifted these proportions because Division 47 is comprised of members with clinical and counseling psychology backgrounds, whereas AASP includes high membership with a sport science 
background. Regardless, the prevalent educational paths of SPCs appear to be clinical/counseling psychology and sport sciences. Though standard curriculum within these disciplines can provide a sense of the educational content learned, the preferred curriculum for applied sport psychology undergraduate and graduate programs continued to be explored and debated (Silva, 2013; Silva et al., 2011).

Current graduate curriculum appears to be comprised of course work from sport science and counseling/psychology. A blend of both disciplines intends to teach students physiological and psychological determinants of performance and principles of facilitating behavior change. Common sport science courses include motor behavior and development, biomechanics, exercise psychology, sport sociology, and psychological aspects of sport performance (Weinberg \& Gould, 2011). Psychology courses might entail abnormal psychology, theories of counseling, and theories of behavior change. Furthermore, SPCs benefit from coursework about research and measurement to be critical consumers, researches, and conduct psychological assessments (if appropriately trained to do so). Silva and colleagues (2011) proposed five areas of coursework for applied sport psychology graduate programs: (a) sport psychology/psychology, (b) social and developmental psychology, (c) measurement and research, (d) exercise and health psychology, and (e) counseling and professional issues practicum in sport psychology (p. 27). These domains cover a vast amount of content, which integrated together prepare SPCs with the knowledge and skills to implement service delivery. Another gatekeeping mechanism to determine minimal competency to practice is certification as a Certified Consultant - AASP (CC-AASP). Efforts are currently underway to align curriculums with CC-AASP certification, as well as, update certification requirements and procedures. 
Graduate applied training. Sport psychology graduate programs offer applied practice practicum experiences, but the structure and amount of supervision differs between programs (Silva, Conroy, \& Zizzi, 1999). Silva and colleagues (2011) advocated a formal and more standardized practicum experience with supervision, which is considered essential to other psychology degrees. During practicum and internship experiences, graduate students directly work with clients and experience firsthand service delivery with individuals and groups. Common settings for practica are youth, high school, and collegiate sport teams, but other settings, such as academic or career advising, injury rehabilitation organizations, and substance abuse clinics or education, can provide useful learning opportunities (Silva et al., 1999). Tod (2010) identified several ways graduate students may develop professionally. Most prominently, supervision of applied training practicum was believed to influence students and facilitate the growth novice SPC (for discussion of supervision in sport psychology, see Knowles, Gilborne, Tomlinson, \& Andrson, 2007; Silva et al., 2011; Tod, 2007; Watson, McAlarnen, \& Shannon, 2014; Winstone \& Gervis, 2006; Van Raatle \& Andersen, 2000). Experiencing personal counseling, engaging in reflective practice, and building a professional network were also considered instrumental to grown (Tod, 2010).

Not only does applied practicum experience develop students professionally, but also initiates accumulation of service delivery hours for CC-AASP certification. Certification is one medium of establishing guidelines and competency for practice. SPCs who attain CC-AASP have met minimum competency in coursework and supervised hours of service delivery. As clarification, CC-AASP related to performance enhancement service delivery and is not equated with clinical licensure. Competency areas are divided in to 12 domains with a particular number of coursework credit. Each domain requires three credit hours, expect sport psychology ( 9 
credits) and skills/techniques/analysis within sport which requires applicants to list experience of sport participation. The twelve domains are: (a) professional ethics and standards, (b) sport psychology, (c) biomechanical and/or physiological bases of sport, (d) historical, philosophical, social, or motor behavior bases of sport, (e) psychopathology and its assessment, (f) counseling skills, (g) skills/techniques/analysis within sport or exercise and related, (h) research design, statistics, and psychological assessment, (i) biological bases of behavior, (j) cognitive-affective bases of behavior, (k) social bases of behavior, and (1) individual behavior (AASP, 2013b). Additionally, 400 supervised hours are needed of which 100 hours must be direct hours and 40 hours should be supervision meetings (AASP, 2013b).

Although CC-AASP demonstrates efforts to designate competent practitioners, concerns have been expressed regarding its format and requirements. Fletcher and Maher (2013) listed the following concerns for certification and the current professional state of sport psychology: (a) important competencies are missing from the current criteria, (b) competencies are superficially described, (c) broad competencies require sub-competencies, (d) unclear or missing definitions of competencies, (f) a lack of competencies based on developmental stages in favor of general topic areas, and (g) a lack of multidimensional assessment of competency and over-use of selfassessment (Fletcher \& Maher, 2013). Furthermore, Aoyagi and colleagues (2012) expressed concern that performance-based and therapeutic work are not delineated and separated within certification criteria for AASP. Andersen and Tod (2011) addressed the broad and vague criteria, particularly which professional background qualified a person to supervise and believed 400 hours were too few compared to other profession's requirements.

Post-graduate Work. Sport psychology consultants work in a variety of settings depending on their interests, education, and training. Many professionals split time between 
academic or similar full-time positions and applied practice (Meyers et al., 2001; Moran, 2004). Consultants may work with athletes and organizations at the youth, interscholastic, intercollegiate, professional, and Olympic levels. Although the number of full time SPCs, who make a living solely from their applied practice, continues to increase, these numbers have not increased as originally expected Meyers et al., 2001). Employment settings are varied among SPCs, with a majority in academic and private practice environments (Meyers et al., 2001). Although intercollegiate athletic departments are often assumed to be an available employment opportunity, there seems to be a disparity between interest in sport psychology services and hiring of SPC (Connole, 2013) and services are provided mostly by part-time SPCs, graduate students, and faculty members or individual teams hire a SPC (instead of an SPC for the athletic department (Voight \& Callaghan, 2001). Many individuals trained in applied sport psychology transfer to careers outside the field of applied sport psychology, but within the discipline of performance. For example, the United States Army Comprehensive Soldier and Family Fitness (CSF2 is the largest employer of individuals with applied sport psychology training, whose job title is Master Resilience Trainer (MRT) (Portenga et al., 2012). Beyond military performance, SPCs have worked with performing arts, business, and medicine (Hays \& Brown, 2004; see also Hirschhorn, 2010; Jones, 2010). Finally, SPCs may design and implement health programming or conduct consultations for health behavior change with non-athlete populations as part of the larger sub-field of exercise psychology (Abilbso, Zizzi, \& Reger-Nash, 2010; Moran, 2004).

As the field of sport psychology continues to wrestle with its place in the helping professions and how to design graduate training most efficaciously, meaningful conversation regarding education, applied training, and appropriate and available work experiences continue. The education and applied training attempts to interweave coursework to prepare graduate 
students for this interdisciplinary field. Certified Consultant - AASP, though flawed in some aspects, is an effort to emphasize important coursework and applied experience for competent sport psychology consultation.

\section{Sport Psychology Consultant Skills}

For this study, sport psychology consultants are understood as communicators in problem solving situations. Three sport psychology consultant skills are identified: (a) mindfulness, (b) cognitive flexibility, and (c) communication flexibility.

Mindfulness. A quick glance at the literature regarding mindfulness, one quickly wonders which disciplines are not exploring mindfulness as an intervention. Indeed, Shapiro (2009) commented on the burst of research (including randomized controlled trials), funding, and publications in the field of mindfulness. Such proliferation of research, books, and popular publications about mindfulness prompts clarification of this construct, which is debated and scrutinized among researchers (Bishop et al., 2004; Brown \& Ryan, 2004; Carmody, 2009; Kabat-Zinn, 2003; Langer \& Moldoveanu, 2000; Roemer \& Orisillo, 2003; Wallace \& Shapiro, 2006).

Mindfulness originated from the Buddhist tradition, specifically the Pāli Canon, the ancient collection of Buddhist texts, and satipatthāna, the well-known Buddhist meditation (Bodhi, 2011; see also, Dreyfus, 2011; Olendzki, 2011). The word, mindfulness, originally meant "the quality of being aware and paying attention" and it "has the connotation of remembering and having a purpose in mind," though these secondary connotations have diminished with time (Dreyfus, 2011, p. 44). The English mindfulness is used to translate the Buddhist term sati (in Pāli, smrti in Sanskrit, and dran pa in Tibetan) (Dreyfus, 2011). According to the Buddhist tradition, the principal element of mindfulness is giving sustained 
attention to the (mental) object held, regardless if the object arises from the past, present, or future (Dreyfus, 2011).

The concept and practice of mindfulness has integrated into western psychology and medicine over the last thirty years. Despite attempts to remain congruent with traditional Buddhist meanings, concerns continue about the Western interpretation and understanding of mindfulness (Bodhi, 2011; Dreyfus, 2011; Rapgay \& Bystrisky, 2009; Rosch, 2007) and how this translation affects the design of mindfulness interventions, measurement, and instruments (Rosch, 2007). Specifically, researchers worry about using instruments constructed from a Western perspective to conduct cross-cultural studies, especially for societies with long-standing histories of mindfulness practice and tradition (Christopher, Charoensuk, Gilbert, Neary, \& Pearce, 2009). Nevertheless, researchers have continued to develop operational definitions for furthering research and practice.

Although defining mindfulness, especially for research purposes, has challenged researchers and practitioners alike, strides have been made to operationally define mindfulness (Shapiro, 2009). An initial Western definition by Kabat-Zinn (1990; 2003) conceptualized mindfulness as, "The awareness that emerges from paying attention on purpose, in the present moment, and nonjudgmentally to the unfolding of experience moment by moment" (Kabat-Zinn, 2003, p. 145). In an effort to develop consensus and a testable operational definition, Bishop and colleagues (2004) generated the following two-component definition:

The first component involves the self-regulation of attention so that it is maintained on immediate experience, thereby allowing for increased recognition of mental events in the present moment. The second component involves adopting a particular orientation toward one's experiences in the present moment, an orientation that is characterized by curiosity, openness, and acceptance. (p. 232) 
To expand on this definition, self-regulation emphasizes a direct, non-elaborative contact with what is occurring. Non-elaborative means refraining from becoming immersed in one's thoughts about a thought, feeling, or sensory experience and continuing to ruminate. However, nonelaborative differs from suppression because all thoughts, feelings, and sensations are acknowledged, but attention returns to the present moment or the centering object used in meditation (such as the breath). The skill of going between what arises and returning to the present moment is called switching and requires flexibility of attention (Bishop et al., 2004). A second skill within self-regulation is sustained attention, or vigilance over a period of time, and allows recognition of thoughts, feelings, or sensations as each arises (Bishop et al., 2004). Given this understanding and these components of self-regulation, Bishop and colleagues posit that mindfulness can be partly understood as a meta-cognitive process.

The second component of the Bishop and colleagues (2004) definition describes the orientation to one's experience, especially during mindfulness meditation. This orientation progresses in three inter-related steps. First, an individual exhibits curiosity towards one's thought, feeling, or sensory experience. Then, acceptance of the moment as it is instead a predetermined agenda or preference occurs. Finally, the individual is an active participant to maintain openness toward the on-going experience. This orientation may decrease avoidant coping behaviors, increase dispositional openness, and change the psychological context in which phenomenon is experienced; thereby, potentially decreasing suffering and distress, as well as, increasing self-observation and understanding. Observing one's stream of consciousness and reactions toward its content may generate insight and a de-centering perspective (Bishop et al., 2004). 
Over the last thirty years Western researchers and practitioners within medicine and psychology have explored mindfulness. Because humans possess a natural capacity to experience mindfulness and also one's ability may be improved or self-regulated through training, mindfulness can be considered a quasi-trait (Bergomi et al., 2013a) and a trainable skill part of a larger psychological process (Bishop et al., 2004).

Cognitive flexibility. Cognitive flexibility is a component of human cognitive functioning (Jacques \& Zelazo, 2005), which encompasses the "the human ability to adapt the cognitive processing strategies to new and unexpected conditions in the environment" (Cañas, Antolí, Fajardo, \& Salmerón, 2003, p. 95). Within the discipline of communication, cognitive flexibility is referred to as: the "awareness that in any given situation there are options and alternatives available, a willingness to be flexible and adapt to the situation, and the self-efficacy, or belief, that one has the ability to be flexible" (Martin \& Rubin, 1995, p. 623). Cognitive flexibility is considered one aspect of communication competence, which is defined as:

A description of a person's ability to interact effectively with other people...as judged by the following three criteria: (a) ability to formulate and achieve objectives, (b) ability to collaborate effectively with others, i.e., to be interdependent, and (c) ability to adapt appropriately to situational or environmental variations. (Bochner \& Kelly, 1974, p. 288)

Improved cognitive flexibility occurs naturally through the biopsychosocial developmental process (Jaques \& Zelzoa, 2005; Shibl, 2010) and through learning and training (Spiro, Vispoel, Schmitz, Samarapungavan, \& Boerger, 1987; Spiro, Coulson, Feltovich, \& Anderson, 1988). As such, cognitive flexibility is a universal human cognitive process, but may differ between individuals due to cognitive development based on genetics, environmental influences, and training. Which variables are most important for its developmental are unknown (Shibl, 2010). 
A quick search of cognitive flexibility in popular research databases produces over 11, 000 results. Research spanned the fields of medicine, learning/skill acquisition, mental health, and neuroscience. Narrower searches focused on consultation and sport psychology produced limited and mostly unrelated studies. Although, cognitive flexibility and consultation did not generate any results, a handful of publications appeared for cognitive flexibility and variants of counseling (i.e. counselor). However, searches did not produce research related to cognitive flexibility and sport psychology consultation or of SPCs. Therefore, despite the variety and magnitude of research exploring cognitive flexibility, limited previous research pertains to counselors and even less to SPCs. Yet, it can be argued based on the definition of cognitive flexibility, its role in communication competency, the available literature, and experiential knowledge that cognitive flexibility may play an essential role in SPCs' work and there is a need for more research in SPCs' cognitive flexibility, as well as, its relationship with mindfulness.

Communication flexibility. Communication flexibility is "concerned solely with one's communication behavior and how one changes his/her communication behavior to be effective within the constraints of the situation" (Martin \& Rubin, 1990, p. 5). Communication flexibility is considered one component of communication competence (Booth-Butterfield, 1998; Duran, 1992). The behavioral emphasis differentiates communication flexibility from cognitive flexibility and communication adaptability, through positively related to communication adaptability (Martin \& Rubin, 1994). Communication adaptability includes the ability to perceive and select adjustments to behavior (Martin \& Rubin, 1990). Cognitive flexibility pertains to the selection knowledge from a broad knowledge base in order to adapt it to a specific situation (Spiro et al., 1988). Communication flexibility is not concerned with these cognitive processes or the communication style of an individual; only the behavior exhibited. It is 
speculated that persons in specific occupations, such as counseling, teaching, and marketing, may demonstrate more communication flexibility than other individuals due to the required skills set of job (Martin \& Rubin, 1990). Communicatively flexible individuals receive less negative feedback, engage in numerous social interactions, and require less interpersonal energy from others due to their situational adaptability (Bochner \& Kelly, 1974; Booth-Butterfield, 1998).

\section{Consultant Performance Tasks}

Sport psychology consultants may engage in many performance tasks; however, two prevalent performance tasks were identified from consultation literature (Davis, 2013; Sears et al., 2006). The performance tasks, problem solving and communication, will be explored in the proposed study.

Problem solving. The problem-solving process through which SPCs provide consultation and facilitate consultee growth is called service delivery. Sport psychology consultants may work with individual athletes, teams, coaches, administrators, staff members, or some combination these groups depending on the role of the SPC and entry point within the athletic organizational system. For instance, SPCs could work with an individual athlete at the bequest of that athlete, for a specific team (including coaches and staff members), or for an entire athletic organization (athletic department, sport organization) and expected to work with multiple teams and levels of the organization. Therefore, when approaching a consultation SPCs should tailor their service delivery to the specific situation and its corresponding needs and requirements for the SPC (Poczwardowski, Sherman, \& Henschen, 1998).

Consultants use an individual psychology approach when meeting with an athlete in personal sessions, which typically focus on assisting the athlete (or other staff member) experiencing distress or facilitating change directly with that athlete. While the athlete may 
change his or her relationship to the system, the consultant does not work with the system directly to improve its functioning, thereby facilitating growth for all members within the system. There may be limited ability to change the environment or system and individual psychology approaches allow consultants to help the athlete function as optimally as possible within the current system or to process individual concerns. Individual psychotherapy models are a common method of consultation within sport psychology and expert SPCs have endorsed an array of theoretical orientations that shape their interactions with athletes/performers, such as cognitive-behavioral, social psychology, humanistic psychology, behaviorism, mindfulness, eclectic, existential psychology, and working alliance theory (Friesen \& Orlick, 2010; McCarthy \& Jones, 2013), as well as, positive psychology, solution focused (Hays \& Brown, 2004), and psychodynamic (Andersen, 2010; Giges, 1989; Strean \& Strean, 1989).

Although individual psychology approaches provide a framework for working with individual consultees, meta-level system approaches present a framework to understand the interactions within the whole system (Wagner, 2000), which can provide a "vital complement (or antidote) to the individualistic focus of therapy" (Hays \& Brown, 2004, p. 17). Researchers have encouraged implementing systems approaches to sport psychology consultation (Andersen, 2000; Fletcher \& Wagstaff, 2009; Hays \& Brown, 2004; Maher, 2012; 2013; Zito, 2010) and Maher (2013) identified three levels of service: (a) organizational, (b) team, and (c) individual. Consultation at each level occurs in varied environments, contrary to traditional counseling and psychology. Sport psychology consultants work where the members of the athletic organizational system perform, which may include locker rooms, hotel lobbies, meeting rooms, at competition sites, on buses or planes, at the sporting site, and in administrative offices (Andersen, Van Raatle, \& Brewer, 2001). Because there are multiple and complex variables 
inherent to service delivery (entry, system, and environment), SPCs can benefit from models to guide service delivery.

A variety of sport psychology consultation models have emerged to structure and facilitate SPCs' service delivery (for review, see Perna, Neyer, Murphy, Ogilivie, \& Murphy, 1995 and Pocwardowski et al., 2004). In particular, the following models assist sport psychology consultations: (a) educational or psychological skills training (Vealy, 1988; Weinberg \& Gould, 2011), (b) clinical or counseling (Danish \& Nellen, 2012; Danish, Petitpas, \& Hale, 1992), (c) supervisory (also termed "organizational empowerment," Smith, 2013; Smith \& Johnson, 1990), (d) cognitive-behavioral (Claspell, 2010; Perna et al., 1995), and (e) interdisciplinary sport science model (Bompa, 1999). SPCs' professional philosophy often drives which consultation model is selected and how the SPC conceptualizes behavior change (see Friesen \& Orlick, 2010; Henricksen \& Diment, 2011; McCarthy \& Jones, 2013; Poczwardowski, Sherman, \& Ravizza, 2004). Although each aforementioned consultation model presents a useful guide for SPCs, two frameworks, Systems Framework for Sport and Performance Psychology by Maher (2013; see also Maher, 2012) and Revised Sport Psychology Service Delivery (SPSD-R) heuristic by Poczwardowski and Sherman (2011), provide a broader perspective, incorporate system and individual approaches, and greater detail of the problem solving process specific to sport psychology service delivery.

Maher (2013) conceptualized a Systems Framework for Sport and Performance Psychology to help SPCs organize the level of service, process of practice, and content of practice within their professional practice. Each aspect of the systems approach is both separate and inter-related as decisions in one area influence other areas and each aspect is often cooccurring. Level of service refers to the scale and entry point at which the SPC delivers services 
and it consists of three levels: (a) organizational, (b) team, and (c) individual. Some examples of entities that may receive services at each level are: (a) sport academies, schools, community recreation organizations, and professional/collegiate athletic departments, (b) athletic teams or sub-units within a team, coaches within an organization, and support service groups (medical, academic), and (c) coach, athlete, and parent (Maher, 2013). When the level at which the SPC works is known, then the process of practice begins. According to Maher, the process of practice is the core of practice and answers the "what, why, when, how, and by whom" (p. 5) questions regarding the service. This aspect of service delivery is divided into four phases, (a) clarification, (b) design, (c) implementation, and (d) evaluation, and each phase includes specific tasks. Clarification phase focuses on identifying who will receive services, what their needs are, and how services might be provided and used. During the design phase, the SPC constructs the intervention and programming. Next, throughout the intervention phase, the intervention is implemented, monitored, and adjusted as needed. Last, the evaluation phase consists of feedback retrieval from participants, objective measurements, the stated goals, and the SPCs' own reflections. These reactions are compiled and communicated to relevant personnel. The third and final component is the content of practice. On the schematic, the content is the area within the boxes, intersected by level and process. As such, the content may depend on level and phase within the process. Some examples of content include: (a) needs assessments, (b) designing mental skills programs, (c) meet with leadership, such as professional franchises' management team, athletic directors, team captains, coaching staff, (d) help with athletes transition to and from sport, and (e) present workshops for coaches, medical teams, or athletes regarding an array of topics (e.g., pressure, anxiety, arousal, overtraining, substance abuse, eating disorders, confidence, goal setting, and more). Much of sport psychology education is spent 
learning the large amount of content information needed to understand performance from an inter-disciplinary perspective (e.g. exercise science and psychology) (Maher, 2013).

Reviewing the detailed, yet flexible components of the Systems Approach, the numerous considerations, decisions, and actions required of SPCs suggest that problem solving and communication with various personnel about an array of content are vital performance tasks. Moreover, the potential usefulness of mindfulness, cognitive flexibility, and communication flexibility amongst these tasks and interactions is reinforced. Finally, although graduate programs strive to properly educate and train future SPCs, it is unclear if future SPCs graduate with a minimum level of competency in the tasks and skills required of SPCs at each level, process phase, and content area within a consultation.

Poczwardowski and Sherman (2011) presented the SPSD-R heuristic based on qualitative interviews and the original findings of Poczwardowski, Sherman, and Henschen (1998). The SPSD-R provides structure to consultation, but also integrates related extraneous variables that impact service delivery. Similar to Maher (2013), the components of SPSD-R are interrelated and the process of consultation is emphasized. The fundamental factor, process and service, is comprised of: (a) entry and conceptualization, (b) implementation, and (c) conclusion and termination. The tasks listed in each process phase mirror the tasks outlined in Maher (2013) except the element, "manage the self as an intervention instrument," emerged as a component of process and service: implementation. Unlike Maher (2013), Poczwardowksi and Sherman bookended process and service with foundation of service and working alliance. Foundation of service forms the basis from which SPCs approach and carry out the process of service delivery. It is comprised of: (a) education, training, and professional experience, (b) professional ethics, and (c) professional philosophy. This study draws from the first element, education, training, 
and professional experience, and aims to further understand this element's influence. Working alliance emerged from the data analyses and was not included in the initial heuristic (Poczwardowski et al., 1998). It relates to the interpersonal alliance and relationship between the consultant and client that is influenced by consultant and client variables. Finally, three factors, person-focus values, immersion, and goodness of fit, appeared to underlie each aspect of the SPDS-R. In conclusion, Poczwardowski and Sherman noted that need for SPCs "to be creative and flexible and to adapt to ever changing people and contexts" (p. 529). This statement, along with the factors, elements, and underlying processes presented in the SPSD-R strengthen the importance of examining SPCs' educational and professional backgrounds and its relationship with SPCs' mindfulness, cognitive flexibility, and communication flexibility, three skills that may impact the SPC-as-instrument.

To summarize, Maher (2013) and Poczwardowski and Sherman (2011) models of service delivery organize the problem solving process in which SPCs engage. Several shared components and processes underlie both service delivery approaches. These components include: (a) the assessment of concerns and problem identification, (b) awareness and attention to each level's presenting concerns, needs, appropriate intervention medium, and the process phases of interventions, (c) adaptation to changes in concerns, needs, relationships, the environment (physical, emotional, and personal) in which SPCs implement interventions, and (d) the ability to communicate information and connect with individuals both broadly across all service levels, and also deeply with groups and individuals. These shared components based on professional practice experiences and research with expert SPCs, endorse problem solving and communication as two important performance tasks of sport psychology consultations. Although the frameworks emphasized inter-personal and content communication throughout service 
delivery, communication within consultations has received additional attention within the literature.

Communication. Sport psychology consulting demands communication skills for developing relationships through which change is facilitated and knowledge is shared. In other words, consultation carries out "positive change through interactions" (Davis, 2011) in which the conversation is the intervention (Sears et al., 2006; Wagner, 2000). Thus, communication skills are embedded within the interactions between consultant and consultees. Whether brief or extensive, the sum of these interactions produces a consultee-consultant relationship, which is recognized as foundational to effective work of helping professionals (Andersen \& Speed, 2010; Rodolfa et al., 2005; Sharp \& Hodge, 2011). Unsurprisingly, professional sport psychology organizations consider relationship building an essential competency for SPCs as well as, skilled communication of psychological knowledge, principles, methods, needs, and policy requirements by SPCs to consultees (AASP, 2013c; BPS, 2012; Tenenbaum et al., 2003).

These communication behaviors are embedded in sport psychology service delivery heuristics previously discussed (Maher, 2013; Poczwardowski \& Sherman, 2011) and are beginning to receive more study. Research with elite performers indicated that performers preferred a collaborative relationship with their SPC and direct, timely, and informative feedback from attentive SPCs that could be integrated into their performance (Hays \& Brown, 2004). In order to generate and sustain this productive relationship, consultants should possess knowledge in "assertiveness, supportiveness, confrontation, listening, management style, and group process" (Sears et al., 2006, p. 16), as well as, conflict resolution, directing conversation, and sending and receiving communication messages (Parsons \& Myers, 1984). 
Recently, Blom, Visek, and Harris (2013) acknowledged the importance of communication and coordination between stakeholders (i.e., parents, coaches, SPCs) of youth athletes and posited the Youth Sport Psychology Consultation Triangle as a guide for SPCs engaged in youth sport consultations. A player-centered, family systems approach was recommended with coaches and parents as key supporters. Suggestions were provided for maximizing each dyad (i.e., parent-SPC, parent-coach, coach-SPC, SPC-athlete). For example, the SPC may mediate dialogue between coaches and parents regarding an athlete, present educational workshops for parents to teach skills, such as creating motivational climates, engage athletes in enjoyable activities to learn sport psychology skills, and help coaches implement sport psychology into their coaching (Blom et al., 2013). Overall, sport psychology has a long history of examining relationships and communication behavior in sport teams, as well as, coach-athlete and parent-athlete dyads (see Burke, 2010; Eccles \& Tran, 2012; Jowett \& LaValle, 2007; Weinberg \& Gould, 2011). Although, general knowledge may be adapted from these investigations, the particular communication demands of sport psychology consultations and facilitative communication behaviors of SPCs require more study.

Despite the complexity of both sport psychology consultation task demands, many SPCs successfully deliver competent sport psychology services and facilitate athletes and performers' professional and personal growth. A variety of factors may contribute to SPCs' abilities and productive consultations, but two areas will be specifically explored are consultant skills and professional backgrounds. 


\section{Section II: Consultant Skills Relationship with Professional Background and Consultant Skills}

Sport psychology consultants' graduate education and applied training are the foundations from which competent SPCs emerge and reflect on for guidance as they engage in post-graduate work. To date, limited research within sport psychology has investigated how professional backgrounds (i.e., graduate education, graduate applied training, and post-graduate work) may influence the consultant skills of mindfulness, cognitive flexibility, and communication flexibility despite interest (Baer et al., 2008; Poczwardowski \& Sherman, 2011). Indeed, based on a literature review of qualities and skills within consultation, Davis (2013) commented, "Mindfulness has been identified as potentially playing a role in cultivating [consultants' cognitive, attitudinal, and social] qualities and therefore [has] a possible positive impact on consultation" (p. 7).

The following section presents previous research on consultant skills (i.e., mindfulness, cognitive flexibility, and communication flexibility) and available findings regarding their relationship with professional background (i.e., graduate education, graduate applied training, and post-graduate work) and consultant performance tasks (i.e., problem solving and communication).

\section{Professional Background}

Mindfulness. Previous research in mindfulness, as well as, sport psychology consultation have advocated for further examination of the relationship between educational level/content and mindfulness. Mindfulness is considered an emerging topic in sport psychology and expert SPCs interviewed by Poczwardowski and Sherman (2011) did not explore this concept directly. Poczwardowski and Sherman asserted, "Newly trained sport psychology consultants (e.g. 5-10 
years into their careers) might offer rich perspectives on [mindfulness] and other elements of effective practice" (p. 529), which more established SPCs not learn in graduate school.

In a study investigating the influence of mediation experience and psychological wellbeing, Baer and colleagues (2008) also wondered if educational level influenced mindfulness. Baer and colleagues (2006) investigated the influence of mediation experience and psychological well-being using the Five Facet Mindfulness Questionnaire (FFMQ; Baer, Smith, Hopkins, Krietemeyer, \& Toney, 2006). A sample meditation group reported high education levels, such as graduate degrees in the mental health fields, and a significant relationship was not observed between this sample group and the mindfulness facet, act with awareness. Therefore, "it is possible that education cultivates the ability to act with awareness, or that individuals who pursue more education have higher levels of this skills, and meditation adds little to the effects of education" (Bear et al., 2008, p.339). Both research studies recommend further exploration of professional background and mindfulness.

Cognitive flexibility. Previous research provided commentary on how professional backgrounds (graduate education, graduate applied training, and post-graduate work) may influence cognitive flexibility. In regards to education and learning, cognitive flexibility can be applied to advanced knowledge acquisition, which is the stage between introductory learning and expertise. During advanced knowledge acquisition, learners must master complex material and "attain a deeper understanding of content material, reason with it, and apply it flexibly in diverse contexts" (Spiro et al., 1988, p. 545). Learners must grapple with the ill-structuredness of content; its inter-connected nature, complexity, and lack of uniformity in applied cases (Spiro et al., 1988). Sport psychology students and SPCs encounter ill-structured content and situations throughout their advancement in their coursework, applied training, and post-graduate work. 
Spiro and colleagues (1987) suggested that when situations lack known protocols, complete comprehension is impossible, and the situation cannot be fully anticipated based on prior learning, then:

the key factors affecting the success with which prior knowledge is used to improve performance in a new situation will be the flexibility with which the relevant proper knowledge is represent in memory, and the mastery or control the individual has over those flexible representations. (p. 5)

Cognitive flexibility theory is an approach toward knowledge acquisition. It outlines procedures to diminish reductive biases and identifies the conditions that assists complex knowledge processing and knowledge transfer to novel situations (Spiro et al., 1988, p. 548). Reductive biases diminish complexities, lead to knowledge misconceptions, and consist of: (a) oversimplification of complex and irregular structure, (b) overreliance on a single bias for mental representation, (c) overreliance of "top down" processing, (d) context-independent conceptual representation, (e) overreliance on precompiled knowledge structures, (f) rigid compartmentalization of knowledge components, and (g) passive transmission of knowledge (Spiro et al., 1988). Therefore, adopting a cognitive flexibility orientation in teaching and learning of sport psychology according to the cognitive flexibility theory would entail:

the use of multiple mental and pedagogical representations; the promotion of multiple alternative systems of linkage among knowledge elements; the promotion of schema assembly (as opposed to the retrieval of prepackaged schemata); the centrality of 'cases of application' as a vehicle for engendering functional conceptual understanding; and the need for participatory learning, tutorial guidance, and adjunct support for aiding the management of complexity" (Spiro et al., 1988, p. 544).

Previous researchers (Spiro et al., 1987; Spiro et al., 1988) have developed educational methods to assist knowledge acquisition of complex disciplines in order to facilitate performance (i.e. knowledge transfer) in ever-changing situations, such as sport psychology consultations. 
Cognitive flexibility is emphasized as a mechanism to both the knowledge acquisition and transfer processes.

In addition to graduate education, SPCs gain knowledge and expertise in sport psychology consultation through graduate applied training and post-graduate work. Previous research has examined the relationship between expertise in laboratory performance tasks, age, and cognitive flexibility.

Previous researchers have asserted that expertise is negatively related to cognitive flexibility (Adelson, 1984; Frensch \& Sternberg, 1989), yet other finding suggested that experts are better at adjusting their mental representations to changing environments and situations (Reder \& Schunn, 1999). Cañas, Quesada, Antolí, and Fajando (2003) investigated cognitive processes and problem solving strategies during laboratory performance tasks. Cañas and colleagues focused specifically on how environmental changes affect experts' performance in a task, whereas Reder and Shcunn (1999) assessed which cognitive skills were characteristic of adaptiveness to performance tasks. Cañas and colleagues findings suggested that "experts are affected by environmental changes, but only when these changes are related to the particular strategies that each expert develops" (p. 498). In other words, if the environmental change disrupts the selected environmental change, then the expert's performance is affected. Previous research and theories contested the expert performance-environment relationship from two perspectives: either (a) environmental changes will influence expert performance, or (b) experts will adapt quickly and effectively to new changes. Results began the process of teasing out the expert performance-environment relationship. Cañas and colleagues argued that subject area experts differ from the "experts" referred to in laboratory studies and participants whom have been engaged in a work area for a length of time, but still may not have expertise. More studies 
are required with subject area expert samples to make any claims regarding expertise and task performance (Cañas et al., 2003).

A follow-up study by Cañas, Antolí, Fajardo, and Salmerón, (2007) demonstrated that the type of training participants received in the laboratory task (i.e. Fireball task) influenced cognitive flexibility. Participants that experienced constant training conditions (with no need to adjust) maintained their original strategy when they encountered changes to the Fireball task. On the contrary, participants who practiced with variable conditions were forced to adjust strategies throughout their training and were more likely to modify their strategy when faced with environmental changes during the performance task. These findings may have implications for the role of education to develop cognitively flexible SPCs.

Age is another method to stratify potential expertise. Overall, research indicated inconsistencies regarding age and cognitive flexibility (Shibl, 2010). Although Smith (2002) reported a weak, negative relationship $(\mathrm{r}(32)=-.37, \mathrm{p}=.03)$ between age and cognitive flexibility, a cross-generational study of age and communication traits indicated that males under 21 and females older than 55 exhibited the lowest cognitive flexibility of all age groups (Martin and Andersen, 1996). It should be noted that Smith (2002) and Martin and Anderson (1996) measured cognitive flexibility with different measurements, the Personal Need for Structure Scale (Thompson, Naccarato, \& Parker, 2001) and Cognitive Flexibility Scale (Martin \& Rubin, 1995), respectively. In a previous study using the Cognitive Flexibility Scale, sex differences were not significant (Martin \& Rubin, 1995). The relationship between age and cognitive flexibility remains unclear, but researchers are recommended to consider other factors, such as the generational gender and societal expectations (Martin \& Andersen, 1996). 
Communication Flexibility. Sport psychology consultants range in age from novice graduate students in their twenties or above and established SPCs in their thirties and older. Given this vast age range, exploring potential differences in communication flexibility due to age is important. Furthermore, Booth-Butterfield (1998) argued that there is a history of constructing scales solely based on college student populations, yet scales may be used for varying age ranges. To this end, communication flexibility scores were compared between college students, never married adults over 30 years old, and working adults over and under the 35 years old with varying martial backgrounds. The working adult sample $(n=96)$ mean score (41.7) mirrored the never married participant sample (42.4) and both scores were significantly lower than the college sample's average (49.99). Within the working adult group, adults less than 35 years old averaged 42.8 and adults more than 35 years old average 41.0. This difference was not significant, but raw scores demonstrate slightly higher communication flexibility for the younger cohort. No significant differences were reported between marital statuses.

Booth-Butterfield (1998) posited that results may reflect the social interactions and adaptations that characterize students' university environment and daily life (e.g. new courses, social groups, residential roommates). Older, working adults may not experience as rapidly changing environments and social interactions or other individuals may adjust to working adults if these adults are in leadership positions (Booth-Butterfield, 1998). These results suggest that communication flexibility may be inversely related to age and highlight potential concerns regarding generalizing instruments normed on college student populations to other age groups.

\section{Performance Tasks}

Service delivery is considered a problem solving process in which SPCs collaboratively participate with consultees. Interpersonal and knowledge communication throughout service 
delivery is an essential task therein. Overall, research suggests that mindfulness may facilitate cognitive flexibility and communication flexibility. Therefore, research in mindfulness, cognitive flexibility and communication flexibility related to problem solving and communication is summarized.

Mindfulness. Davis $(2012 ; 2013)$ initiated exploration into the relationship mindfulness and consultation qualities and tasks, first proposing implementation of mindfulness-based approaches within educational psychology and then conducting a literature review of mindfulness and consultation. The review searched for the following key terms: (a) mindfulness and consultation, (b) mindfulness and therapy, coaching, supervision, counseling, and meditation, (c) consultation and skills, and (d) mindfulness and identified consultant skills (empathy, problem solving, and meta-cognition). Results categorized consultation areas to which mindfulness might be applied; specifically, cognitive, attitudinal, and social processes domains. Sub-categories within each domain classified particular consultant skills or qualities. Recollection, meta-perspective, creative thinking (including cognitive flexibility), and bracketing were specified within the cognitive domain, whereas the attitudinal domain consisted of presence and acceptance/non-judgmentalness. Social processes entailed relationship development, empathy, collaborative working, positive regard, and awareness of social dynamic. Although, to date formal research has not studied the how mindfulness within a consultation context, results suggest usefulness of continuing this line of study since mindfulness may facilitate consultants' skills manifestation.

Counseling is a closely related profession to consulting and previous research has investigated how mindfulness-based interventions may influence counselors' performance and well-being. Bruce and colleagues suggested that mindfulness may help train therapists ability to 
attune to clients and build relationships with them by increasing therapists own self-attunement. Greater interpersonal attunement, which promotes the client-therapist relationship, is considered a by-product of increased self-attunement. Applied researchers in clinical psychology, and counselor education examined the effect of mindfulness training on therapists' performance and self-care. Aggs and Bambling (2010) conducted an eight week mindful therapy training program with therapists to examine how mindfulness might be learned by therapists and aid therapists' efficacy and well-being. Results indicated improved knowledge of mindfulness and increased mindful orientation (i.e. acceptance) during therapy sessions, self-initiated mindful states, and well-being. Similar results of mindfulness interventions were observed with counseling graduate students.

Research by Buser and colleagues (2012) and Campbell and Christopher (2012) supported Bruce and colleagues' assertion and Aggs and Bambling (2010) findings. Findings of Buser and colleagues (2010) indicated that relationship building skills improve in counseling graduate students after extended (11 weeks) or brief (five weeks) mindfulness training (i.e. practice in sitting meditation, choiceless awareness, and loving kindness meditation) compared to a control group. Counseling graduate students involved in mindfulness based stress reduction reported increased awareness and acceptance of self and others, which suggests greater attention and empathy (Campbell \& Christopher, 2012). Leppma (2011) also observed increased empathy, particularly cognitive empathy, among counseling graduate students involved in loving kindness meditation program. Empathy is considered an essential element in counseling and a decrease of empathy is an indicator of burnout. Surprising, the loving kindness meditation intervention did not report significant scores for problem solving appraisal and social support (Leppma, 2011). Overall, research indicated that mindfulness practice can enhance counselors' 
interpersonal relationship with clients and help sustain counselor wellness. Thus, results encourage further exploration of how mindfulness may not only promote health in clients, but also improve therapists' (or consultants) therapeutic work.

Unlike counseling, generally sport psychology has not adapted mindfulness interventions from helping clients toward helping SPCs. However, Zizzi and Andersen (2010) suggested the adoption of an eastern philosophical orientation toward consultation and recommended three strategies to nurture an eastern philosophical approach in the consultation room: (a) during sessions introduce and practice mindfulness training, such as single task focusing, (b) practice non-attachment by helping clients identify attachments and how reactions removes oneself from the present moment, and (c) use metaphors, stories, and images to share concepts. Although benefits for the SPC were not implicitly stated, cultivating a mindful consulting experience and explaining the teachings of eastern philosophy can serve as a reminder for a SPC's own way of experiencing (and reacting to) service delivery, consulting sessions, and life events.

Mindfulness theorists considered cognitive and behavioral flexibility as a natural byproduct of mindfulness. Shapiro and colleagues (2006) suggested that the reperceiving aspect of mindfulness begets more flexible responses to the environment because "we are able to see a situation and own internal reactions to it with greater clarity, we will be able to respond with greater freedom of choice (i.e., in less conditioned, automatic ways) (p. 381). Carson and Langer (2006) did not reference Buddhist traditions, but considered mindfulness a cognitive process and claimed that the "hallmarks of the mindful condition are: (a) the ability to view both objects and situation from multiple perspectives and (b) the ability to shift perspectives depending upon context" (p.30) further implicating the impact of mindfulness on cognitive flexibility. Research is beginning to test these theories and similar to Davis (2013) consider cognitive flexibility 
representative of creativity. Thus, the following studies include direct measures of cognitive flexibility and constructs related to creativity.

Limited research has investigated the relationship between mindfulness and cognitive flexibility, particularly regarding implications for daily life tasks (Moore \& Malinowski, 2009). Moore and Malinowski (2009) hypothesized that because mindfulness meditation emphasizes attentional refocusing on the present moment, mindfulness meditation may facilitative cognitive flexibility because adaptation requires attention to the changing situation. The Stroop task and d2-test of attention assessed participants' ability to maintain or adjust one's attention in response to situational stimuli (Moore \& Malinowski, 2009). Participants ( $n=50,20-40$ years old, 12 males and 13 females in each group) were divided by match pair into a meditation group and a non-meditators control group.

The Kentucky Inventory of Mindfulness Skills (KIMS, Baer et al., 2004) measured trait mindfulness and an item was selected to test state mindfulness after the intervention (brief meditation or reading a textbook). Findings indicated a significant, positive relationship between high mindfulness scores and d2-test scores and Stoop task score. Such a correlation suggests mindfulness relates to processing speed, attention and inhibitory control, and speed in performance tasks which require non-habitual responses and attentional control (Moore \& Malinowksi, 2009). Moreover, negative correlations between mindfulness and the performance tasks provided initial evidence that mindfulness may "reduce error... [and initiate] greater attentional control, accuracy of visual scanning, inhibitory control, carefulness, cognitive flexibility, and quality performance" (Moore \& Malinowski, 2009, p.182). Of the mindfulness facets specified in the KIMS, acting with awareness and accepting without judgment correlated highest with task performance. Meditators exhibited significantly higher mindfulness scores, 
attentional task performance scores, and thereby, cognitive flexibility than non-mediator group. In sum, findings suggested that mindfulness and meditation practice may be linked to cognitive flexibility and responses, particularly automatic, can be disrupted and brought back under the individual's control.

Non-insight and insight problem solving assessed creativity in problem solving situations. Non-insight problem solving is logic based and completed through a series of steps (see Metcalfe, 1986), whereas insight problem solving refers to a restructuring of the problem when prior experience and knowledge fails to provide a solution and is associated with creativity (see Ohlsson, 1992; Schooler, Ohlsson, \& Brooks, 1993). Ostafin and Kassman (2012) inquired into the effect of mindfulness on performance during insight problem solving. The creative response and sudden realization, which characterizes insight problem solving, may be hindered by past experiences, associations, and bias with the type of or content within problem. Because the emphasis of trait or state mindfulness is present moment awareness, openness, and nonjudgmental observation, it was posited that mindfulness might relate to successful completion of insight problems (Ostafin \& Kassman, 2012). The Mindful Attention Awareness Scale (MAAS; Brown \& Ryan, 2003) assessed trait mindfulness. Participants (study one $=86,43$ females; study two $=71,28$ females; total $=157$ undergraduate students) responded to one item on the MAAS regarding present moment mindfulness to measure state mindfulness after a tenminute audiotape, which increased bodily awareness in a nonjudgmental manner (see Cropley, Ussher, \& Charitou, 2007). A control group read a history textbook instead of the brief mindfulness practice. Overall findings supported a trait and state mindfulness relationship with insight problem solving, but not with relationship with non-insight problems. Specifically, findings indicated: (a) a significant positive relationship between trait mindfulness and insight 
problem solving $(\mathrm{r}(71)=.30, p=.01)$, (b) mindfulness predicted insight problem solving when positive affect was controlled $(\mathrm{t}(67)-2.47, p=.02, \mathrm{~B}=.29)$, (c) brief mindfulness practice, which elicited state mindfulness, predicted better insight problem solving $(F(1,69)=5.10, p=$ .03 , mindfulness mean $=1.14, S E=.12$, control mean $=.075, S E=.12$, Cohen's $d=.52)$, and (d) brief mindfulness practice was a partial mediator between reported state mindfulness and insight problem solving (Ostafin \& Kassman, 2012). These findings suggested that mindfulness, when interpreted as a trait and a state, may predict insight problem solving, potentially by decreasing habitual responses, disrupting association with content based on previous experience and learning, and prompting creativity (Ostafin \& Kassman, 2012). In short, mindfulness may open one's mind to new perspectives and solution during insight problem solving situations.

Cognitive flexibility. In problem solving situations, cognitive flexibility is one cognitive process that may affect problem solving strategy selection and implementation, as well as, adaptation to the situation (Cañas et al., 2003). Research conducting laboratory performance tasks in participants adopt successful performance strategies and must adapt to unexpected environmental changes supported that a cognitively flexible individual possesses the attentional control required to disrupt automatic thoughts and patterns of behavior in favor of non-habitual responses (Cañas et al., 2003), resulting in potentially novel problem solving thinking processes and behaviors. Higher scores on inductive reasoning have predicted the presence and extent to which participants engaged in adaptive strategy use during laboratory performance tasks (Reder \& Shcunn, 1999; Schunn \& Reder, 2001).

Creativity can facilitate problem solving situations by demonstrating novel ways to explain the world and represent ideas. Cognitive flexibility is considered an essential cognitive component of creativity (Ritter et al., 2012). Diversifying experiences, considered "highly 
unusual and unexpected events or situations that are actively experienced and that push individuals outside the realm of normality" (Ritter et al., 2012, p. 961), have been correlated with increased cognitive flexibility in studies measuring multicultural experiences (Maddux, Adam, \& Galinsky, 2010). Research by Ritter and colleagues (2012) evaluated the cognitive process underlining the relationship between diversifying experiences and creativity. Findings indicated that actively engaging in any schema violating activity (i.e. an unusual or unexpected experience) may increase cognitive flexibility more than vicarious watching of the activity, participating in normal schema activity, or observing normal schema activity. In other words, changing a typical pattern of behavior (e.g. the order of getting ready in the morning or making a sandwich) can correlate to higher levels of cognitive flexibility (Ritter et al., 2012). Moreover, cognitive flexibility was highly correlated with verbal fluency, or idea generation (Ritter et al., 2012). Thus, encountering diversifying experiences within daily activities or one's life history may promote cognitive processes representative of high cognitive flexibility.

Because counselors, like consultants, enter sessions without knowing clients' content, affect, and deeper implications of the concerns, Whiteley, Sprinthall, Mosher, and Donaghy (1967) asserted that "cognitive flexibility would seem a dimension most pertinent to any counseling interaction, as one in which the objective is for the client gradually to clarify his own view and, indeed, achieve his own solutions" (p. 227). Examples of cognitive flexibility within counseling sessions were attending to client content and affect and a structuring balanced sessions comprised of open dialogue without too much rigidity or non-directedness (Whiteley et al., 1967). Indeed, Doyle and Conklin (1970) observed: 
Qualities of cognitive flexibility, perceptual style, and psychological openness relate directly to the counselor's ability to sense and communicate feelings, including selfcommunication, appear to be a warranted assumption [that a relationship exists with counselor effectiveness]. In addition, to be aware of one's own feelings, the ability of self-communication and concomitant willingness to risk what Rogers (1957) has termed "congruence" appear to relate directly to the variables under discussion. (p. 274)

Given the potential importance of cognitive flexibility in counseling, previous research has investigated the relationship between cognitive flexibility and counselor effectiveness of graduate students enrolled in counseling education (Passons \& Olsen, 1969; Whiteley et al., 1967; Smith, 2002). In each study, counselor effectiveness was rated on standard evaluation forms based on supervisors' observations of the criteria for counseling effectiveness. Whiteley and colleagues divided counselor effectiveness into three categories: (a) overall application of intellectual knowledge to counseling setting, (b) cognitive attitudes toward counseling, and (c) cognitive attitudes toward supervision. Passons and Olsen (1969) used ratings of empathetic sensitivity to represent counselor effectiveness. Smith (2002) used three independent raters who reviewed participants' counseling session tape with the Counselor Rating Form (Barak \& LaCrosse, 1975).

Results from Whiteley and colleagues demonstrated moderate-high direct relationship between cognitive flexibility and supervisors rating (counselor effectiveness) based on two projection tests $(\mathrm{r}=.78)$ and written responses to case studies $(\mathrm{r}=.73)$. Scores on the Personal Differentiation Test, time point responses to a video of a counseling session, and participants' Graduate Record Exam or Miller Analogies Test scores were insignificant. Results from Passons and Olsen (1969) also indicated a moderate, positive relationship $(r=.41, p<.05)$ between cognitive flexibility and empathetic sensitivity, but significant relationships were not observed between empathetic sensitivity and open mindedness, positive self-concept, and cognitive 
flexibility. Also, the willingness of counselors to engage in conversations about feelings appeared more predictive than the ability to sense feelings. Smith (2002) findings suggested that cognitive flexibility was not significantly correlated to counselor effectiveness, nor did cognitive flexibility account for variance within a regression model predicting counselor effectiveness from cognitive flexibility, spirituality, and self-actualization.

More recently, multicultural competency has been recognized as an essential competency for effective counseling (AASP, 2013c; Martin, 2010). Shibl (2010) assessed racial identity statuses and multicultural competency of White counselors. Shibl (2010) findings reported a significant relationship between multicultural competency and cognitive flexibility, but not White racial identity status (Helms, 1995). Significant relationships were observed between cognitive flexibility and multicultural competence. Although, a significant relationship was not found between cognitive flexibility and four of five White racial identity statues (i.e. contact, reintegration, pseudo-independence, autonomy), the Disintegration status reported a negative significant relationship (Shibl, 2010). Thus, racial identity statuses exhibited minimal influence on a White counselor's cognitive flexibility. Shibl (2010) posited several explanations for findings, including the generalist nature of the Cognitive Flexibility Scale (Martin \& Rubin, 1995), which may not have captured the processing strategies of Helms' (1995) White racial identity status. Positive emotion, which may improve cognitive flexibility (Sacharin, 2009), was suggested as a potential mediator between cognitive flexibility and White racial identity statuses (Shibl, 2010), but other studies have not observed any mediation from emotions (Ostafin \& Kassman, 2012; Ritter et al., 2012).

Communication Flexibility. Previous research examined the relationship between communication flexibility and aggressive communication traits within a college student sample 
(Martin, Anderson, \& Thweatt, 1998b), as well as, communication flexibility and age differences (college age and working adult; Booth-Butterfield, 1998). Both studies also served as validation studies for the Communication Flexibility Scale. Martin and colleagues (1998) observed a positive relationship between communication flexibility and argumentativeness, as well as, tolerance for disagreement. A negative relationship was reported between communication flexibility and verbal aggressiveness, as well as, Machiavellianism, which is characterized by social competition, manipulation, and less affective involvement. These results provided initial evidence that individuals who report higher levels of communication flexibility tend to approach, instead of avoid, confrontations and can have a discussion in which there may be disagreement without using verbal aggression. Furthermore, the indirect relationship between communication flexibility and Machiavellianism, as well as, the direct relationship between social desirability and communication flexibility suggested that flexible communicators desire social approval. Limitations of this study included small sample size $(n=30)$, limited population sample (i.e. college students), and self-reported items without observational data of behaviors.

\section{Mindfulness Exposure}

Research has begun to explore how meditation, yoga, exercise, sport and music may influence mindfulness, as well as, how mindfulness may affect meditation, yoga, exercise, sport, and music. Although there are a various types of meditation, yoga, exercise, and music, and thus, many ways to experience these activities, the proposed study will not differentiate within each group. Instead, participants will endorse the general behavior of meditation, yoga, exercise, sport, and music. However, music will relate to playing an instrument, specifically. The following section will summarize the current literature regarding mindfulness and meditation, music, exercise, and music (especially playing an instrument). 
Meditation is a foundational component for traditional Buddhist spiritual practice, from which Western mindfulness practice is derived (Wallace \& Shapiro, 2006). A meta-analysis by Sedlmeier and colleagues (2012) reviewed the impact of meditation on a variety of psychological variables $(n=163$ studies). Overall, meditation exhibited a larger impact on emotional psychological variables, than cognitive variables. For example, the largest effect sizes of meditation were: (a) interpersonal relationships $(\mathrm{r}=.44)$, (b) state anxiety $(\mathrm{r}=.37)$, (c) negative emotions $(\mathrm{r}=.34)$, and $(\mathrm{d})$ trait anxiety $(\mathrm{r}=.32)$. Studies which examined meditation and open or focused attention reported medium effect size $(\mathrm{r}=.28)$. Additionally, the impact of meditation type was explored. Comparable effect sizes were observed across meditation types (transcendental meditation, mindfulness meditation, and "other" meditations, guided meditation or idiosyncratic). However, transcendental meditation demonstrated a relatively stronger effect on reducing negative emotions, trait anxiety, neuroticism, and the facilitating learning, memory, and self-actualization. Mindfulness mediation exhibited a relatively stronger effect on diminishing negative personality traits and stress, as well as, enhancing attention and mindfulness. Because of the comparable, yet differential, effect of meditation type on psychological variables, further research is needed to clarify the effects of each meditation type. Overall, Sedlmeier and colleagues (2012) advocated for more methodologically sound research and theorizing of how meditation works.

Similar to Sedlmeier and colleagues (2012), Chiesa and colleagues (2011) emphasized the need for an increase in meditation research that is methodologically standardized. Chiesa and colleagues conducted a systematic review of mindfulness meditation practices, cognitive abilities, and neuropsychological findings ( $n=23$ studies). The reviewed studies presented conflicting findings regarding the influence of mindfulness meditation on cognitive abilities (i.e. 
sustained attention, selective attention, executive attention, attention switching, and working memory). Both positive and negative results were reported across studies. Overall, it remains unclear how mindfulness meditation may impact cognitive abilities and further study is required to advance this understanding (Chiesa et al., 2011).

Similar to meditation, research in yoga practice may produce psychological and physiological benefits (Hewett, Ransdell, Gao, Petlichkoff, \& Lucas, 2011; Rocha et al., 2012). Specifically, previous research has observed an association between yoga practice and decreased perceived stress (Brisbon \& Lowery, 2011; Gard et al., 2012; Hewett et al., 2011) and improved mindfulness (Brisbon \& Lowery, 2011), quality of life (Gard et al., 2012), cognition (Rocha et al., 2012), and physiological health (Hewett et al., 2011). Moreover, previous research has examined the relationship between mindfulness and exercise adherence. In a study of community exercisers, more adherent participants reported higher mindfulness and acceptances scores, as well as, lower suppression scores (Ulmer et al., 2010). Through inferences are limited because the cross-sectional design, findings provided initial evidence that mindfulness and acceptance may mediate individuals' level of exercise adherence, as well as, support for continued investigation.

In addition to exercise adherence, mindfulness may influence how one listens to, performs, and conducts music. Diaz (2011) examined the effect of mindfulness induction on music listening experience. Participants reported that mindfulness induction diminished distractions, increased focus, and a particular affective experience of the music (Diaz, 2011). Langer and colleagues (2009) studied individual orchestra members' mindful creation of distinct musical performances while playing an ensemble. Participants shared a preference for and enjoyment of performances cultivated in a mindful state compared to typical performances. 
Lastly, Grant (2006) described how Zen mindfulness can facilitate music-making and the performance of conductors and provided activities to encourage mindfulness. In sum, mindfulness has received varying amounts of attention within meditation, exercise, and music literature. How mindfulness may mediate the psychological or behavioral outcomes of meditation, exercise, and music requires further study.

In sum, individuals who participate in meditation, yoga, exercise, and music may experience an array of psychological and physiological benefits, of which improved mindfulness may be one benefit. Individuals engaged in these activities, particularly over an extended time period, may report higher levels of mindfulness regardless of intervention (Ulmer et al., 2010). As these areas continue to receive attention and studies are conducted with sophisticated methodology, the relationship between meditation, yoga, exercise, and music and mindfulness may be understood more completely.

\section{Summary}

Perhaps Cough, Earle, and Sewell (2002) best explained the job of a SPC: "Being asked to solve a problem that is ill-conceived, ill-defined and ill-considered is the lifeblood of sport psychology" (p. 32; as also cited in Moran, 2004). Despite the lack of research regarding SPCs' professional background (graduate education, graduate applied training, and post-graduate work) and consultant skills (mindfulness, cognitive flexibility, and communication flexibility), research from related fields provided insight into these components of sport psychology consultation. Specifically, initial evidence suggests that mindfulness may mediate cognitive flexibility, particularly its attentional component and influence on problem solving. Additionally, cognitive flexibility can be considered an important cognitive process that plays a role in counselor effectiveness, problem solving and adaptive strategies in performance tasks, knowledge 
acquisition and conceptualization, communication process, and creativity. Communication flexibility is an important behavior component of which limited research in sport psychology has addressed.

The current study examined the relationship between sport psychology consultants' educational backgrounds and consultant skills within sport psychology consultations. The aim of this study was to contribute to the growing body of knowledge of sport psychology professional development, mindfulness, and cognitive flexibility. 


\section{References}

Abilbso, C. G., Zizz, S. J., \& Reger-Nash, B. (2010). Evaluating an insurance sponsored weight management program with the RE-AIM model, West Virginia, 2004-2008. Preventing Chronic Disease, 7(3). Retrieved from http://www.ncbi.nlm.nih.gov/ pmc/articles/PMC2879978/

Adelson, B. (1984). When novices surpass experts: The difficulty of a task may increase with expertise. Journal of Experimental Psychology: Learning, Memory, and Cognition, 10, 483-495.

Aggs, C., \& Bambling, C. (2010). Teaching mindfulness to psychotherapists in clinical practice: The Mindful Therapy Programme. Counselling and Psychotherapy Research, 10(4), 278286. Doi: $10.1080 / 14733145.2010 .485690$

Akin-Little, K. A., Little, S. G., \& Delligatti, N. (2004). A preventative model of school consultation: Incorporating perspectives from positive psychology. Psychology in Schools, 4(1), 155-162. doi: 10.1002/pits.10147

American Psychological Association. (2005). Sport psychology: Knowledge and skills checklist. Retrieved from http://www.apadivisions.org/division-47/about/resources/checklist.pdf Andersen, M.B. (2000). Beginnings: Intakes and the initiation of relationships. In M. B. Andersen (Ed.), Doing sport psychology (pp. 3-16). Champaign, IL: Human Kinetics.

Andersen, M.B. (2010). Psychodynamic models of therapy. In S. J. Hanrahan \& M. B. Andersen (Eds.), Routledge handbook of applied sport psychology (pp. 160-167). New York: Routledge. 
Andersen, M. B., \& Speed, H. D. (2010). Therapeutic relationships in applied sport psychology. In S. J. Hanrahan \& M. B. Andersen (Eds.), Routledge handbook of applied sport psychology (pp. 3-11). New York: Routledge.

Andersen, M. B., \& Tod, D. (2011). Professional pathways and territories in sport psychology. In T. Morris \& P. Terry (Eds.), The new sport and exercise psychology companion (pp.403423), Morgantown, WV: Fitness Information Technology.

Andersen, M. B., Van Raatle, J. L., \& Brewer, B. W. (2001). Sport psychology service delivery: Staying ethical while keeping loose. Professional Psychology: Research and Practice, 32(1), 12-18. Doi: 10.1037//0735-7028.32.1.12

Association for Applied Sport Psychology. (2013a). About Applied Sport and Exercise Psychology. Retrieved from http://www.appliedsportpsych.org/about/about-appliedsport-and-exercise-psychology/

Association for Applied Sport Psychology. (2013b). Become a Certified Consultant. http://www.appliedsportpsych.org/certified- consultants/become-a-certified-consultant/ Association for Applied Sport Psychology. (2013c). Ethics code: AASP ethical principles and standards. Retrieved from http://www.appliedsportpsych.org/about/ethics/ethics-code/

Aoyagi, M. W., Portenga, S. T., Pocwardowski, A., Cohen, A. B., \& Statler, T. (2012).

Reflections and directions: The profession of sport psychology past, present, and future. Professional Psychology: Research and Practice, 43(1), 32-38. doi: 10.1037/a0025676

Baer, R. A., Smith, G. T., \& Allen, K. B. (2004). Assessment of mindfulness by self-report: The Kentucky Inventory of Mindfulness Skills, Assessment, 11(3), 191-206. doi:10.1177/1073191104268029 
Baer, R. A., Smith, G. T., Hopkins, J., Krietemeyer, J., \& Toney, L. (2006). Using self-report assessment methods to explore facets of mindfulness. Assessment, 13(1), 27-45. doi: $10.1177 / 1073191105283504$

Baer, R. A., Smith, G. T., Lykins, E., Button, D., Krietemeyer, J., Sauer, S., ...Williams, M. G. (2008). Construct validity of the Five Facet Mindfulness Questionnaire in meditating and nonmeditating samples. Assessment, 15(3), 329-342. doi: 10.11771073191107313003

Barack, A., \& LaCrosse, M. B. (1975). Multidimensional perception of counselor behavior. Journal of Counseling Psychology, 22, 471-476.

Bishop, S. R., Lau, M., Shapiro, S., Carlson, L., Anderson, N., Carmody, J., ...Devins, G. (2004). Mindfulness: A proposed operational definition. Clinical Psychology: Science and Practice, 11(3), 230-241. doi: 10.1093.clipsy/bph077

Bergomi, C., Tschacher, W., \& Kupper, Z. (2013a). Measuring mindfulness: First steps toward the development of a Comprehensive Mindfulness Scale. Mindfulness, 4, 18-32. doi:10.1007/s12671-012-0102-9

Bochner, A. P., \& Kelly, C. W. (1974). Interpersonal competence rational, philosophy, and implementation of a conceptual framework. The Speech Teacher, 23(4), 279-301.

Blom, L. C., Visek, A. J., \& Harris, B. S. (2013). Triangulation in youth sport: Healthy partnership among parents, coaches, and practitioners. Journal of Sport Psychology in Action, 4(2), 86-96. doi:10.1080/21520704.2012.763078

Bodhi, B. (2011). What does mindfulness really mean? A canonical perspective. Contemporary Buddhism, 12(1), 19-39. Doi:10.1080/1469947.2011.564813

Booth-Butterfield, M. (1998). Measurement of communication flexibility: Working adults vs. college students. Communication Research Reports, 15(4), 365-369. 
Bompa, T. O. (1999). Periodization: Theory and methodology of training ( $4^{\text {th }}$ ed.). Champaign, IL: Human Kinetics.

Brisbon, N. M., \& Lowery, G. A. (2011. Mindfulness and levels of stress: A comparison of beginner and advanced Hatha yoga practitioners. Journal of Religious Health, 50, 931941. doi: 10.1007/s10943-009-9305-3

British Psychological Society. (2012). Accreditation through partnership handbook: Guidance for sport and exercise psychology programmes. Retrieved from www.bps.org.uk/partnership

Brown, D. (1993). Training consultants: A call to action. Journal of Counseling \& Development, $72,139-143$.

Brown, K. W., \& Ryan, R. M. (2003). The benefits of being present: Mindfulness and its role in psychological well-being. doi: 10.1037/0022-3514.84.4.822

Brown, K. W., \& Ryan, R. M. (2004). Perils and promise in defining and measuring mindfulness: Observations from experience. Clinical Psychology: Science and Practice, 11(3), 242-248. doi: 10.1093/clipsy/bph078

Bruce, N. G., Manber, R., Shapiro, S. L., \& Constantino, M. J. (2010). Psychotherapist mindfulness and the psychotherapy process. Psychotherapy Theory: Research, Practice, Training, 47(1), 83-97.

Buser, T. J., Buser, J., K., Peterson, \& C. H., Seraydarian, D. G. (2012). Influence of mindfulness practice on counseling skills development. Journal of Counselor Preparation and Supervision, 4(1), 20-36. 
Burke, K. L. (2010). Constructive communication. In S. J. Hanrahan \& M. B. Andersen (Eds.), Routledge handbook of applied sport psychology (pp. 315-324). New York: Routledge.

Campbell, J. C., \& Christopher, J. C. (2012). Teaching mindfulness to create effective counselors. Journal of Mental Health Counseling, 34(3), 213-226.

Cañas, J. J., Quesada, J. F., Antolí, A., \& Fajardo, I. (2003). Cognitive flexibility and adaptability to environmental changes in dynamic complex problem-solving tasks. Ergonomics, 46(5), 482-501. doi: 10.1080/0014013031000061640

Cañas, J. J., Antolí, A., Fajardo, I., \& Salmerón, L. (2007). Cognitive inflexibility and the development and use of strategies for solving complex dynamic problems: Effects of different types of training. Theoretical Issues in Ergonomics Science, 6(1), 95-108. Doi: $10.1080 / 14639220512331311599$

Carmody, J. (2009). Evolving conceptions of mindfulness in clinical settings. Journal of Cognitive Psychotherapy: An International Quarterly, 23(3), 270-280. doi: 10.1897/0889-8391.23.3.270

Carson, S. H., \& Langer, E. J. (2006). Mindfulness and self-acceptance. Journal of RationalEmotive \& Cognitive Behavior Therapy, 24(1), 29-43. doi: 10.1007/s10942-006-002-5

Caplan, G., \& Caplan, R. B. (1993). Mental health consultation and collaboration. San Francisco, CA: Jossey-Bass.

Chiesa, A., Calati, R., \& Serretti, A. (2011). Does mindfulness training improve cognitive abilities? A systematic review of neuropsychological findings. Clinical Psychology Review, 31, 449-464. doi: 10.1016/j.cpr.2010.11.003 
Christopher, M. S., Charoensuk, S., Gilbert, B. D., Neary, T. J., \& Pearce, K. L. (2009). Mindfulness in Thailand and in the United States: A case of apples versus oranges? Journal of Clinical Psychology, 65(6), 590-612. doi: 10.1002.jclp.20580

Claspell, E. (2010). Cognitive-behavioral therapies. In S. J. Hanrahan \& M. B. Andersen (Eds.), Routledge handbook of applied sport psychology (pp. 131-140). New York: Routledge.

Clough, P., Earle, K., \& Sewell, D. (2002). Mental toughness: The concept and its measurement. In Cockerill (Ed.), Solutions in sport psychology (pp. 32-43), London: Thompson Publishing.

Conley, K. A., Danish, S. J., \& Pasquariello, C. D. (2010). Sport as a context for teaching life skills. In T. Morris \& P. Terry (Eds.), The new sport and exercise psychology companion (pp.168-176), Morgantown, WV: Fitness Information Technology.

Connole, I. J. (2013). Athletic administrators' preferred characteristics of sport psychology positions in NCAA athletics: A consumer market analysis. (Doctoral dissertation, West Virginia University) Retrieved from http://search.proquest.com//docview/1465419931

Cropley, M., Ussher, M., \& Charitou, E. (2007). Acute effects of a guided relaxation routine (body scan) on tobacco withdrawl symptoms and cravings in abstinent smokers. Addiction, 102, 989-993.

Danish, S. J., \& Nellen, V. C. (2012). New roles for sport psychologists: Teaching life skills through sport to at-risk youth. Quest, 49(1), 100-113. doi: 10.1080/00336297. 1997.10484226

Danish, S. J., Petitpas, A. J., \& Hale, B. D. (1992). A developmental-educational intervention model of sport psychology. The Sport Psychologist, 6, 403-415. 
Davis, T. S. (2011). Evidence base for mindfulness and Mindfulness Based Conversations. Retrieved from www.mindful-conversations.com/index.php?evidence-base/

Davis. T.S. (2012). Mindfulness-based approaches and their potential for educational psychology practice. Educational Psychology in Practice: Theory, research and practice in educational psychology, 28(1), 31-46.

Davis, T. S. (2013, May). A literature review exploring the potential of mindfulness as a tool for developing skills and qualities for effective consultation. Mindfulness. doi: $10.1007 / \mathrm{s} 12671-013-0219-5$

Diaz, F. M. (2011). Mindfulness, attention, and flow during music listening: An empirical investigation. Psychology of Music, 42, 45-58. doi: 10.1177/0305735611415144

Doyle, W. L. \& Conklin, R. C. (1970). Counselor effectiveness: A changing emphasis. Counseller Canadien, 4(4), 269-276

Dreyfus, G. (2011). Is mindfulness present-centered and non-judgmental? A discussion of th cognitive dimensions of mindfulness. Contemporary Buddhism, 12(1), 41-54. doi: $10.1080 / 14639947.2011 .564815$

Duran, R. L. (1992). Communication adaptability: A review of conceptualization and measurement. Communication Quarterly, 40(3), 253-268.

Eccles, D. W., \& Tran, K. B. (2012). Getting them on the same page: Strategies for enhancing coordination and communication in sports teams. Journal of Sport Psychology in Action, 3, 30-40. doi: 10.1080/21520704.2011.649229

Epstein, R. M., \& Hundert, E.M. (2002). Defining and assessing professional competence. JAMA Journal of the American Medical Association, 287, 226-235. doi: 10.1001/jama. 287.2.226 
Fletcher, D., \& Maher, J. (2013). Toward a competency-based understanding of the training and development of applied sport psychologists. Sport, Exercise, and Performance Psychology. doi: 10.1037/a0031976

Fletcher, D., \& Wagstaff, C. R. D. (2009). Organizational psychology in elite sport: Its emergence, application, and future. Psychology of Sport and Exercise, 10, 427-434. doi: 10.1016/j.psychsport.2009.03.009

Friesen, A., \& Orlick, T. (2010). A qualitative analysis of holistic sport psychology consultants' professional philosophies. The Sport Psychologist, 24, 227-244.

Gard, T., Brach, N., Hölzel, B. K., Noggle, J. J., Conboy, L. A., \& Lazar, S. W. (2012). Effects of a yoga-based intervention for young adults on quality of life and perceived stress: The potential mediating roles of mindfulness and self-compassion. The Journal of Positive Psychology, 7(3), 165-175. doi: 10.1080/17439760.2012.667144

Giges, B. (1998). Psychodynamic concepts in sport psychology: Comment on Strean and Strean (1998). The Sport Psychologist, 12, 223-227.

Grant, D. (2006, Fall). Zen in the art of conducting: Applying the principles of selflessness and mindfulness. Canadian Winds, 14-16.

Gordon, S. (2013). When you come to a fork in the road, take it!. In P. McCarthy \& M. Jones (Eds.), Becoming a Sport Psychologist (pp. 64-72). New York: Routledge.

Hays, K. F., \& Brown, C. H., Jr. (2004). You're On! Consulting for peak performance. Washington, DC: American Psychological Association.

Helms, J. E. (1995). An update on Helm's White and people of Color racial identity models. In J. E. Helms (Ed.), Black and White racial identity: Theory, research, and practice (pp. 6780). Westport, CT: Greenwood Press. 
Henning-Stout, M., \& Conoley, J. C. (1987). Consultation and counseling as procedurally divergent: Analysis of verbal behavior. Professional Psychology: Research and Practice, 18(2), 124-127.

Henriksen, K., \& Diment, G. (2011). Professional philosophy: Inside the delivery of sport psychology service at Team Denmark. Sport Science Review, 10(1-2), 5-21.

Hewett, Z. L., Ransdell, L. B., Gao, Y., Petlichkoff, \& Lucas, S. (2011). An examination of the effectiveness of an 8-week Bikram yoga program on mindfulness, perceived stress, and physical fitness. Journal of Exercise Fitness, 9(2), 87-92.

Hirschhorn, G. (2010). 8 ways to great: Peak performance on the job and in your life. New York, NY: G. P. Putnam's Sons.

Jacques, S., \& Zelazo, P. D. (2005). On possible roots of cognitive flexibility. In H. Bruce \& C. S. Tamis-LeMonda (Eds.), The Development of Social Cognition and Communication (pp. 53-81). Mahwah, NJ: Lawrence Erlbaum Associates Publishers.

Jones, G. (2010). Performance excellence: A personal perspective on the link between sport and business. Journal of Applied Sport Psychology, 14(4), 268-281.

Jowett, S., \& Lavallee, D. (Eds). (2007). Social psychology in sport. Champaign, IL: Human Kinetics.

Kabat-Zinn, J. (1990). Full catastrophe living: Using the wisdom of your body and mind to face stress, pain, and illness. New York, NK: Delacorte.

Kabat-Zinn, J. (2003). Mindfulness-based interventions in context: Past, present, and future. Clinical Psychology: Science and Practice, 10(2), 144-156. doi:10.1093/clipsy/bpg016 
Keegan, R. J. (2010). Teaching consulting philosophies to neophyte sport psychologists: Does it help, and how can we do it?. Journal of Sport Psychology in Action, 1, 42-52. doi: $10.1080 / 21520704.2010 .518663$

Knowles, Z., Gilbourne, D., \& Tomlinson, V., Anderson, A. G. (2007). Reflections on the application of reflective practice for supervision in applied sport psychology. The Sport Psychologist, 21, 109-122.

Langer, E. J., \& Moldoveanu, M. (2000). The construct of mindfulness. Journal of Social Issues, $56(1), 1-9$.

Langer, E. J., Russell, T., \& Eisenkraft, N. (2009). Orchestral performance and the footprint of mindfulness. Psychology of Music, 37, 125-136. doi: 10.1177/0305735607086053

Leppma, M. (2011). The effect of loving-kindness meditation on empathy, perceived social support, and problem solving appraisal in counseling students. (Doctoral dissertation, University of Central Florida). Retrieved from http://etd.fcla.edu/CF/CFE0003656/ Leppma_Monica_201105_PhD.pdf

Lubker, J. R., Watson, J. C., II., Visek, A. J., \& Geer, J. R. (2008). Physical appearance and the perceived effectiveness of performance enhancement consultants. The Sport Psychologist, 19, 446-458.

Maddux, W. W., Adam, H., \& Galinsky, A. D. (2010). When in Rome...learn why the Romans do what they do: How multicultural learning experiences enhance creativity. Personality and Social Psychology Bulletin, 36, 731-741.

Maher, C. A. (2012). Planning and evaluating human services program: A resource guide for practitioners. Bloomington, Indiana: AuthorHouse. 
Maher, C. (2013, June, 22). A systems approach for professional practice of sport psychology: Conceptualizing, organizing, and focusing the task. Paper presented at the $14^{\text {th }}$ Annual Workshop in Applied Sport Psychology conducted by Dr. Jack Lesyk, Middlebury Heights, $\mathrm{OH}$.

Martin, M. M., \& Anderson, C. M. (1996). Communication traits: A cross-generalization investigation. Communication Reports, 13(1), 58-67.

Martin, M. M., \& Anderson, C. M. (1998). The Cognitive Flexibility Scale: Three validity studies. Communication Reports, 11(1), 1-9.

Martin, M. M., \& Anderson, C. M., \& Thweatt, K. S. (1998). Aggressive communication traits and their relationships with the Cognitive Flexibility Scale and the Communication Flexibility Scale. Journal of Social Behavior and Personality, 13(3), 531-540.

Martin, M. M. \& Rubin, R. B. (1990, November). The development of a Communication Flexibility Scale. Paper presented at the Speech Communication Association Annual Meeting, Chicago, IL.

Martin, M. M., \& Rubin, R. B. (1994). Development of a communication flexibility measure. The Southern Communication Journal, 59, 171-178.

Martin, M. M., \& Rubin, R. B. (1995). A new measure of cognitive flexibility. Psychological Reports, 76, 623-626.

McCarthy, P., \& Jones, M. (Eds.). (2013). Becoming a Sport Psychologist. New York: Routledge.

Metcalfe, J. (1986). Feeling of knowing in memory and problem solving. Journal of Personality and Social Psychology, 49(113), 120. 
Meyers, J. (2002). A 30 year perspective on best practices for consultation training. Journal of Education and Psychological Consultation. 13(1\&2), 35-54.

Meyers, A. W., Coleman, J. K., Whelan, J. P., \& Mehlenbeck, R. S. (2001). Examining careers in sport psychology: Who is working and who is making money? Professional Psychology: Research and Practice, 32, 5-11.

Meyers, A. B., Meyers, J., Graybill, E. C., Proctor, S. L., \& Huddleston, L. (2012). Ecological approaches to organizational consultation and systems change in educational settings. Journal of Educational and Psychological Consultation, 22, 106-124. doi:10.1080/10474412.2011.649649

Moore, A., \& Malinowski, P. (2009). Meditation, mindfulness, and cognitive flexibility. Consciousness and Cognition, 18, 176-186. doi: 10.1016/j.concog.2008.12.008

Moran, A. (2004). Sport and exercise psychology: A critical introduction. New York: Routledge.

Ohlsson, S. (1992). Information-processing explanations of insight and related phenomena. In M. Keane \& K. Gilhooly (Eds.). Advances in the psychology of thinking (Vol.1, pp. 1-44). London, OK: Harvester Wheatsheaf.

Olendzki, A. (2011). The construction of mindfulness. Contemporary Buddhism, 12(1), 56-70. doi: $10.1080 / 14639947.2011 .564817$

O'Roark, A. M. (2007). The best of consulting psychology 1900-2000: Insider perspectives. Consulting Psychology Journal: Practice and Research, 59(3), 189-202. doi: 10.1037/1065-9293.59.3.189

Ostafin, B. D., \& Kassman, K. T. (2012). Stepping out of history: Mindfulness improves insight problem solving. Consciousness and Cognition, 21, 1031-1036. doi:

10.1016/j.concog.2012.014 
Passons, W. R. \& Olsen, L. C. (1969). Relationship of counselor characteristics and empathic sensitivity. Journal of Counseling Psychology, 16(5), 440-445.

Parsons, R. D. \& Meyers, J. (1984). Developing consultation skills. Washington, DC: JosseyBass, Inc. Publishers.

Patten, M. L. (2000). Understanding research methods: An overview of the essentials ( $2^{\text {nd }}$ ed.). Los Angeles, CA: Pyrczak Publishing.

Perna, F., Neyer, M., Murphy, S. M., Ogilvie, B. C., \& Murphy, A. (1995). Consultations with sport organizations: A cognitive-behavioral model. In S. Murphy (Ed.), Sport psychology interventions (pp. 235-252). Champaign, IL: Human Kinetics.

Poczwardowski, A., \& Sherman, C. P. (2011). Revisions to the Sport Psychology Services Delivery (SPSD) heuristic: Explorations with experienced consultants. The Sport Psychologist, 25. 511-531.

Poczwardowski, A., Sherman, C. P. \& Ravizza, K. (2004). Professional philosophy in the sport psychology service delivery: Building on theory and practice. The Sport Psychologist, 18, 445-463.

Poczwardowski, A., Sherman, C. P., \& Henschen, K. P. (1998). A sport psychology service delivery heuristic: Building on theory and practice. The Sport Psychologist, 12, 191-207.

Portenga, S., Aoyagi, M., Balague, G., Cohen, A., \& Harmison, B. (2012). Defining the practice of sport and performance psychology. Division 47 (Exercise and Sport Psychology) of the American Psychological Association. Retrieved from http://www.apadivisions.org/division-47/about/resources/defining.pdf 
Quartiroli, A., \& Zizzi, S. J. (2011). A primer on the development of SEP in North America vs. Europe: Comparing the developmental paths of FEPSAC and AASP. Athletic Insight Journal, 3(1), 1-16. 1172, 148-162. Doi: 10.1111/j. 1749-6632.2009.0445.x

Rapgay, L., \& Bystricky, A. (2009). Classical mindfulness: An introduction to its theory and practice for clinical application. Longevity, Regeneration, and Optimal Health,

Reder, L. M., \& Schunn, C. D. (1999). Bringing together the psychometric and stratefy worlds: Predicting adaptability in a dynamic task. In D. Gopher \& A. Koriat (Eds.), Cognitive regulation of performance: Interaction of theory and application. Attention and Performance XVII, pp. 315-342.

Ritter, S. M., Damian, R. I., Simonton, D. K., van Baaren, R. B., Strick, M., Derks, J. ...Dijksterhuis, A. (2012). Diversifying experiences enhance cognitive flexibility. Journal of Experimental Social Psychology, 48, 961-964. doi: 10.1016/j.esp.2012.02.009

Rocha, K.K.F, Ribeiro, A. M., Rocha, K. C. F., Sousa, M. B. C, Albuquerque, F. S., Riberio, S., \& Silva, R. H. (2012). Improvement in physiological and psychological parameters after 6 months of yoga practice. Consciousness and Cognition, 21, 843-850. doi:

10.1016/j.concog.2012.01.014

Rodolfa, E., Bent, R., Eisman, E., Nelson, P., Rehm, L., \& Ritchie, P. (2005). A cube model for competency development: Implications for psychology educators and regulators. Professional Psychology: Research and Practice, 36, 347-354. doi: 10.1037/07357028.36.4.347

Roemer, L., \& Orsillo, S. M. (2003). Mindfulness: A promising intervention strategy in need of further study. Clinical Psychology: Science and Practice, 10(2), 172-178. doi: 10.1093/clipsy/bpg020 
Rosch, E. (2007). More than mindfulness: When you have a tiger by the tail, let it eat you. Psychological Inquiry, 18(4), 258-264. doi: 10.1080.104784007071598371

Sacharin, V. (2009). The influence of emotions on cognitive flexibility (Doctoral dissertation, University of Michigan). Retrieved from http://deepblue.lib.umich.edu/bitstream/ handle/2027.42/64652/vsachari_1.pdf?sequence=1

Schooler, J. W., Ohlsson, S., \& Brooks, K. (1993). Thoughts beyond words: When language overshadows insight. Journal of Experimental Psychology: General, 122, 166-183.

Sears, R., Rudisill, J., Mason-Sears, C. (2006). Consultation skills for mental health professionals. Hoboken, NJ: John Wiley \& Sons, Inc.

Sedleier, S. Eberth, J., Schwarz, M., Zimmermann, D., Haarig, F., Jager, S., \& Kunze, S. (2012). The psychological effects of meditation: A meta-analysis. Psychological Bulletin, 138(6), 1139-1171. doi: 10.1037/a0028168

Shapiro, S. L. (2009). The integration of mindfulness and psychology. Journal of Clinical Psychology, 65(6), 555-560. Doi: 10.1002.jclp.20602

Shapiro, S. L., Carlso, L. E., Astin, J. A., \& Freedman, B. (2006). Mechanisms of mindfulness. Journal of Clinical Psychology, 62(3), 373-386.

Sharp, L. A. \& Hodge, K. (2011). Sport psychology consulting effectiveness: The sport psychology consultant's perspective. Journal of Applied Sport Psychology, 25, 360-376. doi: $10.1080 / 10413200.2011 .583619$

Shibl, G. W. (2010). The relationship among White counselors' cognitive flexibility, racial identity statuses, and perceived multicultural counseling competence. (Doctoral dissertation, California School of Professional Psychology at Alliant International University, San Diego). 
Silva, J., M. III. (2013). Coalition for the advancement of graduate training in the practice of sport psychology: A report and discussion. Symposium conducted at the meeting of Association of Applied Sport Psychology, New Orleans, LA.

Silva, J. M., III., Conroy, D. E., \& Zizzi, S. J. (1999). Critical issues confronting the advancement of applied sport psychology. Journal of Applied Sport Psychology, 11(2), 298-320. doi: 10.1080/10413209908404206

Silva, J. M., III., Metzler, J. N., \& Lerner, B. (2011). Training professionals in the practice of sport psychology $\left(2^{\text {nd }}\right.$ ed.). Morgantown, WV: Fitness Information Technology.

Smith, M. R. (2002). The relationship between personality traits and trainee effectiveness in counseling sessions: Cognitive flexibility, spirituality, and self-actualization. (Doctoral dissertation, University of Nevada-Reno).

Smith, R. E. (2013). From clinical science to sport research and intervention. In P. McCarthy \& M. Jones (Eds.), Becoming a Sport Psychologist (pp. 121-128). New York: Routledge.

Smith, R. E. \& Johnson, J. (1990). An organizational empowerment approach to consultation in professional baseball. The Sport Psychologist, 4, 347-357.

Spiro, R. J., Coulson, R. L., Feltovich, P. J., \& Anderson, D. K. (1988). Cognitive flexibility theory: Advanced knowledge acquisition in ill-structured domains. (Report No. 441). Program of the Tenth Annual Cognitive Science Society. Hillsdale, NJ: Lawrence Erlbaum Associates, Inc. Retrieved from http://files.eric.ed.gov/fulltext/ED302821.pdf 
Spiro, R. J., Vispoel, W. P., Schnitz, J. G., Samarapungavan, A., \& Boerger, A. E. (1987). Knowledge acquisition for application: Cognitive flexibility and transfer in complex content domains. In B. L. Britton \& S. M. Glynn (Eds.), Executive Control Processes in Reading, Hillsdale, NJ: Lawrence Erlbaum Associates, Inc.

Strean, W. B. \& Strean, H. S. (1998). Applying psychodynamic concepts to sport psychology practice. The Sport Psychologist, 12, 208-222.

Taylor, J. (1994). Examining the boundaries of sport science and psychology trained practitioners in applied sport psychology: Title usage and area of competence. Journal of Applied Sport Psychology, 6, 185-195. doi: 10.1080/10413209408406293

Tenenbaum, G., Papaianou, A., \& Samulski, D. (2003). Competencies (occupational standards, knowledge, and practice), and their accomplishment (learning specification; essential knowledge and skills) in sport and exercise psychology: An ISSP position stand. International Journal of Sport and Exercise Psychology, 1(2), 155-166. doi:10.1080/1612197X.2003.9671709

Thompson, M. M., Naccarato, M. E., Parker, K. E., \& Moskowitz, G. B. (2001). The personal need for structure and personal fear of invalidity measures: Historical perspectives, current applications, and future directions. In G. B. Mosocowitz (Ed.), Cognitive social psychology: The Princeton symposium on the legacy and future of social cognition (pp. 19-39). Mahwah, NJ: Lawrence Erlbaum.

Tod, D. (2007). The long and winding road: Professional development in sport psychology. The Sport Psychologist, 21, 94-108. 
Tod, D. (2010). Training and professional development in applied sport psychology. In S. J. Hanrahan \& M. B. Andersen (Eds.), Routledge handbook of applied sport psychology (pp. 21-29). New York, NY: Routledge.

Ulmer, C. S., Stetson, B. A., \& Salmon, P. G. (2010). Mindfulness and acceptance are associated with exercise maintenance. Behaviour Research and Therapy, 48, 805-809.

Doi:10.1016/j.brat.2010.04.009

Van Raalte, J., \& Andersen, M. (2000). Supervision I: From models to doing. In M. Andersen (Ed.), Doing sport psychology (pp.153-165). Champaign, IL: Human Kinetics.

Vealey, R. S. (1988). Future directions in psychological skills training. The Sport Psychologist, 2(4), 318-336.

Voight, M., \& Callaghan, J. (2001). The use of sport psychology services at NCAA Division I Universities from 1998-1999. The Sport Psychologist, 15, 91-102.

Wagner, P. (2000). Consultation: Developing a comprehensive approach to service delivery. Educational Psychology in Practice, 16(1), 9-18.

Wallace, B. A. \& Shapiro, S. L. (2006). Mental balance and well-being: Building bridges between Buddhism and Western psychology. American Psychologist, 61(7), 690-701.

Ward, D. G., Sandstedt, S. D., Cox, R. H., \& Beck, N. C. (2005). Athlete-counseling competencies for U.S psychologists working with athletes. The Sport Psychologist, 19, 318-334.

Watson, J. W. II., McAlarnen, M. M., Shannon, V. R. (in press). Facilitating our future: Roles, responsibilities, and the development of the sport, exercise, and performance supervisor. In G. Cremades \& L. Tashman (Eds.), Becoming a sport, exercise, and performance professional: A global perspective (pp. 236-242). New York, NY: Psychology Press 
Weinberg, R. S., \& Gould, D. (2011). Foundations of Sport and Exercise Psychology (5 ${ }^{\text {th }}$ ed.). Champaign, IL: Human Kinetics.

Whiteley, J. M., Sprinthall, N. A., Mosher, R. L., \& Donaghy, R. T. (1967). Selection and evaluation of counselor effectiveness. Journal of Counseling Psychology, 14(3), 226-234.

Winstone, W., \& Gervis, M. (2006). Countertransference and the self-aware sport psychologist: Attitudes and patterns of professional practice. The Sport Psychologist, 20, 495-511.

Zito, M. (2010). Family systems interventions in sport. In S. J. Hanrahan \& M. B. Andersen (Eds.), Routledge handbook of applied sport psychology (pp. 177-185). New York, NY: Routledge.

Zizzi, S. J. \& Andersen, M. B. (2010). An Eastern philosophical approach. In S. J. Hanrahan \& M. B. Andersen (Eds.), Routledge handbook of applied sport psychology (pp. 194-202). New York, NY: Routledge. 


\section{APPENDIX B}

Key Terms

Consultation: "The process of interaction between two professional persons - the consultant, who is a specialist, and the consultee, who invokes the consultant's help in regard to a current work problem with which the latter is having some difficulty, and which he has decided is within the former's area of specialized competence" (Caplan \& Caplan, 1993, p. 11).

Applied sport psychology: "The study and application of psychological principles of human performance in helping athletes consistently perform in the upper range of their capabilities and more thoroughly enjoy the sport performance process" (Portenga et al., 2012, p. 9).

Sport psychology consultation: "The process by which a qualified practitioner organizes for and provides services to clients, such as athletes and coaches, and, whereby, the practitioner is duly compensated for their services, while being responsible for the quality and outcomes of their work" (Maher, 2013, p. 1). Also referred to as service delivery.

Sport psychology consultant (SPC): "Uniquely trained and specialized to engage in a broad range of activities including the identification, development, and execution of the mental and emotional knowledge, skills, and abilities required for excellence in athletic domains; the understanding, diagnosing, and preventing of the psychological, cognitive, emotional, behavioral, and psychophysiological inhibitors of consistent, excellent performance; and the improvement of athletic contexts to facilitate more efficient development, consistent execution, and positive experiences in athletes" (Portenga et al., 2012, p. 9-10). For the purposes of this study, sport psychology consultants will include individuals who do performance enhancement and clinical work and, as such, may or may not be clinically licensed. 
Graduate education: The type graduate education and highest degree earned by a participant.

Graduate applied training: Experiences during sport psychology consultation practicum and internship during graduate school. Within the structural equation model, this variable is defined as years $\mathrm{x}$ hours of graduate level consulting experience.

Consultant skills: Identified as mindfulness, cognitive flexibility, and communication flexibility.

Mindfulness: A quasi-trait and defined as "the self-regulation of attention so that it is maintained on immediate experience, thereby allowing for increased recognition of mental events in the present moment. The second component involves adopting a particular orientation toward one's experiences in the present moment, an orientation that is characterized by curiosity, openness, and acceptance" (Bishop et al., 2004, p. 232).

Cognitive flexibility: Broadly defined as, "the human ability to adapt the cognitive processing strategies to new and unexpected conditions in the environment" (Cañas et al., 2005, p. 95). Within communication defined as "awareness that in any given situation there are options and alternatives available, a willingness to be flexible and adapt to the situation, and the self-efficacy, or belief, that one has the ability to be flexible" (Martin \& Rubin, 1995, p. 623).

Communication flexibility: "One's communication behavior and how one changes his/her communication behavior to be effective within the constraints of the situation" (Martin \& Rubin, 1990, p. 5).

Consultant performance tasks: Identified as problem solving and communication.

Problem solving: The cognitive process of working through and finding solutions to well- or ill-defined problems (Dictionary.com, 2014; Wikipedia, 2014). Within consulting, 
problem solving consists of the following process: “(a) define the problem, (b) identify alternative solutions, (c) weigh the consequences of alternative solutions, (d) implement the decision, I evaluate the consequences of the decision, and (f) redefine the problem and restart the problem-solving sequence" (Sears et al., 2006, p. 21).

Communication: "The act or process of using words, sounds, signs, or behaviors to express or exchange information or to express your ideas, thoughts, feelings, etc., to someone else" (Merriam-Webster.com, 2014).

\section{References for Key Terms}

(if definition not cited in previous references)

Communication. (n.d). Retrieved March 16, 2014 from Merriam-Webster: http://www.merriamwebster.com/dictionary/communication

Problem solving. (n.d.). Retrieved March 16, 2014 from Dictionary.com: http://dictionary.reference.com/browse/problem+solving. Retrieved March 16, 2014 from Wikipedia: http://en.wikipedia.org/wiki/Problem_solving. 


\section{APPENDIX C}

Internet-based Questionnaire: Graduate Education and Applied Training

\section{Graduate Education}

1. Are you a graduate student?

Yes $\rightarrow$ Skip to graduate student questions

No $\rightarrow$ Skip to professional questions and post-graduate schoolwork

\section{Graduate students' questions}

1. In which type of program are you enrolled? Select all that apply.

Master's in Kinesiology/Sport

Sciences/Physical Education

Master's in Counseling

Ph.D. in Kinesiology with a Master's in

Counseling
Ph.D. in Kinesiology/Sport Sciences

Ph.D/Psy.D in Clinical or Counseling Psychology

Other:

2. Please identify any other graduate degrees you have earned. Select all that apply.

Master's in Kinesiology/Sport

Sciences/Physical Education

Master's in Counseling

Professionals' questions
Master's in Social Work

Other:

1. What is your highest degree earned? Select all that apply.

Ph.D. in Kinesiology/Sport Sciences

$\mathrm{Ph} . \mathrm{D}$. in Kinesiology with a Master's in

Counseling

$\mathrm{Ph} . \mathrm{D} / \mathrm{Psy} . \mathrm{D}$ in Clinical or Counseling

Psychology
Master's in Kinesiology/Sport

Sciences/Physical Education

Master's in Counseling

Other:

2. Please identify any other degrees you have earned. Select all that apply. Master's in Kinesiology/Sport Master's in Social Work Sciences/Physical Education Master's in Counseling

Other: 


\section{Graduate Applied Training}

Instructions: Answer the following questions based on your current or previous sport psychology consultation experience in graduate school.

1. Approximately, how much time do or did you spend on consulting related activities (e.g. preparation, sessions)?
Consulting experience
Years
Hours per week
(drop down -0-5+)
$0-5,6-10,11-15,16-20,21+$

2. With which population do or did you work in graduate school? Select all that apply.

Sport/Athletic Exercisers Performing Art Military Business Other:

3. How often did you engage in mentoring or supervision about your consulting?
Mentoring/Supervision Mentoring/Supervision Group Individual

Never

Once a Week

2-3 Times a Week

2-3 Times a Month

4. Have you received clinical training in counseling or clinical/counseling psychology?

Yes

No

\section{Post-Graduate Work}

Description: The following section focuses on professionals' consultation experience after graduate school.

1. With which population do you primarily consult?
Sport
Exercisers
Military
Performing Business
Medical

Art

2. Approximately, how much time do you spend consulting?

Years you have consulted

0-10-20-30-40-50-60-70-80-90-100

Current hours per week engaged in consulting $\quad 0-10-20-30-40-50-60-70-80-90-100$

related activities (e.g. preparation, sessions)

3. Approximately, how often do you seek guidance regarding client concerns?

Never

Less than Once a Month

Once a Month
2-3 Times a Month

Once a Week

2-3 Times a Week

4. Are you a mentor/supervisor to novice sport psychology consultants? (e.g. graduate students) Yes/No 


\section{APPENDIX D}

Internet-based Questionnaire: Comprehensive Inventory of Mindfulness Experiences-beta Instructions: Using the six-point scale below, please indicate how frequently you currently have each experience. Please consider 'currently' to refer to the last two weeks.

Almost never - infrequently - somewhat infrequently - somewhat frequently - frequently almost always

1. When my mood changes, I notice it right away.

2. In the ups and downs of life, I am kind to myself.

3. In everyday life, when a specific situation becomes difficult only because of my negative attitude towards that situation, I will notice this.

4. It is clear to me that my evaluations of situations and people can easily change.

5. When I am sitting or lying, I perceive the sensations in my body.

6. I cannot help but smile when I notice how I sometimes see things as more complicated than they actually are.

7. I am hard on myself when I make a mistake.

8. When I have distressing thoughts or images, I feel calm again relatively soon afterward.

9. I perceive colors and shapes in nature clearly and consciously.

10. I break or spill things out of inattention or because I think of something else.

11. I see my mistakes and difficulties without judging myself.

12. It is easy for me to stay focused on what I am doing.

13. When I have distressing thoughts or images, I am able just to notice them without having to react immediately.

14. When I talk to other people, I notice what feelings I am experiencing.

15. When I have needlessly given myself a hard time, I can see it with a bit of humour. 
16. In difficult situations, I can pause for a moment without reacting immediately.

17. In everyday life, I get distracted by many memories, images or day-dreaming.

18. When I ride in a car or train, I am aware of the surroundings, such as the landscape.

19. I try to stay busy to keep specific thoughts or feelings from coming to mind.

20. When caught in thoughts and emotions, it does not take me long until I notice it and then can distance myself from these experiences.

21. I pay attention to sensations, such as the wind in my hair or sunshine on my face.

22. I try to distract myself when I feel unpleasant emotions.

23. In everyday life, I am aware that many of my thoughts are interpretations that do not necessarily correspond to reality.

24. I am able to smile when I see how I made a problem out of a small difficulty.

25. I am able to observe my thoughts and feelings without getting tangled up in them.

26. When I read, I have to reread paragraphs because I was thinking of something else.

27. I notice sounds in my environment, such as birds chirping or cars passing.

28. I notice my feelings and thoughts and can at the same time observe them from a certain distance.

29. I clearly notice changes in my body, such as quicker or slower breathing.

30. I do not like it when I am angry or fearful and try to get rid of these feelings.

31. In everyday life, I am aware that my view on things is subjective and does not necessarily correspond to the facts.

32. Even when I make a big mistake, I treat myself with understanding.

33. When I am in pain, I try to avoid this sensation as much as possible.

34. In everyday life, I am aware of how I am currently feeling.* 
35. In everyday life, I am aware that my own opinions, which I take very seriously at a given moment, may change considerably.*

36. I resent my own mistakes and weaknesses.*

37. When I make life needlessly difficult for myself, I usually notice it shortly after.* *Omitted unintentionally. 


\section{APPENDIX E}

Internet-based Questionnaire: Cognitive Flexibility Scale

Instructions: The following statements deal with your beliefs and feelings about your own behavior. Read each statement and respond by circling the number that best represents your agreement with each statement.

Strongly Disagree - Disagree -Slightly Disagree - Slightly Agree - Agree - Strongly Agree

1. I can communicate an idea in many different ways.

2. I avoid new and unusual situations. (*)

3. I feel like I never get to make decisions. (*)

4. I can find workable solutions to seemingly unsolvable problems.

5. I seldom have choices when deciding how to behave. $(*)$

6. I am willing to work at creative solutions to problems.

7. In any given situation, I am able to act appropriately.

8. My behavior is a result of conscious decisions that I make.

9. I have many possible ways of behaving in any given situation.

10. I have difficulty using my knowledge on a given topic in real life situations. $(*)$

11. I am willing to listen and consider alternatives for handling a problem.

12. I have the self-confidence necessary to try different ways of behaving.

Note Items marked $(*)$ are reverse scored. 


\section{APPENDIX F}

Internet-based Questionnaire: Communication Flexibility Scale

Here are some situations that illustrate how people sometimes act when communicating with others. Imagine that you are in each of the situations and indicate how much your own behavior would be like that described in the scenario. If it is exactly like you, circle a 5; if it is a lot like you, circle a 4; if it is somewhat like you, circle a 3; if it is not much you, circle a 2; and if it is not at all like you, circle a 1 .

* 1. You are invited to give a speech about the university at a city council meeting. Everything seems fine at first, but then fifteen minutes into the speech, several members of the audience start talking to each other. You quickly end the speech and thank the group for their time.

* 2. Last week, you were discussing your monetary situation with your family. As the family came up with several possible solutions, you agreed that there were several different ways to address the problem and decided to consider all the possibilities.

* 3. You and a group of friends get into a discussion on gun control. After a while, it is obvious that your opinions differ greatly from the rest of the group. You explain the opposing position but agree to respect the group's opinion also.

* 4. With the whole evening free, you go to a theatre complex to see a particular movie. The ticket seller tells you that the movie is sold out but that you could buy a ticket to a later show or buy a ticket for another movie. You leave, stating that you are no longer interested in seeing any movie.

* 5. You are invited to a Halloween Party. Assuming it was a costume party, you dress up as the Easter Bunny. When you arrive at the party and find everyone else dressed in formal attire, you are embarrassed and decide to go home.

* 7. Your daily schedule is very structured. The calendar is full of appointments and commitm4nts and when asked to make a change in the schedule, you reply that changes are impossible.

*9. Discussing a roommate problem with a group of friends, you notice that many different solutions are offered. Although several of the solutions seemed feasible, you already have an opinion and do not listen to any of the alternative solutions.

*10. A friend wants to discuss a problem with you at your house. When your friend does not arrive at the scheduled time, you are unable to get any work done until your friend arrives.

*11. When you are shown to your seat at the football game, you notice you do not 
recognize anyone sitting nearby You introduce yourself and attempt to strike up a conversation with the people sitting next to you.

*12. You go to a party where over 50 people attend. You had a good time, but spend most of the evening talking to one close friend.

*13. You are talking with a new friend, Chris, over lunch. When Chris tells you about a family problem, you decide the conversation is getting a little too personal and respond by quickly finishing lunch and leaving.

16. You are asked by a friend to babysit for an afternoon. You were expecting a young boy and planned to take the boy to the petting zoo around the corner, so you are surprised when a teenage boy arrives. But you decide to take the boy to the petting zoo anyway.

*17. You are engaged in a conversation about politics at a dinner party. You disagree with everyone else's views and argue that everyone else is wrong. Finally, you leave the room and refuse to listen to any one else.

*19. You enjoy being with Chris, but do not enjoy Chris's habit of always interrupting you. You decide that every time Chris interrupts you, you will then interrupt Chris in order to teach Chris a lesson.

*20. You are asked to give a speech at a Chamber of Commerce breakfast. Because you do not know anyone at the breakfast and would feel uncomfortable not knowing anyone in the audience, you decline the invitation.

Note: Numbering from original 20 -item scale. 


\section{APPENDIX G \\ Internet-based Questionnaire: Mindfulness Exposure Questions}

Thank you for completing two-thirds of this questionnaire. This last section should only take you 3 minutes, but is essential to the study. I appreciate your perseverance.

1. Do you engage in any of the following activities? If so, how often per week?

$\begin{array}{lc}\text { Activity } & \text { How often per week? } \\ \text { Yoga } & 0-1-2-3-4-5-6-7+ \\ \text { Meditation } & 0-1-2-3-4-5-6-7+ \\ \text { Exercise } & 0-1-2-3-4-5-6-7+ \\ \text { Sport } & 0-1-2-3-4-5-6-7+ \\ \text { Playing an } & 0-1-2-3-4-5-6-7+\end{array}$

2. To what extent do you agree with the following statement: Mindfulness is an important skill for a sport psychology consultant.

Strongly agree - Disagree - Neither Agree not Disagree - Agree - Strongly Agree

3. How did you learn about mindfulness, if at all? Select all that apply to you.

Graduate school course work

Professional development courses

Conference lecture/workshop

Own my own (books, videos, etc)
Applied Training (sport psychology or clinical training experiences Mentor/Advisor

I have not learned about mindfulness

4. What percentage of the time do you think you are mindful when consulting?

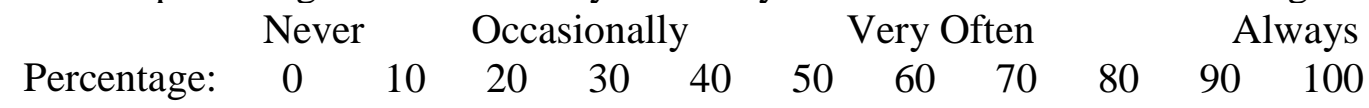




\section{APPENDIX H}

Internet-based Questionnaire: Basic Demographic Questions

Instructions: Please complete the following demographic information.

1. Identified gender:

$\begin{array}{llll}\text { Female } & \text { Male } & \text { Thansgender } & \text { No response }\end{array}$

2. Please indicate your current age range:

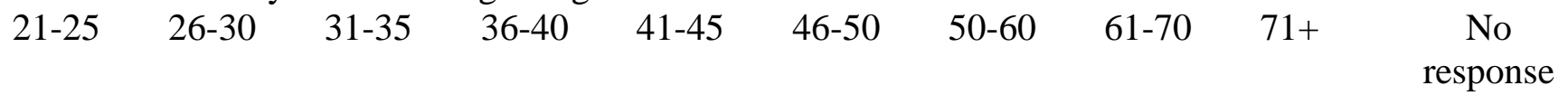

3. Racial/Ethnic background:

Asian

American Indian or

Alaskan Native

4. Country of origin:

United States of

America

Canada
Black or African

American

Caucasian or White

Australia

China
Hispanic or Latino Other:

Native Hawaiian or No response

Other Pacific Islander

Great Britain

France
Other:

No response 


\section{APPENDIX I}

Mindfulness Interview Schedule

Participants will be asked the following questions:

(a) You scored high on the mindfulness instrument. Looking back on your experiences, tell me about how you developed this skill.

(b) Help me understand the role of mindfulness for you as a sport psychology consultant. 


\section{APPENDIX J}

Internet-based Survey: Cover Letter, Introduction and Inclusion Criteria

\section{Introduction}

Thank you for your participation in this study. One dollar will be donated for each participant to the Association for Applied Sport Psychology Foundation toward continued professional development opportunities of sport psychology professionals (http://www.appliedsportpsych.org/foundation/).

\section{Informed Consent}

Please be sure that all information will be kept confidential in a password-protected file. Demographic information will only be used for descriptive statistics. Please note that your status will not be affected by refusal to participate in the study or by withdrawal from the study. Your participation is completely voluntary, you may withdraw at any time, and you do not need to answer every question. This study has been reviewed and I have received permission to conduct it from WVU's IRB (1404276037).

\section{Inclusion Criteria}

A qualification to participate in this study is active performance psychology consultation for at least one year as a graduate student or professional. The population may include athletes, performing artists, military personnel, or other performers. The primary focus of consultation should be performance enhancement.

-I meet this criteria and agree to informed consent -I do not meet this criteria 


\section{APPENDIX K}

\section{WVU IRB Protocol Approval}

Id: 88201

From: admin

Recipients: eetzel , mmcalarn

Channel: KC Notification Channel

Producer: Notification System

Type: FYI

Priority: Normal

Send Date: 2014-06-03T10:27:57.000-04:00

Removal Date: none

Title: IRB Protocol Notice: Protocol 1404276037 Approved

Content: IRB protocol number: 1404276037

Title: Exploring the relationship between professional background and sport psychology consultants' skills

PI: Edward Etzel

The West Virginia University Institutional Review Board approved the above-referenced protocol on 3-Jun-2014. To access this protocol, click on the protocol number link provided. The approval letter can be found in the History subsection of the Summary \& History section located on the Protocol Actions page. For more information, see the Viewing Correspondence quick reference guide. Any future protocol action requests can be completed through WVU+kc.

\section{QUESTIONS?}

Questions related to NHSR, Full Board, Emergency Use, Clinical Trials, or CIRB protocols as well as amendments, renewals, deviations/violations/exceptions, or adverse events/UPIRTSOs should be directed to Lilo Ast at 304.293.7555 or lilo.ast@ mail.wvu.edu. Questions related to Expedited protocols should be directed to Barb White at 304.293.5971 or barb.white@mail.wvu.edu.

Questions related to Exempt protocols, training, or troubleshooting should be directed to Jonathan Young at 304.293.1119 or jonathan.young@ @ail.wvu.edu. 


\section{APPENDIX L}

\section{Recruitment Script 1: Pre-survey Notice}

Because of your experiences as a sport psychology consultant or educator of novice consultants, you have been identified as an eligible participant for a study exploring sport psychology consultants' professional backgrounds and consulting skills is currently occurring! This study will begin in one week! For each participant, one dollar will be donated to the Association for Applied Sport Psychology Foundation (http://www.appliedsportpsych.org/foundation/).

Hello! My name is Michelle McAlarnen, M.S., M.A. and I am currently a fourth year Ph.D. candidate in the Sport and Exercise Psychology program at West Virginia University. I am actively recruiting participants for my dissertation study on sport psychology consultants. The purpose of my study is to explore how sport psychological consultant backgrounds relate to their consulting skills. The study includes a one-time survey that will take approximately 20-30 minutes with the option for follow-up interviews. Your experiences would be an asset to my research study.

The inclusion criteria for this study includes:

a) you must be 18 years or older

b) you must have at least one academic year of sport psychology consulting experience with any population type

Please be sure that all information will be kept confidential in a password-protected file. Demographic information will only be used for descriptive statistics. Please note that your status will not be affected by refusal to participate in the study or by withdrawal from the study. Your participation is completely voluntary and you do not need to answer every question. This study has been reviewed and I have received permission to conduct it from WVU's IRB (\#1404276037).

Look forward to receiving a follow-up e-mail from me with further directions in the next week.

Your participation would be greatly appreciated. If you have any questions or concerns, do not hesitate to contact my chair or me.

Thank you,

Michelle M. McAlarnen, M.S., M.A.

Primary Investigator

West Virginia University

Dept. of Sport and Exercise Psychology

Mac.McAlarnen@mail.wvu.edu

240-418-7577
Dr. Edward Etzel, Ed.D.

Dissertation Chair

Licensed Psychologist/Professor

West Virginia University

Dept. of Sport and Exercise Psychology

Edward.Etzel@mail.wvu.edu

304-293-7062 


\section{APPENDIX M}

\section{Recruitment Script 2: Invitation to Participate}

If you have consulted with performers/athletes, then you are eligible to participate in a study exploring sport psychology consultants' professional backgrounds and consulting skills! For each participant, one dollar will be donated to the Association for Applied Sport Psychology Foundation (http://www.appliedsportpsych.org/foundation/).

Hello! My name is Michelle McAlarnen, M.S., M.A. and I am currently a fourth year Ph.D. candidate in the Sport and Exercise Psychology program at West Virginia University. I am actively recruiting participants for my dissertation study on sport psychology consultants. The purpose of my study is to explore how sport psychological consultant backgrounds relate to their consulting skills. The study includes a one-time survey that will take approximately 20-30 minutes with the option for follow-up interviews. Your experiences would be an asset to my research study.

The inclusion criteria for this study includes:

a) you must be 18 years or older

b) you must have at least one academic year of sport psychology consulting experience with any population type

Please be sure that all information will be kept confidential in a password-protected file. Demographic information will only be used for descriptive statistics. Please note that your status will not be affected by refusal to participate in the study or by withdrawal from the study. Your participation is completely voluntary and you do not need to answer every question. This study has been reviewed and I have received permission to conduct it from WVU's IRB (\#1404276037).

If you would like to be a participant, click on the link below. Your participation would be greatly appreciated. If you have any questions or concerns, do not hesitate to contact my chair or me.

Thank you,

Michelle M. McAlarnen, M.S., M.A.

Primary Investigator

West Virginia University

Dept. of Sport and Exercise Psychology

Mac.McAlarnen@mail.wvu.edu

240-418-7577
Dr. Edward Etzel, Ed.D.

Dissertation Chair

Licensed Psychologist/Professor

West Virginia University

Dept. of Sport and Exercise Psychology

Edward.Etzel@mail.wvu.edu

304-293-7062 


\author{
APPENDIX N \\ Invitation to SPORTPSY Listserv
}

Dear colleagues:

Hello! My name is Michelle McAlarnen, though many of you know me as Mac. I am a fifth year Ph.D. candidate in the Sport and Exercise Psychology program at West Virginia University. I am currently recruiting participants for my dissertation study on performance psychology consultants as communicators in problem solving situations. Specifically, the purpose of this study is to explore how performance psychological consultants' professional backgrounds relate to their consulting communication skills.

A few colleagues have already received a pre-notice email and I am very thankful to these professionals who completed the survey or forwarded it onward. Now, I am reaching out to the SPORTPSY listserv because many of you have experience consulting or teach and mentor students who are consulting.

Important information:

- This study includes a one-time survey that will take approximately 15-20 minutes with the option for a follow-up interview.

- For each participant, one dollar will be donated to the Association for Applied Sport Psychology Foundation to support the research and practice of performance psychology consultants (http://www.appliedsportpsych.org/foundation/)

- The survey link can be used by you and anyone to whom you forward this email.

The inclusion criteria for this study is:

- You must be 18 years or older

- You must have at least one academic year of performance psychology consulting experience with any population type (sport, performing arts, military, etc.).

- Consultation experience can have occurred at any time in your professional development (graduate school and beyond) and does not need to be current.

- The primary focus of consultation can be performance enhancement, mental health, or life skills.

Survey Link: http://wvu.qualtrics.com/SE/?SID=SV_bPgtOriuODwE1wh

Your participation would be greatly appreciated. If you believe other colleagues or graduate students might be eligible to participate, please feel free to forward this email. Detailed information, including formal cover letter, is explained below and attached. If you have any questions or concerns, please do not hesitate to contact Dr. Etzel or myself.

Thank you,

Mac 
Michelle M. McAlarnen, M.S., M.A.

Primary Investigator

West Virginia University

Dept. of Sport and Exercise Psychology

Mac.McAlarnen@mail.wvu.edu

240-418-7577

Dr. Edward Etzel, Ed.D.

Dissertation Chair

Licensed Psychologist/Professor

West Virginia University

Dept. of Sport and Exercise Psychology

Edward.Etzel@mail.wvu.edu, 304-293-7062

\section{Use of data and volunteerism:}

All information will be kept confidential in a password-protected file. Demographic information will only be used for descriptive statistics and only the primary researcher will have access to individual responses. Please note that your occupational, student, and professional status will not be affected by refusal to participate in the study or by withdrawal from the study. Your participation is completely voluntary and you do not need to answer every question. This study has been reviewed and I have received permission to conduct it from WVU's IRB (\#1404276037). The opportunity to partake in an optional follow-up interview is provided. These interviews will be video/audio taped and will remain secure in a password protected file and locked cabinet and deleted according to Federal Regulation guidelines. 


\section{APPENDIX O \\ Invitation to Participate to Division 47 Members}

\section{Greetings Division 47 members!}

Hello! My name is Michelle McAlarnen, though many of you know me as Mac. I am a Ph.D. candidate in the Sport and Exercise Psychology program at West Virginia University. I am currently recruiting participants for my dissertation study on performance psychology consultants as communicators in problem solving situations. Specifically, the purpose of this study is to explore how performance psychology consultants' professional backgrounds relate to their consulting communication skills.

You may have already received a recruiting email through the SPORTPSY listserv and I am very thankful to these professionals who have completed the survey or forwarded it onward. Now, I am reaching out to APA Division 47 because many of you have experience consulting or teach and mentor students who are consulting.

As a thank you for participation, one dollar (USD) will be donated to the professional organization of your choice: APA Division 47, AASP, or FEPSAC. APA Division 47 donations will go to the general Division 47 fund and provide funding for research and professional development in sport psychology. Once you begin the survey, you will be able to select your preferred organization.

There are 3 parts to this survey and it will take approximately 15 minutes. At the end of the survey, you will have the opportunity to sign up for an optional follow-up interview.

To be eligible to participate, you must be at least 18 years old and have had at least one academic year of relevant performance psychology consulting experience. This consulting experience:

1. can have occurred at any time during your professional development (graduate school and beyond),

2. Need not be current,

3. Can have been conducted with any population (sport, performing arts, military, etc.),

4. And have been primarily focused on performance enhancement, mental health, or life skills.

Participants of all nationalities are welcomed. Your participation in this study is completely voluntary and you may opt out at any time. All information will be kept confidential in a password-protected file and demographic information will only be used for descriptive statistics. Taped interviews will be password protected and deleted according to Federal Regulation guidelines. This study has been reviewed and approved by West Virginia University IRB (\#1404276037).

Thank you for your time and consideration! If you believe other colleagues or graduate students might qualify, please feel free to send them the survey link (given below), which will bring them 
to this webpage. If you have any questions or concerns, please do not hesitate to contact Dr. Etzel or me. A link to the formal cover letter and IRB approval is also provided below.

Thank you,

Mac

Survey link: http://wvu.qualtrics.com/SE/?SID=SV_bPgtOriuODwE1wh\&Q_JFE=0

Formal cover letter and IRB

approval: http://wvu.qualtrics.com/CP/File.php?F=F_1SwpiarYpB8Itgx

Michelle M. McAlarnen, M.S., M.A

Doctoral Candidate

West Virginia University

Dept. of Sport Sciences: Sport and Exercise Psychology

Mac.McAlarnen@mail.wvu.edu

Edward Etzel, Ed.D

Dissertation Chair

Professor and Licensed Psychologist

West Virginia University

Dept. of Sport Sciences: Sport and Exercise Psychology

Edward.Etzel@mail.wvu.edu 


\title{
APPENDIX P
}

\author{
Social Media Postings
}

Facebook:

Calling all sport psych peeps! Help me reach my dream of doing a path analysis for my dissertation. So close to enough participants...are you one? Pass it along to colleagues and grad students. $\$ 1$ donated to prof org of your choice! Click on link to learn more.

Just how are performance psych consultants as communicators? Hmm..

https://jfe.qualtrics.com/form/SV_bPgtOriuODwE1wh

Twitter:

How are performance psych consultants' communication skills? \$1 donated to @ SportPsyAASP @E_C_S_S @APADivision47 https://jfe.qualtrics.com/form/SV_bPgtOriuODwE1wh 


\author{
APPENDIX Q \\ Invitation to Private Consultants
}

Dear [Name],

Hello! My name is Michelle McAlarnen, though most people just call me Mac, and I am a Ph.D. candidate in the Sport and Exercise Psychology program at West Virginia University. I hope it is a beautiful day in DC! I am originally from Silver Spring, MD and there is nothing quite like wandering the Mall on a early fall morning!

I am reaching out to you because my dissertation focuses on performance psychology consultants and it is important to me to hear from you as an active, applied practitioner. I hope this study will help the field understand effective consultants better and develop graduate programming that will teach these important skills. [personalized message based on website]. I hope you will offer your perspective to this study!

Specifically, this study frames performance psychology consultants as communicators in problem solving situations and its purpose is to explore how performance

psychology consultants' professional backgrounds relate to their consulting communication $\underline{\text { skills. }}$

Important information:

- This study includes a one-time survey that will take approximately 15 minutes with the option for a follow-up interview. Click for survey.

- For each participant, one dollar will be donated to the Association for Applied Sport Psychology Foundation to support the research and practice of performance psychology consultants. (http://www.appliedsportpsych.org/foundation/)

- The survey link can be used by you and anyone to whom you forward this email.

- Participants of any nationality are welcomed.

The inclusion criteria for this study is:

- You must be 18 years or older. You must have at least one academic year of performance psychology consulting experience with any population type (sport, performing arts, military, etc.).

- Consultation experience can have occurred at any time in your professional development (graduate school and beyond) and does not need to be current.

- The primary focus of consultation can be performance enhancement, mental health, exercise, or life skills.

Your participation would be greatly appreciated. If you believe other colleagues might be eligible to participate, please feel free to forward this email. Detailed information, including formal cover letter, is explained below and attached. If you have any questions or concerns, please do not hesitate to contact Dr. Etzel or myself.

Thank you, 
Mac

Michelle M. McAlarnen, M.S., M.A.

Primary Investigator

West Virginia University

Dept. of Sport and Exercise Psychology

Mac.McAlarnen@mail.wvu.edu, 240-418-7577

Dr. Edward Etzel, Ed.D.

Dissertation Chair

Licensed Psychologist/Professor

West Virginia University

Dept. of Sport and Exercise Psychology

Edward.Etzel@mail.wvu.edu, 304-293-7062

Use of data and volunteerism:

All information will be kept confidential in a password-protected file. Demographic information will only be used for descriptive statistics and only the primary researcher will have access to individual responses. Please note that your occupational, student, and professional status will not be affected by refusal to participate in the study or by withdrawal from the study. Your participation is completely voluntary and you do not need to answer every question. This study has been reviewed and I have received permission to conduct it from WVU's IRB (\#1404276037). The opportunity to partake in an optional follow-up interview is provided. These interviews will be video/audio taped and will remain secure in a password protected file and locked cabinet and deleted according to Federal Regulation guidelines.

To review this study and IRB approval: Cover letter - Invitation to Participate

Follow this link to the Survey:

Take survey

Or copy and paste the URL below into your internet browser: http://wvu.qualtrics.com/SE/?SID=SV_bPgtOriuODwE1wh 


\section{APPENDIX R}

\section{Invitation to Colleagues for Snowball Sampling}

Subject: Help Mac reach her dream of a path analysis!

Hello WVU family,

So wonderful to see those of you who could make it to AASP! I hope everyone is adjusting back to their regular schedule. It is time for me to descend into the icy fields of data analysis on research mountain. However, my dream of enjoying some time with path analysis may elude me without a few more participants. I know many of you have already done this survey, but I thought I'd try a last effort for anyone who has not. If you know of graduate students or professionals who have or are consulting and feel comfortable forwarding the link, it would mean a lot. All the information is included on the first page of the survey before you enter it. Plus, you can donate to a professional organization of your choice!

Thank you!! I plan on closing the survey by Monday. Have a wonderful week! Mac

Survey or https://jfe.qualtrics.com/form/SV_bPgtOriuODwE1wh 


\section{APPENDIX S \\ Invitation for Follow-up Interviews}

[Name],

Hello! My name is Michelle, but everyone calls me Mac, and I am a sport and exercise psychology doctoral candidate at West Virginia University. I appreciate the time you took to complete my dissertation survey this fall. I am writing in regards to the second part of my study on sport psychology consultants as communicators in problem solving situations. Would you be available to be an interview participant?

The interview will consist of an applied activity and reflection. My pilot interview lasted 30-40 minutes. Preparation is not needed and it can be conducted over Skype or FaceTime. The interview will be audio and video recorded with an option to opt out of video recording if you are uncomfortable with it (in which case, phone to phone would be possible instead of Skype/FaceTime).

I know it is a busy time of year and I hope to complete interview s by the end of January. It would be great to hear your thoughts and have you as part of the second part of the study. Please let me know if you are interested and if there are preferred dates/times that might work best for you. I am flexible and happy to work around your schedule and any time zone differences.

Thank you, Mac 


\section{APPENDIX T \\ Bracketing Statement: Mindfulness Interview Memo}

\section{Question 1}

Hmm what a good question. Um well, I think some days are better than others, it's always in development. Maybe that's being mindful is just knowing that on quote unquote bad mindfulness day is being mindful. Um I don't know if I in term of mindfulness from my faculty members and educators throughout my, growing up. In high school I had a teacher and she gave me... and I always had an interesting religion classes growing up from fourth grade onward and I really liked learning about world religions and I really liked Islam, you know true Islam, I really liked it, and I really liked Buddhism and I felt pretty drawn to it, and in high school we had more in-depth religion classes and I liked it and my teacher gave me a book on graduation that was um the Laws of Success by Depak Chopha, which at the time I didn't understand, but [liked having on my bookshelf] and she gave me um that book along with a little bookmark thing that was a moon that said um you can be the light or the one that reflects the light. You know both things light the world, reflecting the light and being the light. So I've always kept that and she gave me she said it is "something that interests you" and I filed it and I kinda have. [if you don't look for it, it comes to you naturally.] um I remember sitting with Noah after we presented our models of consultation with him as a group. He pulled me aside after we [presented] and was like "have you ever heard about unconsciously unaware, unknown, or whatever, that whole, you're conscious that you don't know that whole thing. And I thought that was fascinating even though I can't remember it right now very well. And then Dr. Shannon brought it up to me because anyway, he was more Buddhist philosophy that you have here going on and it reminded me again of that background that I have that I kind of lost in college. And then I came to West 
Virginia and I basically just got incepted [laughing] with this philosophy of, of I don't know humanistic and [] Buddhist, I don't know. I combination of all of those things, mindfulness between Dr. Tunick, Dr. Etzel who I guess has been the product of Dr. Tunick and Zizzi, who I also a product of Dr. Etzel so I guess I go all of the generations at one on me. And Dr. Ed I guess, he is it. It feels like sometimes and so is Zizzi sometimes, sometimes he is, sometimes he's not, but and I think I was looking for another way to live life and it was []. I think I was seeing Dr. Ed so much and so intensely my first year, well all my years, the first two and three I was just always with him that and watching how he handled things, [] and his presence that is a very quiet but very connected so um those are some people that really brought that out of me and reminded me of that so.

How did I actively develop it? I think reading. Of course, the first thing I ever do is go to a book, which is good and bad, um and reading what professors [] me to read. Even Mindy, IC coach, gave me the Having Heart in Hard Times, I forget the name of it, by Pema Chodron, I can't pronounce the last name, and um it was a really good book and it really helped me a lot and I can always go back to it and my meditations at night and reading some of Jack Kornfield's book and reading what Dr. Ed emails me [laughter] so all the reading an then just watching and listening to how Zizzi and Etzel handle things and see [what works for me here]. Noticing what I am attached and what pain that might cause. Becoming comfortable with being aware of those things [] Learning from people into my own life and then consulting really helps too. I don't know. I just hated the traditional PST crap and I think rugby really helped me see the value in being really flexible, not flexible that you bend, but really just being with what is in front of me and responding and I remember him [Etzel] when I showed him all these models, he was like at 
that level and at every level it's just being present and that's it. So that was a good lesson. And then, I think being around counseling was good too, helped. And using it in my own life.

\section{Question 2}

Well, I use it for myself a lot. And for my client and in AASP you go to the lectures and that kinda helps me learn some more activities and some more ideas but it's kinda basic. Um, but for me as a consultant, it helps me notice what I'm bring to a consultation and how I am reacting in it or being pushed or pulled or how what I am attaching to or what I am, or how I am responding and being in that moment and what that energy sends out. Um kind of noticing that and hopefully adjusting or just learning from that and using that as feedback for my work. So I am feeling a fear, a loss, or anything, or whatever I am feeling, reading that and sensing that message for all of us and conversation um also consultation can be really exhausting and always changing and you are trying to fit and become your own island among all these people but attached to them, but yourself, apart form the coach, apart from the ATCs but yet connected to everybody so for me mindfulness is allows me to take each moment of a long training trip and just be at that practice and then be at the next thing and handle all that load and that really helps me a lot. Um, just discussing [] I try to teach it a little bit, kind of, help them use it either my doing some mindfulness techniques or by acceptance and openness, even things like openness to pain which for them is you know, they have a really hard fitness test that was miserable but it was just like fighting the pain is more work than just knowing its there and being with hit and how can you give that energy to the run. The pre-run annoyances and being frustrated and going on about it and then during the run talking chatter in your mind about it, where could that energy go and just do it um and helping see that the shuttles are just one shuttle at a time. Don't make a big deal out of it. So that kind of stuff is how I use mindfulness while staying other opportunities 
for them to see where they are because there is so much happening and staying open to the coaching staff and what they are saying, open to learning and expecting (inspecting?) where their at in terms of their play, in terms of their limitations, as a team and even the coaching staff and all of the drama that is USOC um helping them deal with coaching changes and stressful economic struggles and critical stuff and how they can stay [fluid] among that and just present so yea.

\section{Analytic Memo}

My journey with mindfulness is shaped by interactions and readings. It seems to undulate based on my environment. Early exposure in a world religions type of way through high school and with teachers and then it disappeared in college. Teachers modeled and exposed me to a mindful approach and living. My own research, reading, and conference attendance also encouraged. I've tried to implement my learnings into my own life and notice my attachments and approach to the world. It seems professionally that I use mindfulness to benefit myself as a consultant and also to help others. There are some techniques, put mostly it is the approach toward situations - remaining open and curious, present. 


\section{APPENDIX U}

Analytic Memos

\begin{tabular}{|c|c|c|}
\hline Date & Topic & Analytic Memo \\
\hline 13-Nov & Use of Notes & $\begin{array}{l}\text { Use analytic notes to track thought process. Possible to } \\
\text { write manuscript to disclose this process or help early } \\
\text { researchers, etc like the portraiture article? }\end{array}$ \\
\hline 6-Jan & Andy interview & $\begin{array}{l}\text { Took a much broader organizational view (including } \\
\text { financial, medical, and compliance) of consultation and role } \\
\text { within it. CBT useful, but found it somewhat misaligned } \\
\text { with own experience. Personal practice most pertinent. }\end{array}$ \\
\hline 15-Jan & $\begin{array}{l}\text { Using the term } \\
\text { 'mindfulness' }\end{array}$ & $\begin{array}{l}\text { The first four interviewees expressed that did not use the } \\
\text { term mindfulness in consulting, even if implementing } \\
\text { mindfulness interventions. Used focus, awareness, } \\
\text { presence. How come we feel uncomfortable using - we } \\
\text { believe athletes won't accept that language and } \\
\text { connotation? }\end{array}$ \\
\hline 15-Jan & Defining mindfulness & $\begin{array}{l}\text { First four interviewees defined mindfulness as presence or } \\
\text { awareness or self-regulation. What then is the difference } \\
\text { between these terms? Kabat-Zinn and ACT were also } \\
\text { common. Can we infer that this is the 'branch/school' of } \\
\text { mindfulness that is followed as all are western/us educated } \\
\text { too. How do we operationally define mindfulness in SEP } \\
\text { (if differently) that separates it from focus, awareness, etc? }\end{array}$ \\
\hline 19-Jan & Mike & $\begin{array}{l}\text { I find myself disagreeing with Mike's conceptualizations } \\
\text { and how he sees the decision making as one session and } \\
\text { then just come back when Julian has figured it out, instead } \\
\text { of seeing the decision making process as something that a } \\
\text { consultant and be with the client through. He has lots of } \\
\text { experience, but less education in terms of clinical and I } \\
\text { don't know if that is a factor. The focus is on the cog } \\
\text { process of making these decisions, so it does not really } \\
\text { matter, but something that came up for me. }\end{array}$ \\
\hline
\end{tabular}


19-Jan

19-Jan

26-Jan

26-Jan
Interpersonal therapy and mindfulness

Afraid of the term, mindfulness

Mindfulness role in consulting

Coding
Several interviewees mention how mindfulness help them notice own reactions and use in consulting to respond and inform the client or their work. It sounds very much like inter-personal therapy. Again, mindfulness is maybe more of an addition or compliment to these approaches/therapies. Or if it mindfulness that grounds and therapy structure that adds? Mindfulness allowing one to notice and proceed through interpersonal therapy.

What does it say if the practitioners are uncomfortable using the word, mindfulness? Everyone says it would take a big shift to use that word. Really? Maybe I am just in my own world, and yea it is quite abstract instead of concrete, but if we are 'afraid' or shy away from using it, then how will it become more accepted? Do we need people to be comfortable with this term/

Just initial thoughts while listening to tapes. Participants really talk about how mindfulness helps with self-awareness and internal regulation/understanding while working with a client, which influences how they listen, react, notice what is coming up for them in response to client and how to use that info - basically all communication/inter-personal strategies and influences. Of course, I asked what its role is for you as a consultant. mindfulness seems to change them and thereby help them interact and understand their own processes better so that can be a better consultant when with client

some coding options: first cycle, initial, in vivo, maybe process, descriptive / second theoretical; -- is it appropriate with me to come in wanting to create theory or looking for in a way? Important to note that need more participants to do. Consider focused and axial as well. Maybe ok not to know second cycle yet. Will come as go. 
26-Jan Latent and manifest

27-Jan

27-Jan

27-Jan

30-Jan Role of colleagues

30-Jan Systemic theories
Reading Saldaña he mentions latent and manifest concepts and coding - this really connected with my SEM and how the terminology is used similarly (I'm sure there is borrowing and quanting qual- latent and manifest are also general terms). Nevertheless, I had been feeling like I am switching back and forth between 'modes' - SEM vs Qual. I wondered if I was doing neither well because trying to do both and just feeling like a ping pong. I still somewhat feel that was but also thing my mind kind of likes it but also is frustrated because just wants to get immersed in one and then the other hand, hard to be immersed in both simultaneously. Seeing the terms though kind of brought those worlds together. I'm curious to see if these terms apply in my qual coding - if concepts etc emerge in a similar pattern.

This mantra is mentioned by several participants. It also may be that they are come from or work for the same grad school. Nevertheless, it seems to be an important aspect of professional and personal development

The sixth participant also talked about mindfulness allowing attunement to one's inner reactions, emotions during therapy that could be used in the session. Also discussed how the relationship was the work, less so other intervention relationship as intervention. This also sounds very Rogerian along with interpersonal. Of course, they are closely connected and humanistic. So how does mindfulness fit the whole? Is it a piece that allows the clinician (and client) to engage in interpersonal and humanistic therapies better because of this attunement?

is it how the clients perceive it as mentioned in BL or does it have sort of bounded-ness that clarifies what is mindfulness and what is ACT, awareness, focus, etc

Both Dan and Jill mention the importance of colleagues who can challenge you to see yourself, grow, have discussions with that help build awareness and mindfulness - or just the ability to do good work with clients.

Several participants have mentioned the importance of system theories - especially during the think aloud and how they approach their work, who they collaborate with/inform gather/see has key parties to their consulting work such as coach, med staff, family, etc. One participant viewed ACT as systemic of the individual 
2-Feb

Definition of mindfulness research to practice

"In DNA"

18-Feb immersion/integration

19-Feb Psych state and DNA

25-Feb

26-Feb
Rachel's quick look of Jill brought up the same concern I had - is mindfulness now everything and thus nothing? Is it 'unbounded' and require some structure to what it is and what it is not. This came up in the Dan interview as well. He was concerned of it being watered down and considered it openness to learning (among other things, he like Andy mentioned the eastern philosophy part unlike most others). It also seems to be a lack of link or transference between how research defines and then how consultants use it. Most consistently, it is understood and used and termed as awareness by consultants for themselves and for their clients. But does this really showcase it? Then what is the difference between awareness and mindfulness. The definition of mindfulness as understood in the context of us/psychology/sep is discussed in the research and scale design, but how is this debate being discussed among practitioners (if at all) or shared between researchers and practitioners. I have this sense that there is a gap amidst it all, between and among and thus, what are we share and teaching to our clients and to our graduate students that will determine or at least influence how the use and teach it as well.

Several participants mentioned how mindfulness has become a part of them - something integrated into their way or being and doing that they do not have to give much conscious thought to now. See Andy, Jacob, Dan

Davis 2013 p. 2 - cultivate a state in which constructive behaviors emerge - many participants mention that it becomes a part of them and that part of process and moment of consulting

Davis 2013 talks about how it sets up the state to help good consultant skills come through - not build skills directly. Perhaps, this is what I am seeing when I hear other therapeutic approaches being mentioned - like using emotions to understand to inform understand client and responses. Seems more interpersonal, but really just good consulting. Mindfulness is not a therapeutic approach but complements, sets the stage, infuses into these therapies

Is it worth, important to code spc role? Not quite research question but also this sense that mindfulness supports doing those roles. Also discussed in Davis 2013. particular to Dan, right now coding 
27-Feb

28-Feb

28-Feb

28-Feb

1-Mar

10-Mar

Mid-

March

Mid-

Marc

MidMarch

\section{Process of dev mindfulness}

Sitting with silence and inconclusive sessions

Coders

Model and qual results

Present moment focus and attention regulation

Present Focus and Awareness: Different?

\section{Mindfulness process}

There is this process of developing mindfulness. How do I show this in my coding? People mentioning how not always mindful, some days, year better, that they did things over time that helped them develop skills/process/go tools. See Andy, Jacob, Amy

Sarah a lot of process -- [this] so that [that], especially to enhance counseling skills

Amy and Dan both talk about sitting with sessions that are inconclusive - not having to have an answer or say something conclusive and how mindfulness helps with that awareness, noticing tendency to want to jump in or rush or diagnosis and regulating it.

coding styles - Rachel puts the formal terms that is correct in psychology. Kind of nice to see because I do not naturally think that way and offers a grounding in the formal literature for a later stage of coding/discussion

The applied training variable focuses on hours and years (yes it may be messed up by how I made it) and does not correlate with mindfulness, yet most mention applied training in qual - but it is not the amount but the who and what - supervisors, clinical peers, clinical focus that develop mindfulness

Made decision to have Mike, Dan, Andy, Jacob as participants - rationale is that they are the 4 that termed mindfulness a certain way for implementing it into their consultation. They are also the most active consultants.

The term "present moment focus" seems to be a combination of self-regulation of attn. on immediate experience

Is there a difference in "present focus," "awareness," being present" -> I think they are being used interchangeably, but are they actually so?

It is an active process of allowing thoughts but not necessarily an active reflective process - it is more direct experience of thoughts, emotions, sensations as they manifest without the elaboration of reflection and meaningmaking 


\begin{tabular}{|c|c|c|}
\hline $\begin{array}{l}\text { Mid- } \\
\text { March }\end{array}$ & $\begin{array}{l}\text { Self-regulation of } \\
\text { attention and } \\
\text { recognition of mental } \\
\text { events same, } \\
\text { different? }\end{array}$ & $\begin{array}{l}\text { Should self-regulation of attention and recognition of } \\
\text { mental events in present moment be separated. In } \\
\text { participants' definitions sometimes separate present and } \\
\text { aware. }\end{array}$ \\
\hline $\begin{array}{l}\text { Mid- } \\
\text { March }\end{array}$ & $\begin{array}{l}\text { Process of becoming } \\
\text { a mindful consultant }\end{array}$ & $\begin{array}{l}\text { The process of becoming a mindfully oriented consultant - } \\
\text { there is a turning point - both a moment that it happens and } \\
\text { a gradual, fluctuating process toward integration that both } \\
\text { becomes part of "dna" and second nature, but also never } \\
\text { really stops. Many cases mentioned the grappling, unsure is } \\
\text { getting better or worse, but also the doing it that now it just } \\
\text { is part of them. There is a shifting moment and then a } \\
\text { continued process of being and finding your own way. We } \\
\text { might say being a mindful practitioner is no different than } \\
\text { simply practicing mindfulness. The practice is the practice. } \\
\text { We are always in a state of becoming, yet beginning. } \\
\text { Arriving and beginning. There is here, we are always here. } \\
\text { The process and actions of development include mentors as } \\
\text { guides, exposure through informal and formal learning in } \\
\text { coursework and applied training, of reading assignments } \\
\text { and out of interest, and then adopting some sort of practice } \\
\text { that fits needs, personality, etc }\end{array}$ \\
\hline
\end{tabular}

